University of Louisville

ThinkIR: The University of Louisville's Institutional Repository

$4-2012$

\title{
Analysis of induced gamma oscillations with a data alignment technique in autism and attention deficit hyperactive disorder.
}

Eric Gross

University of Louisville

Follow this and additional works at: https://ir.library.louisville.edu/etd

\section{Recommended Citation}

Gross, Eric, "Analysis of induced gamma oscillations with a data alignment technique in autism and attention deficit hyperactive disorder." (2012). Electronic Theses and Dissertations. Paper 538.

https://doi.org/10.18297/etd/538

This Master's Thesis is brought to you for free and open access by ThinkIR: The University of Louisville's Institutional Repository. It has been accepted for inclusion in Electronic Theses and Dissertations by an authorized administrator of ThinkIR: The University of Louisville's Institutional Repository. This title appears here courtesy of the author, who has retained all other copyrights. For more information, please contact thinkir@louisville.edu. 


\title{
ANALYSIS OF INDUCED GAMMA OSCILLATIONS WITH A DATA ALIGNMENT TECHNIQUE IN AUTISM AND ATTENTION DEFICIT HYPERACTIVE DISORDER
}

\author{
By: \\ Eric Gross \\ B.S. Bioengineering, University of Louisville, May $14^{\text {th }} 2011$
}

\author{
A Thesis \\ Submitted to the Faculty of the \\ University of Louisville \\ J.B. Speed School of Engineering \\ As Partial Fulfillment of the Requirements \\ For the Professional Degree
}

\section{MASTER OF ENGINEERING}

Department of Bioengineering

April 2012 

INDUCED EEG GAMMA OSCILLATION ALIGNMENT IMPROVES

DIFFERENTIATION BETWEEN AUTISM AND ADHD RESPONSES IN FACIAL CATEGORIZATION TASK

Submitted by:

Eric Robert Gross

A Thesis Approved On

(Date)

by the Following Reading and Examination Committee:

Ayman El-Baz, Ph.D. Thesis Director

Estate Sokhadze, Ph.D.

Palaniappan Sethu, Ph.D.

Karla Welch, Ph.D. 


\section{ACKNOWLEDGMENTS}

The work presented in this thesis paper is the culmination of the efforts of many people who were crucial to the success of this project. My thesis director, Dr. Ayman ElBaz, has been my advisor and advocate for several years now. His influence extends beyond my education, and I attribute many of the successes of my college career to his guidance and support. Similarly, Dr. Estate Sokhadze has been truly instrumental to my successes with this project. He has spent many hours instructing and assisting me, devoting both his time and resources on my behalf.

Both Dr.'s El-Baz and Sokhadze are part of an outstanding faculty that has supported me throughout this process. Their enthusiasm to their field is unparalleled within the university, and their passion is infectious. Though still a nascent part of the Speed School of Engineering, the Bioengineering department has demonstrated that it is destined to become an important contributor both on a local level, and within the international biomedical research community. I am very fortunate to have been a part of this department during its development, and hope that it continues to grow and shape minds, as it helped to shape me.

Lastly, no great endeavor is completed easily or without obstacles. For the many times I met resistance on this path, my friends and family were there to help me see it through. I would like to thank my mom, Leslie Lewis, my dad, Robert Gross, and my friends Andrea Breaux, Patrick Greenwell, Justin Bottoms, Quentin Johnson, and Claire Bennet for their never ending support, and their ability to convince me that I was not, in fact, going to fail all of my classes. The longest and most difficult of journeys are made better with good company, and I was lucky to have had no short supply of it. 


\begin{abstract}
Introduction: Children diagnosed with an Autism Spectrum Disorder (ASD) often lack the ability to recognize and properly respond to emotional stimuli. These emotional deficits are also observed in children with Attention-Deficit Hyperactivity Disorder (ADHD), but are often overshadowed by the focus on limited attention span. A growing body of research suggests that there may be links between ASD and ADHD, which requires further study. Investigation of this hypothesis often relies on the Theory of Mind (ToM) construct to frame experiments that explore the relationship between these two conditions. Many experiments utilize electroencephalographic (EEG) data to quantitatively assess brain activity. The emotional deficits in ASD and ADHD may cause a difference within the induced EEG gamma wave burst phenomenon $(35-45 \mathrm{~Hz})$ produced approximately 300-400 milliseconds following an emotional stimulus. Because induced gamma oscillations are not fixed at a definite point in time post-stimulus, analysis of averaged EEG data with traditional methods may result in an attenuated gamma burst power. Two hypotheses were proposed in this study. First, a software based data alignment technique could be employed to reduce the attenuation observed in the analysis of these phenomena. Second, improvement of the attenuation would better elucidate similarities and differences to stimuli in an experimental study comparing ASD, ADHD, and control subjects.
\end{abstract}

Methods: A study was designed to test the response of a subject to emotional stimuli, presented in the form of expressive facial images. In a four part experiment, the subjects were instructed to identify gender in the first two blocks of the test, followed by 
differentiating between basic emotions in the final two blocks (i.e. anger vs. disgust). EEG data was collected from ASD $(n=10), \operatorname{ADHD}(n=9)$, and control $(n=11)$ subjects via a 128 channel EGI system, and processed through a continuous wavelet transform and bandpass filter to isolate the gamma frequencies. Data alignment was then employed by using a custom MATLAB code to align the individual trials between 200-600 ms poststimulus for each subject, EEG site, and condition by maximizing the Pearson productmoment correlation coefficient between trials within these groups. The gamma power for the $400 \mathrm{~ms}$ window of maximum induced gamma burst was then calculated and compared between subject groups.

Results: Significant main effects for the alignment condition were present across all subject groups, experiment conditions, and EEG channels. Significant main effects also existed for the experimental condition and subject groups. Condition (anger/disgust recognition, gender recognition) $\mathrm{x}$ Alignment $\mathrm{x}$ Group (ADHD, ASD, Controls) interaction was significant across the parietal topographies. These interactions were better manifested in the aligned data set.

Conclusions: Both hypotheses were supported by the obtained results. The employed data alignment technique significantly reduced the amount of attenuation observed in the averaged signals. Additionally, further analysis showed that significant interactions were more easily observed in the aligned dataset, which suggests that this technique may be beneficial for furthering the comparison of the emotional deficits in ASD and ADHD. 


\section{LIST OF TABLES}

TABLE I: ANOVA TABLE FOR INDUCED GAMMA POWER (Page 29)

TABLE II: DESCRIPTIVE STATISTICS FOR SIGNIFICANT PARIETAL CHANNEL PAIRINGS (Page 33)

TABLE III: INDUCED GAMMA POWER TABLE (Page 54-57) 


\section{LIST OF FIGURES}

Figure 1: An example of how data alignment can be used to improve analysis with simplified impulse signals that vary in time. The first trial within a set is used as an alignment setpoint for subsequent trials, which are shifted in time to line up with the setpoint. Averaging the aligned form of the signals produces a representative signal that resembles the constituent trials, whereas the unaligned averaged signal is significantly attenuated and visually distinct. (Page 9)

Figure 2 - The 128-channel EEG sensor net and testing room used in this study. The net was adjusted to fit the scalp of each subject individually to ensure that the electrodes were appropriately placed. The subject was seated in front of a computer display where visual stimuli were presented for the categorization task. Note that the subject seen in this picture was not a participant of this study. (Page 15)

Figure 3: A visual representation of the categorization task. Each image remained on the screen for $300 \mathrm{~ms}$. The subject was given approximately 1100-1300 ms to categorize the face into one of two groups before the next image appeared on the screen. The time between images varied to discourage anticipation. Segmentation was performed for each image starting $200 \mathrm{~ms}$ before stimulus presentation, to $800 \mathrm{~ms}$ after stimulus presentation. (Page 17)

Figure 4 - A representation of the four block experimental study and examples of the facial images used during the test procedure. Participants were asked to distinguish a face as belonging to one of two groups: male or female, angry or disgusted, or fearful or sad. Each test block consisted of sixty trials, with twenty-four unique images per trial. (Page 18)

Figure 5 - The four experimental categories used for data analysis. For each subject, sixty trials were selected for analysis in the gender and overall emotion recognition categories, while thirty were selected for the individual emotion recognition tasks (i.e. anger versus disgust). (Page 19)

Figure 6 - Location of the eleven electrodes selected for analysis in this study. (Page 20)

Figure 7: A graphical representation of the Morlet window used in the continuous onedimensional wavelet analysis. (Page 22)

Figure 8 - The step-by-step procedure of the alignment technique. First, the setpoint is chosen by segmenting the first signal in a set from 200-600 ms post-stimulus. Subsequent trials are then incrementally segmented in $400 \mathrm{~ms}$ pieces starting at $100 \mathrm{~ms}$ post-stimulus, with a $2 \mathrm{~ms}$ shift each increment. The correlation coefficient is calculated for each 
increment, and the level of shift that produces the highest positive coefficient value is selected as the 'aligned' $400 \mathrm{~ms}$ segment for analysis. This process is repeated for each trial within a set until each trial is aligned to the setpoint. (Page 25)

Figure 9 - A flowchart depicting the steps in the data analysis procedure for the aligned dataset. The unaligned dataset was created similarly, with the exclusion of the data alignment phase in the flowchart. (Page 26)

Figure 10 - Line plots emphasizing the difference between aligned and unaligned averaged power values across subject types (Left) and experimental conditions (Right). (Page 29)

Figure 11 - An example of aligned and unaligned EEG signals in parietal channels for a single subject and experimental condition (i.e. Eric - Anger/Disgust) in two different channels. (Page 30)

Figure 12 - A graph depicting the main effects of experimental condition and subject type across both the aligned and unaligned datasets. The emotional tasks were significantly higher in average mean induced gamma power for all subject types. Similarly, power values from ADHD subjects appeared higher than those from autistic and control subjects. (Page 31)

Figure 13 - Interaction plots for parietal channels depicting differences in Condition, Group, and Alignment pairings. Plots revealed significant interactions in the aligned dataset that would otherwise have gone unnoticed. Top: Channel pair P3-P4, Bottom: Channel pair: P7-P8. (Page 32) 


\section{TABLE OF CONTENTS}

Page

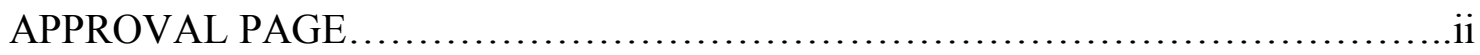

ACKNOWLEDGMENTS...................................................... iii

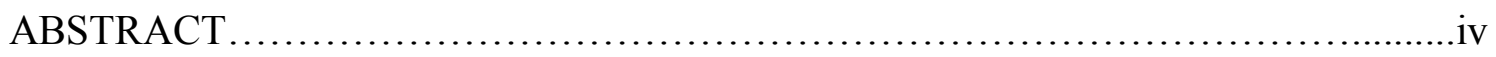

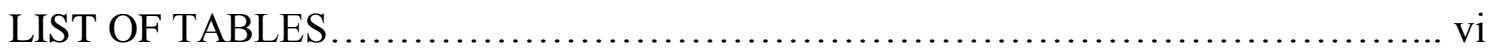

LIST OF FIGURES..............................................................

I. INTRODUCTION.................................................. 1

II. SUBJECT RECRUITMENT AND DEMOGRAPHICS...................11

III. DATA COLLECTION...........................................

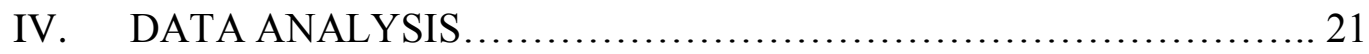

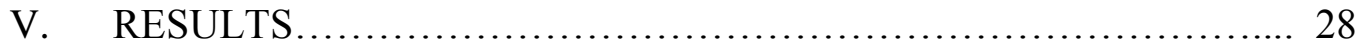

VI. DISCUSSION...................................................... 34

VII. FUTURE WORK................................................. 41

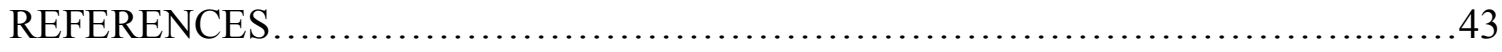

APPENDIX I - MATLAB ALIGNMENT CODE...................................50

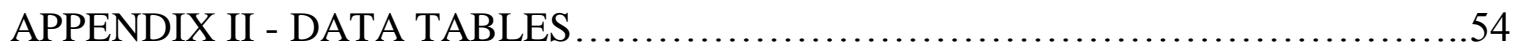

APPENDIX III - FACIAL IMAGES............................................5

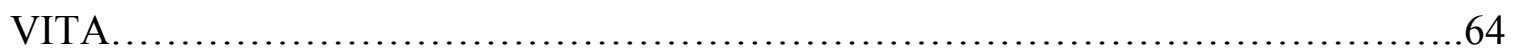




\section{INTRODUCTION}

Autism spectrum disorders (ASD) cover a broad range of early onset neurodevelopmental impairments that may be categorized into one of three groups: social interactions, communication, and repetitive behaviors (American Psychiatric Association, 2000). Severity of the symptoms associated with ASD may vary widely from patient to patient, leading most clinicians and researchers to view the disorder as a spectrum of impairments, which also include Aspberger's and Pervasive Developmental Disorder-Not Otherwise Specified (PDD-NOS) (Chlebowski, Green, Barton, \& Fein, 2010; Newschaffer et al., 2007). Although ASD was once thought to be a relatively rare condition with a prevalence of 2 to 5 children per 10,000, more recent studies have suggested that the rate may actually be an order of magnitude greater (Yeargin-Allsopp et al., 2003). It is not completely understood whether the rate of prevalence has increased over the past several decades or if identification of individuals with ASD has simply improved. The average lifetime public expenditure on each individual with ASD is estimated to be as high as $\$ 4.7$ million (Newschaffer et al., 2007).

Attention deficit/hyperactivity disorder (ADHD) is another early onset condition characterized by inattentiveness and hyperactivity (American Psychiatric Association, 2000). Classic symptoms of ADHD may include being easily distracted, having difficulty 
remaining still, frequent boredom, and having difficulty following directions. A conglomeration of studies using the most recent guidelines for ADHD reported diagnosis rates in school-aged children ranging from 11 to 18 percent in the United States (Faraone, Sergeant, Gillberg, \& Biederman, 2003). The disorder may continue to affect up to 70 percent of individuals with juvenile ADHD into adulthood (Knutson \& O'Malley, 2010). Studies have reported higher costs for families with children who have ADHD, including higher direct medical costs and increased hospital visits (Hakkaart-van Roijen et al., 2007).

Both ASD and ADHD are associated with emotional impairments. In ASD, emotional deficiencies are a definitive symptom of the disorder. These difficulties socializing with other individuals often stem from an inability to quickly and accurately read emotional cues and reciprocate with an appropriate response (Begeer, Koot, Rieffe, Meerum Terwogt, \& Stegge, 2008; Kuusikko et al., 2009; Ryan \& Charragáin, 2010). Although the focus of ADHD research is often on the more conspicuous inattentiveness and hyperactivity observed, a growing interest in the emotional deficits of children with ADHD has spurred new studies to explore this question (Da Fonseca, Seguier, Santos, Poinso, \& Deruelle, 2009). Although this deficiency may be tied back to the original problem of inattentiveness (i.e. an inability to focus on reading emotional cues), a recent study has suggested that the emotional deficiency may be a separate issue in it of itself (Yuill \& Lyon, 2007). Emotional deficiencies are typically evaluated with experimental visual tasks designed to test the subject's facial recognition skills, but other studies have utilized auditory stimuli to explore this phenomena (Baker, Montgomery, \& Abramson, 2010). 
While most studies have typically separated ASD and ADHD as unrelated phenomena, more recent reviews have justified the comparison of these disorders in a combined experimental model (Rommelse, Geurts, Franke, Buitelaar, \& Hartman, 2011). Genetic investigations have suggested that a common initiator may be responsible for ASD and ADHD, and could explain symptoms that indicate a co-morbidity of the two disorders (Mulligan et al., 2009; Ronald, Simonoff, Kuntsi, Asherson, \& Plomin, 2008). Several hypotheses have been proposed to explain the similarities observed in ADHD and ASD subjects, including a model that places the two disorders on a larger spectrum of social disorders. Further investigation is necessary to support the proposed models. While genetic evidence may be an important component of this research, evaluating the performance of subjects with these disorders in clinically relevant tasks (i.e. facial/emotional recognition) may potentially reveal mechanistic differences between similar behaviors in ASD and ADHD, which may challenge or corroborate with other findings.

These experiments often rely on interpreting the results within the Theory of Mind (ToM), which is the method by which an individual assumes another's perspective by characterizing their mental state, or comparing it to their own (Baron-Cohen, 2000). In typically developing (TD) children, the theory of mind begins to develop in infancy, with notable milestones occurring as early as fifteen months on up through six years of age that include the assessment of another's beliefs, and comprehension of beliefs that may be false (Moore \& Pure, 1990; Onishi \& Baillargeon, 2005; Träuble, Marinovi, \& Pauen, 2010). The ToM construct is frequently applied in the study of ASD (Colle, BaronCohen, \& Hill, 2007; Lerner, Hutchins, \& Prelock, 2011; Lind \& Bowler, 2010) and may 
explain why autistic children struggle with understanding facial expressions, body language, figurative speech, and other social cues that convey emotional information. Applications of this theory have been used to assess both the nature and level of emotional deficiencies in adults with ASD (Baron-Cohen, Wheelwright, Jolliffe, \& Therese, 1997).

Many studies investigating other conditions have used the ToM to explain their findings, including schizophrenia (Bora, Yücel, \& Pantelis, 2009), bipolar disorder (Wolf, Brüne, \& Assion, 2010), chronic depression (Zobel et al., 2010), and ADHD (Perner, Kain, \& Barchfeld, 2002). Comparing conditions within the context of ToM may contribute to a better understanding of both disorders. ToM impairment has been compared between ASD and ADHD children in several studies. Tasks requiring children to identify the emotions displayed by a person's face have yielded statistically insignificant differences between ADHD and ASD groups (Bühler, Bachmann, Goyert, Heinzel-Gutenbrunner, \& Kamp-Becker, 2011; Buitelaar, Van Der Wees, SwaabBarneveld, \& Van Der Gaag, 1999). Another study attempted to use mental cartoons (drawings where a character humorously depicting a character's ignorance or false-belief) to find differences between ASD and ADHD adults, and was unable to find significant differences between the two groups (Nydén et al., 2010). In some cases, it is unclear whether the employed tests are too insensitive to detect differences between disorder groups, or whether they truly share a similar level of deficiency.

While it may be sufficient for some studies to use easily observable metrics (i.e. accuracy of responses to posed questions, reaction times, etc.) to understand ToM relationships in neurodevelopmental dysfunction, analysis of the electroencephalographic 
(EEG) data from subjects with neurodevelopmental disorders provides a top-down approach that helps to correlate physiological and behavioral responses. Studies involving subjects with ADHD (Koehler et al., 2009; Kovatchev et al., 2001) and ASD (Bosl, Tierney, Tager-Flusberg, \& Nelson, 2011; Daoust, Lusignan, Braun, Mottron, \& Godbout, 2008; Oberman et al., 2005) have attempted to identify and explain abnormalities in the EEG waveforms, and relate these anomalies to observable phenomena within the study, or typical characteristics of the subjects themselves. Information gathered from these studies may then be used to form or support theories on the development of these disorders, or may be used to characterize the EEG waveforms that can be expected to be observed in a particular subject.

Several studies have compared the EEG waveforms between ADHD and ASD subjects who were either asked to remain still, or perform a particular task. In a study using a feedback based learning task, comparison of event-related potentials (ERPs) collected during the task provided statistically significant differences between ADHD, ASD, and TD children (Groen et al., 2008). Similarly, background abnormalities and frequency of localized paroxysmal discharges were found to be a potentially useful metric in differentiating PDD (and other forms of ASD) from ADHD (Kawatani et al., 2012). A study comparing the absolute and relative powers of EEG frequency bands between ADHD children with and without additional symptoms characteristic of ASD found significant differences in the power levels of these two groups. This would suggest that a comorbidity between ASD and ADHD may exist in some children, which opposes the current standard of diagnosing these disorders (Clarke, Barry, Irving, McCarthy, \& Selikowitz, 2011). These findings justify the continued research of comparative EEG 
waveforms in subjects with ASD, ADHD, and symptoms characteristic of both conditions.

EEG oscillations are separated into several frequency bands, ranging from the slower delta waves $(0-4 \mathrm{~Hz})$ to the faster gamma waves $(30-80 \mathrm{~Hz})$. The gamma frequencies, particularly those centered about $40 \mathrm{~Hz}$, have been tied to visual, attentional, cognitive, and memory processes (Başar, Schürmann, Başar-Eroglu, \& Demiralp, 2001; Müller, Gruber, \& Keil, 2000). Following a stimulus, two gamma oscillations are typically noted: an early evoked oscillation and a late induced oscillation (Başar-Eroglu, Strüber, Schürmann, Stadler, \& Başar, 1996; Başar, et al., 2001). The evoked gamma oscillations typically occur within the first $200 \mathrm{~ms}$ after the onset of a stimulus, and are locked in time from trial to trial. Because little variation is seen in the latency of the evoked gamma with changing stimulus type, it is believed that it may be a result of sensory processes. Conversely, induced gamma oscillations occur later, after $240 \mathrm{~ms}$ post-stimulus, and vary in latency from trial to trial (Tallon-Baudry \& Bertrand, 1999). These variations may suggest that the induced gamma oscillations are related to higher cognitive processes (Tallon-Baudry, 2003). Deviations from typical gamma band activity have been reported in several studies on neurological disorders, including epilepsy, Alzheimer's disease, ADHD, and ASD (Herrmann \& Demiralp, 2005).

Studies have been conducted that observe the gamma EEG frequencies in subjects with either ASD or ADHD. A study examining gamma waveforms that occur while viewing illusory Kanizsa images suggested that the overall gamma activity increased in autistic children (Brown, Gruber, Boucher, Rippon, \& Brock, 2005). Another study observed general increases in high frequency EEG activity (including gamma 
frequencies) in boys with autism, and further suggested that this increased activity may be proportional to the level of deficiency in each child (Orekhova et al., 2007). In a study with ADHD and TD children, no differentiation in the gamma activity was noted between new and familiar images by children with ADHD. Conversely, TD children displayed different gamma responses depending on the familiarity of the image. This suggests that visual memory impairment in ADHD may be associated with this gamma activity (Lenz et al., 2010). A Web of Knowledge search at the time of writing produced no known studies that have compared gamma activity between ADHD and ASD subjects. Given that EEG studies comparing ASD and ADHD while looking at other phenomena have produced interesting results, and that ASD and ADHD subjects have individually shown statistically different gamma activity compared to TD subjects, it is justifiable to conduct a gamma study comparing ASD and ADHD.

Since evoked gamma waveforms are synchronized in time post-stimulus, averaging analogous trials typically reveals the evoked response in the averaged waveform. However, induced gamma waveforms vary in time, and thus, appear to be severely attenuated in the averaged response. This makes the analysis of the induced gamma activity more complex than evoked gamma activity. Studies looking at gamma waveforms have either focused on evoked gamma (Lenz et al., 2008), or found and characterized induced gamma activity on a trial by trial basis (Brown, et al., 2005).

A potential solution to the variance observed in the induced gamma waveforms would be to 'align' the signals prior to analysis. Data alignment is a procedure that correlates analogous features between two signals or images, and standardizes them so they may be more accurately compared to one another (Figure 1). This technique is 
commonly performed in medical imaging studies, where collected images may differ slightly from one another or an amassed source of training data (i.e. level of contrast, angle from which the images were taken, relative position of the object of interest, etc.) (Casanova et al., 2011; El-Baz et al., 2011). A similarity measure (i.e. correlation, mutual information, etc.) is typically used to optimize the alignment process, which reaches an absolute maxima when two images are oriented in the most similar fashion. Alignment corrects these observed incongruences without changing the nature of the phenomena of interest.

A similar methodology can be applied to one-dimensional signals as well, such as EEG waveforms. Data alignment has also been used in EEG studies to align visual evoked potentials with varying latencies via the discrete Fourier transform (Sahin \& Yilmazer, 2010). A similar technique may be used to align the induced gamma 'burst' that occurs after the evoked gamma activity, creating an 'aligned averaged' response that better represents the true induced gamma activity. 


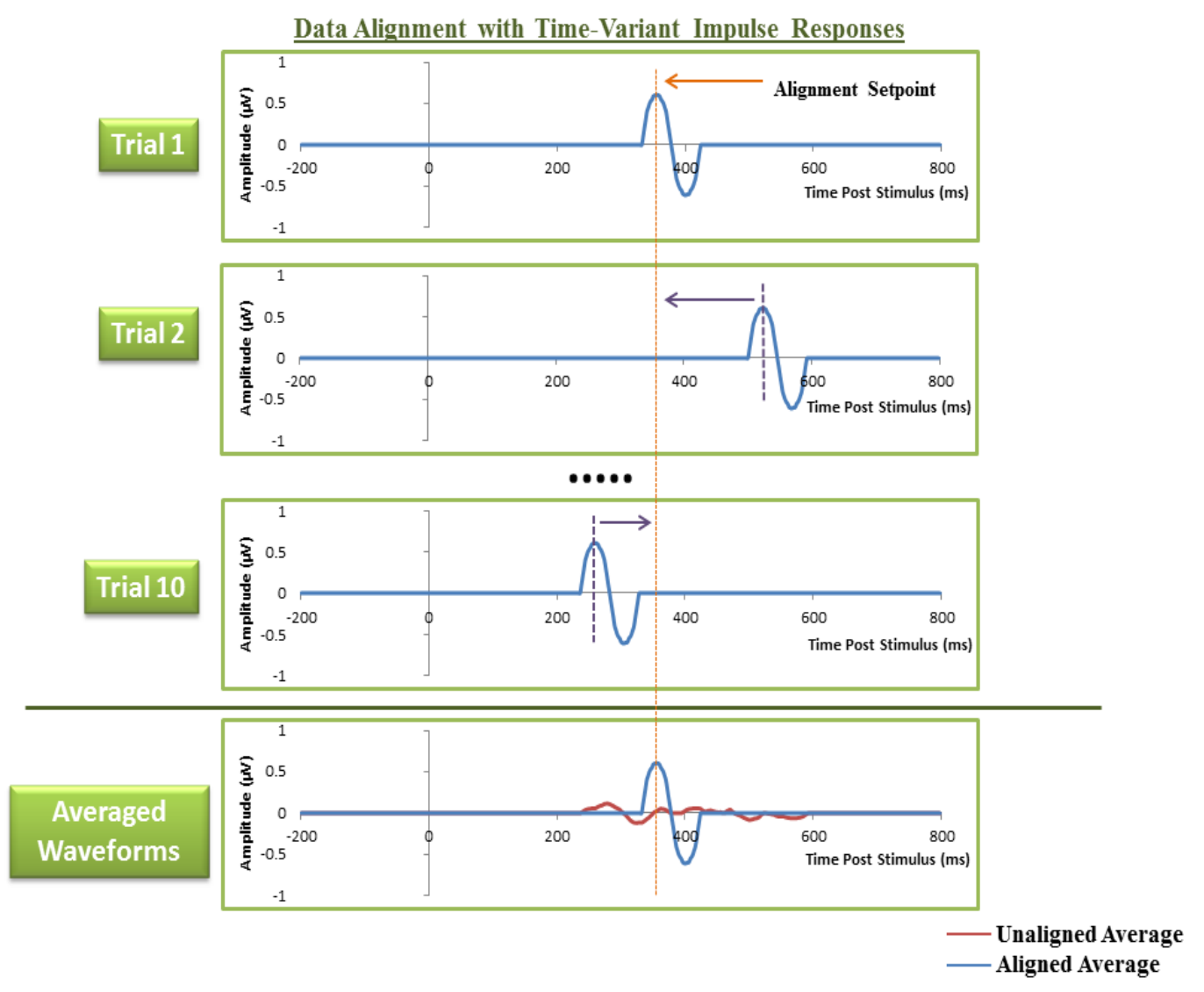

Figure 1: An example of how data alignment can be used to improve analysis with simplified impulse signals that vary in time. The first trial within a set is used as an alignment setpoint for subsequent trials, which are shifted in time to line up with the setpoint. Averaging the aligned form of the signals produces a representative signal that resembles the constituent trials, whereas the unaligned averaged signal is significantly attenuated and visually distinct.

This study proposes a novel method of analyzing the induced gamma activity of an averaged EEG response by using a method of data alignment, which may allow for a more accurate representation of the averaged induced gamma activity of a subject. EEG recordings were collected from $\mathrm{ASD}, \mathrm{ADHD}$, and TD/control children while performing a categorization task of faces depicting various emotions. These tasks have been frequently performed in the literature to record ToM and attention-based measures in control or TD subjects, and identify potential deficits in subjects with 
neurodevelopmental disorders (Baron-Cohen, et al., 1997; Ribeiro \& Fearon, 2010; Schulte-Rüther, Markowitsch, Fink, \& Piefke, 2007).

The gamma power of the responses was estimated by using a wavelet technique in MATLAB described in previous studies to isolate the gamma frequencies (Horrell et al., 2010). Alignment was performed offline for each subject by selecting one waveform out of a set of analogous trials, and designating it as the setpoint for the subsequent trials. The Pearson-Product Moment correlation coefficient was used a similarity measure between the setpoint and subsequent trials, and was used to create an 'averaged aligned' waveform for each set. Gamma power was then calculated from both the aligned and unaligned waveforms.

Our hypothesis was twofold. First, we anticipated that alignment would have a dramatic effect on reducing the attenuation observed in the averaged signal. By maximizing the Pearson-Product Moment correlation coefficient, we attempted to reduce the amount of destructive interference caused by the varying latencies during the averaging process, which was expected to reduce the attenuation, and increase the absolute induced gamma power. Second, we expected that the data alignment technique would allow us to better elucidate the induced gamma activity differences between ADHD, ASD, and control subjects. While it is possible that these differences may manifest themselves in the unaligned averaged waveforms, we anticipated that the alignment technique would emphasize these differences, and increase the statistical significance of the findings. This process may contribute to the analysis of induced gamma activity, ToM and emotional deficits in ASD and ADHD. 


\section{SUBJECT RECRUITMENT AND DEMOGRAPHICS}

Participants with ASD were recruited through the University of Louisville Weisskopf Child Evaluation Center (WCEC). Subject age ranged from nine to twenty years old. Diagnosis was made according to the Diagnostic and Statistical Manual of Mental Disorders (DSM-IV) (American Psychiatric Association, 2000) and was further confirmed with the Autism Diagnostic Interview - Revised (ADI-R) (Le Couteur, 2003). Each subject also had a medical evaluation performed by a developmental pediatrician. All subjects had normal hearing, which was confirmed by auditory tests conducted previously. Participants either possessed normal vision or wore corrective lenses. Subjects with a history of seizure disorder, significant hearing or visual impairment, any brain abnormality identified from imaging studies, or a diagnosed genetic disorder were excluded. All participants with autism were high-functioning persons with full scale IQ > 80 assessed using the Wechsler Intelligence Scale for Children, Fourth Edition (WISCIV) (Wechsler, 2003) or the Wechsler Abbreviated Scale of Intelligence (WASI) (Wechsler, 2004).

The Structured Clinical Interview for DSM-IV (SCID-I/P) (First, 2002b) was used for diagnoses of ADHD. Nine subjects ranging from thirteen to twenty-one years old who currently meet DSM-IV-TR criteria for ADHD or attention-deficit disorder 
(ADD) were included. Subjects were evaluated at the WCEC. Parents and teachers were asked to complete the Child Behavior Checklist or Teacher Report Form (Rescorla, 2001) to complete the diagnosis of ADHD. Parents were also interviewed using DSM-IV criteria for ADHD to further support the diagnosis. Only subjects with clinical features meeting criteria for ADHD in both the home and school setting, and also met DSM-IV criteria, were included. All ADHD participants had a medical history and a psychiatric evaluation. For children, both the parents and the child with ADHD provided information for the assessment.

Controls were recruited through advertisements in the local media. All control participants were free of neurological or significant medical disorders, had normal hearing and vision, and were free of psychiatric, learning, or developmental disorders based on self and parent reports. Subjects were screened for history of psychiatric or neurological diagnosis using the Structured Clinical Interview for DSM-IV Non-Patient Edition (SCID-NP) (First, 2002a). Participants within the control, ADHD, and autism groups were attempted to be matched by age, full scale IQ, and socioeconomic status of their family. Socioeconomic status of ASD, ADHD, and control groups was compared based on parent education and annual household income. Participants in each of the three groups had similar parent education levels.

Participating subjects and their parents or legal guardians were provided with full information about the study including the purpose, requirements, responsibilities, reimbursement, risks, benefits, alternatives, and role of the local Institutional Review Board (IRB). The consent and assent forms approved by the IRB were reviewed and explained to all subjects who expressed interest in participating in the study. All 
questions posed by the subjects, parents, and legal guardians were answered before a consent signature was requested. If the individual agreed to participate, she/he signed and dated the consent form and received a copy cosigned by the investigator who obtained consent.

The mean age of 10 participants enrolled in the ASD group was $14.1 \pm$ (standard deviation) 2.7 years (range 10-18 years, 8 males, 2 females), and the mean age of the ADHD group was $14.2 \pm 3.9$ years $(\mathrm{N}=9$, range $10-19$ years, 7 males, 2 females $)$. The mean age of the Control $(\mathrm{CNT})$ group $(\mathrm{N}=11)$ was $14.8 \pm 4.5$ years $(9-21$ years, 8 males, 3 females). The age difference between groups was not significant. Six subjects from the ADHD group and six subjects from the ASD group were on medication. The children with ADHD were taking prescribed stimulants (Methylphenidate or Dextroamphetamine). Two children with ASD were also taking prescribed stimulants (Concerta, Adderall), and four were taking antidepressants (Fluoxetine, Sertraline) and mood stabilizers (Divalproex, Ariprazole). Two children in the ASD group had comorbid mild mood disorders and two had co-occurring anxiety disorders. One subject from the ADHD group had comorbid mild mood disorder, and one had anxiety disorder. These cooccurring conditions were assumed to be insignificant for the purposes of this study. 


\section{DATA COLLECTION}

All EEG data used in this study was collected with a 128-channel Geodesics system (Net Station 200, v. 4.0) (Electrical Geodesics Inc. [EGI], OR), and was processed with a Macintosh G4 computer. EEG signals were sampled at $500 \mathrm{~Hz}$ during the categorization task and passed through an analog bandpass filter $(0.1-200 \mathrm{~Hz})$. A referential montage was used to standardize the EEG signals, with the reference point set as the vertex at position Cz. The Geodesic Sensor Net used was a lightweight, elastic structure housing silver/silver-chloride electrodes within a synthetic sponge on a pedestal. The sensor net was adjusted prior to the beginning of data collection to ensure that it fit the subject snugly, maximizing the contact made with the scalp, and minimizing the interference from nearby facial muscles (Figure 2). Sponges were soaked in potassium chloride prior to testing to promote electrode conductivity. Sensor impedance was maintained below the recommended manufacturer specification of $40 \mathrm{k} \Omega$. 


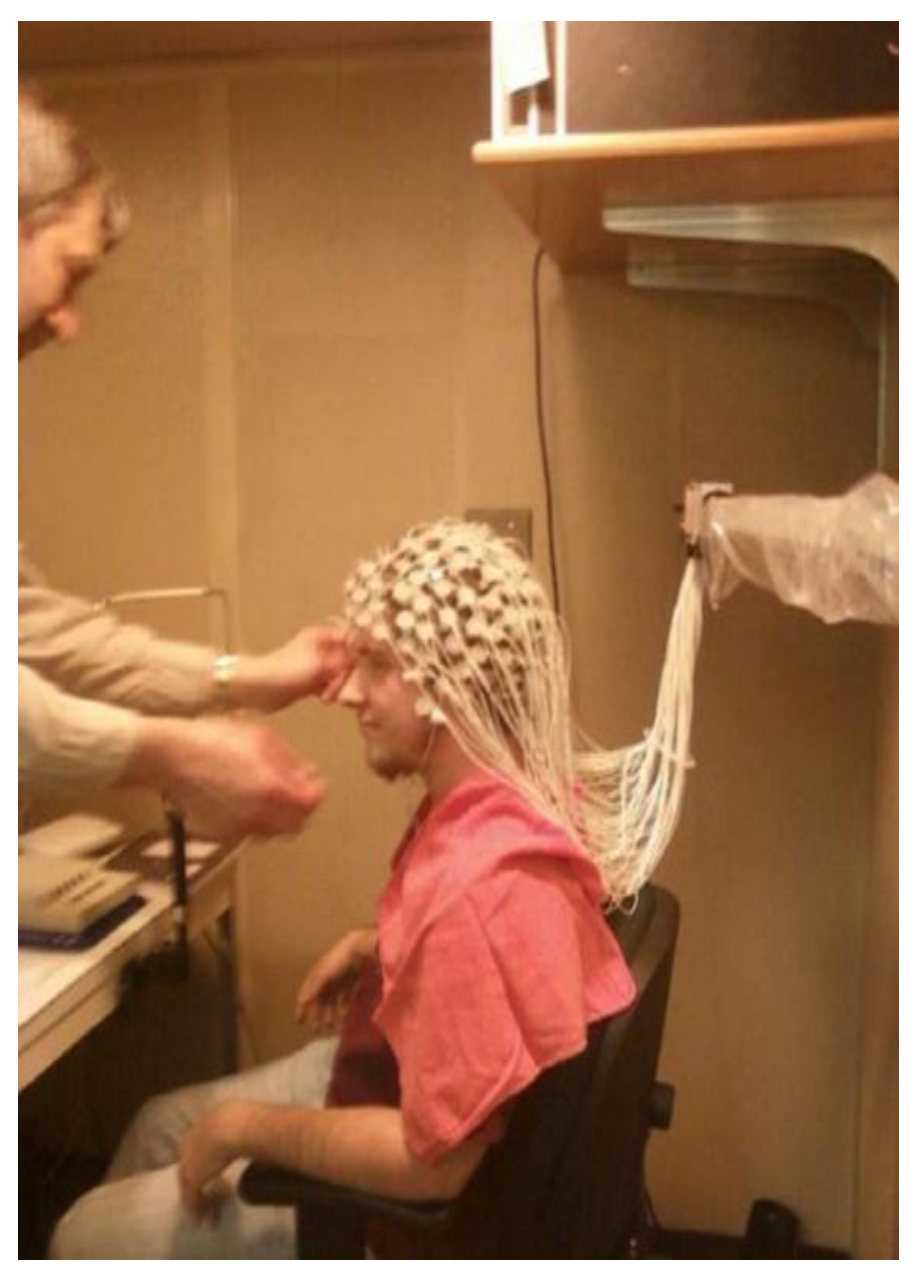

Figure 2 - The 128-channel EEG sensor net and testing room used in this study. The net was adjusted to fit the scalp of each subject individually to ensure that the electrodes were appropriately placed. The subject was seated in front of a computer display where visual stimuli were presented for the categorization task. Note that the subject seen in this picture was not a participant of this study.

Stimulus presentation for the gender/emotion recognition task was controlled via the E-prime software (Psychology Software Tools, Sharpsburg, PA) running on a personal computer. This software package is commonly used to design psychological experimental procedures using timed stimuli and signal recording. Facial images for the categorization task were presented on a fifteen inch flat-panel display. Subjects were seated during the study, and a chinrest was provided to keep the center of the display 
approximately $50 \mathrm{~cm}$ from the subject's eyes. Subject responses to the stimuli were collected via a keypad connected to the testing computer terminal (Serial Box, Psychology Software Tools, Sharpsburg, PA). Instructions varied between the four blocks of the study, and were presented on the screen to the subject prior to beginning a new segment of the test. All four segments required the subject to select one of two choices by pressing the corresponding button on the keypad explained in the instructions.

The experiment was divided into four segments, corresponding to four categories of facial images presented in the experiment: (1) gender recognition with neutral expressions, (2) gender recognition with emotional expressions, (3) anger versus disgust recognition, and (4) fear versus sadness recognition. The presentation of blocks in the study was counter-balanced to keep ordering effects negligible. In each section, the subject was asked to categorize the displayed face into one of two groups, differentiating either the gender or the perceived emotional state of the individual in the image. The subjects indicated their selection by pressing the corresponding button on the keypad. Each category contained sixty images for the subject to differentiate. Every image remained on the screen for a $300 \mathrm{~ms}$ period. Pauses between stimuli ranged from 1100$1300 \mathrm{~ms}$ to avoid anticipatory effects. EEG recording occurred throughout the entire experimental procedure, but was later segmented into smaller data segments for more efficient analysis (Figure 3). The complete four category experiment took approximately twenty minutes to complete, including short breaks that were provided between image categories, presentation of the instructions, and brief practice sessions prior to each category. 


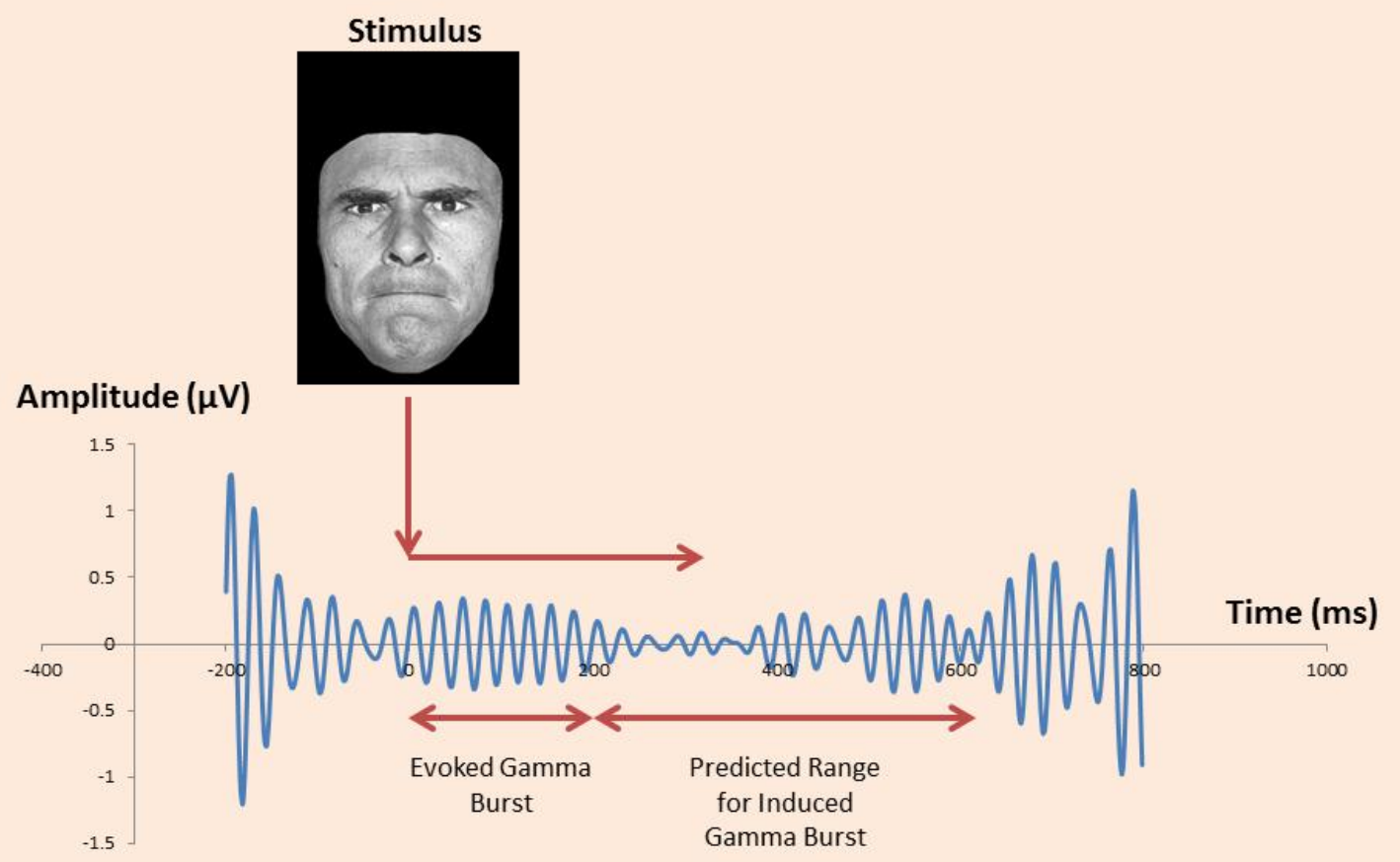

Figure 3 - A visual representation of the categorization task. Each image remained on the screen for $300 \mathrm{~ms}$. The subject was given approximately $1100-1300 \mathrm{~ms}$ to categorize the face into one of two groups before the next image appeared on the screen. The time between images varied to discourage anticipation. Segmentation was performed for each image starting $200 \mathrm{~ms}$ before stimulus presentation, to $800 \mathrm{~ms}$ after stimulus presentation.

Each facial image category contained twenty-four unique black-and-white images, with equal representation of male and female subjects. Similarly, in emotion recognition tasks, each emotion was equally represented. The hair from all subjects in the images was removed to increase the difficulty of the categorization task. Seventy-two total images were used for all four categories, with some reuse between categories. All 
images were randomly selected from standard databases of facial pictures developed for similar studies (Pictures of Facial Affect, Paul Ekman 1976-2004, Berkeley, CA; JACFEE/JACNeuF, David Matsumoto and Paul Ekman, 1988-2004, Berkeley CA). The subjects were required to complete sixty trials for each section corresponding to a different facial image category (Figure 4).

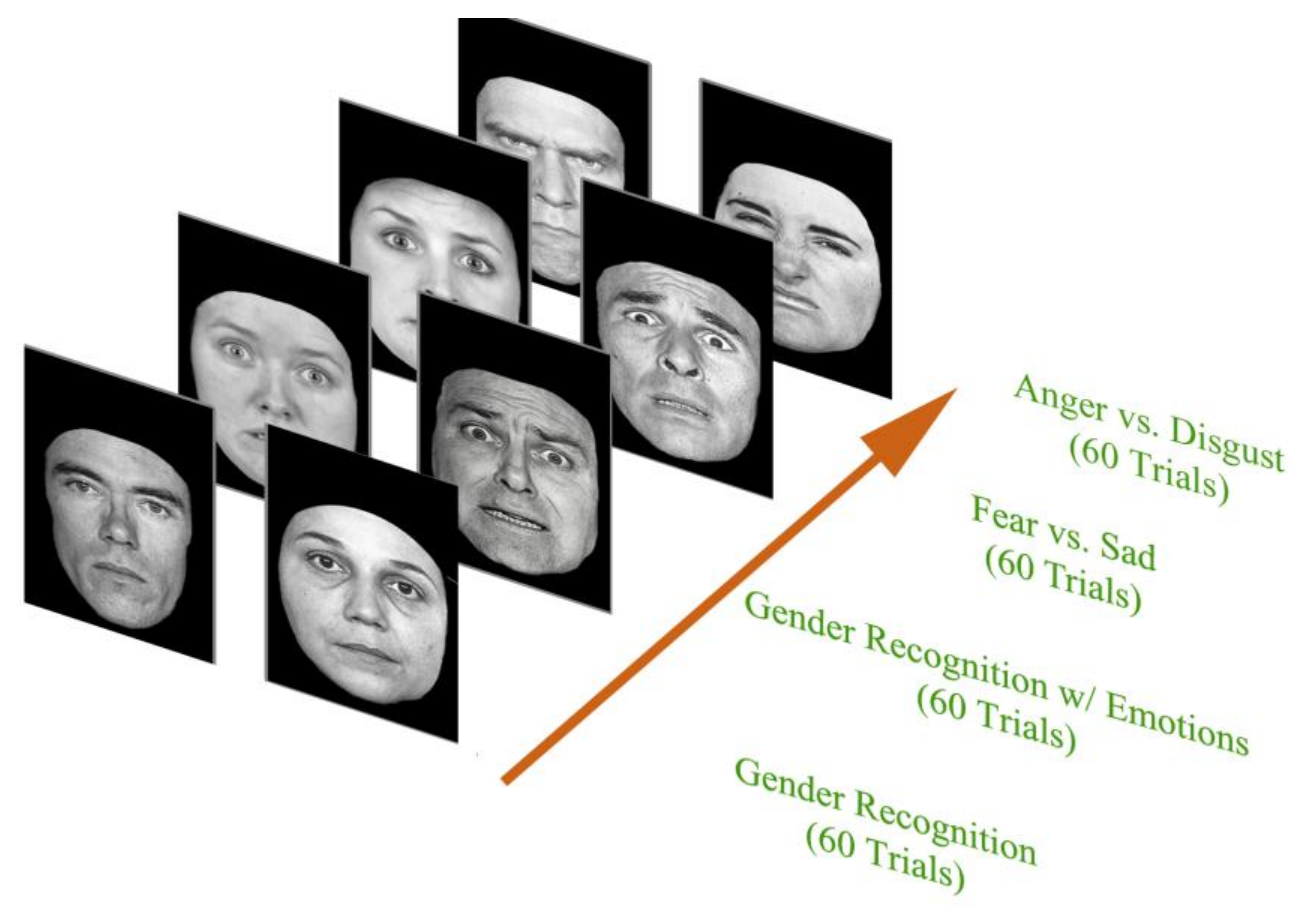

Figure 4 - A representation of the four block experimental study and examples of the facial images used during the test procedure. Participants were asked to distinguish a face as belonging to one of two groups: male or female, angry or disgusted, or fearful or sad.

Each test block consisted of sixty trials, with twenty-four unique images per trial.

The collected EEG recordings were stored in Net Station (EGI), tagged according to test category, and segmented offline into one second trials. The collected trials were first divided by subject type (ADHD, ASD, or control), and then kept separate for each 
individual subject within that type. The data was then organized into four experimental conditions based on the task the subject was asked to perform: 1) Gender RecognitionAll, 2) Emotion Recognition-All, 3) Anger/Disgust Recognition, and 4) Fear/Sad Recognition (Figure 5). 11 of the 128 EEG channels were selected for induced gamma power analysis and further data processing (Figure 6). Approximately thirty trials were used for analysis in the Anger/Disgust and Fear/Sad recognition for each subject, and sixty trials were used in the Gender/Emotion Recognition. This data was exported into MATLAB for further signal processing. All subjects included in this study completed the entirety of the experiment, and had a sufficient amount of data for each experimental condition.

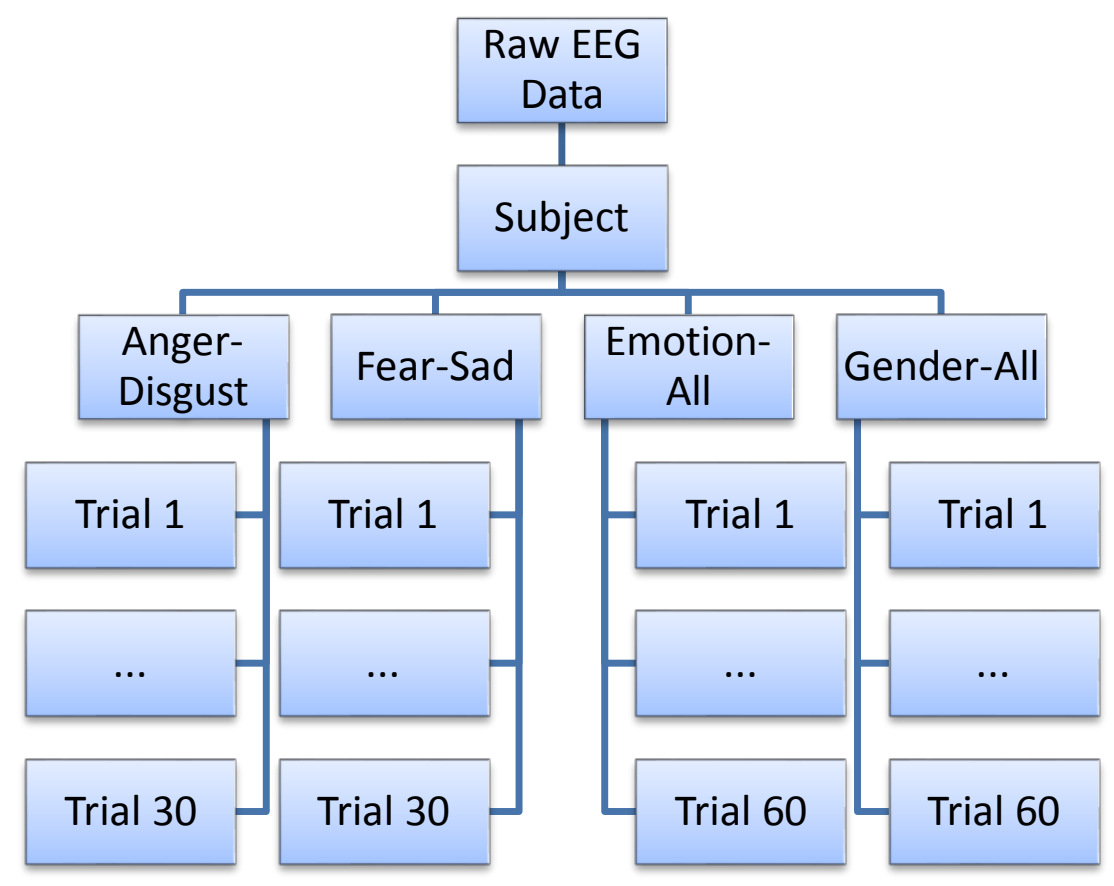

Figure 5 - The four experimental categories used for data analysis. For each subject, sixty trials were selected for analysis in the gender and overall emotion recognition categories, while thirty were selected for the individual emotion recognition tasks (i.e. anger versus disgust). 


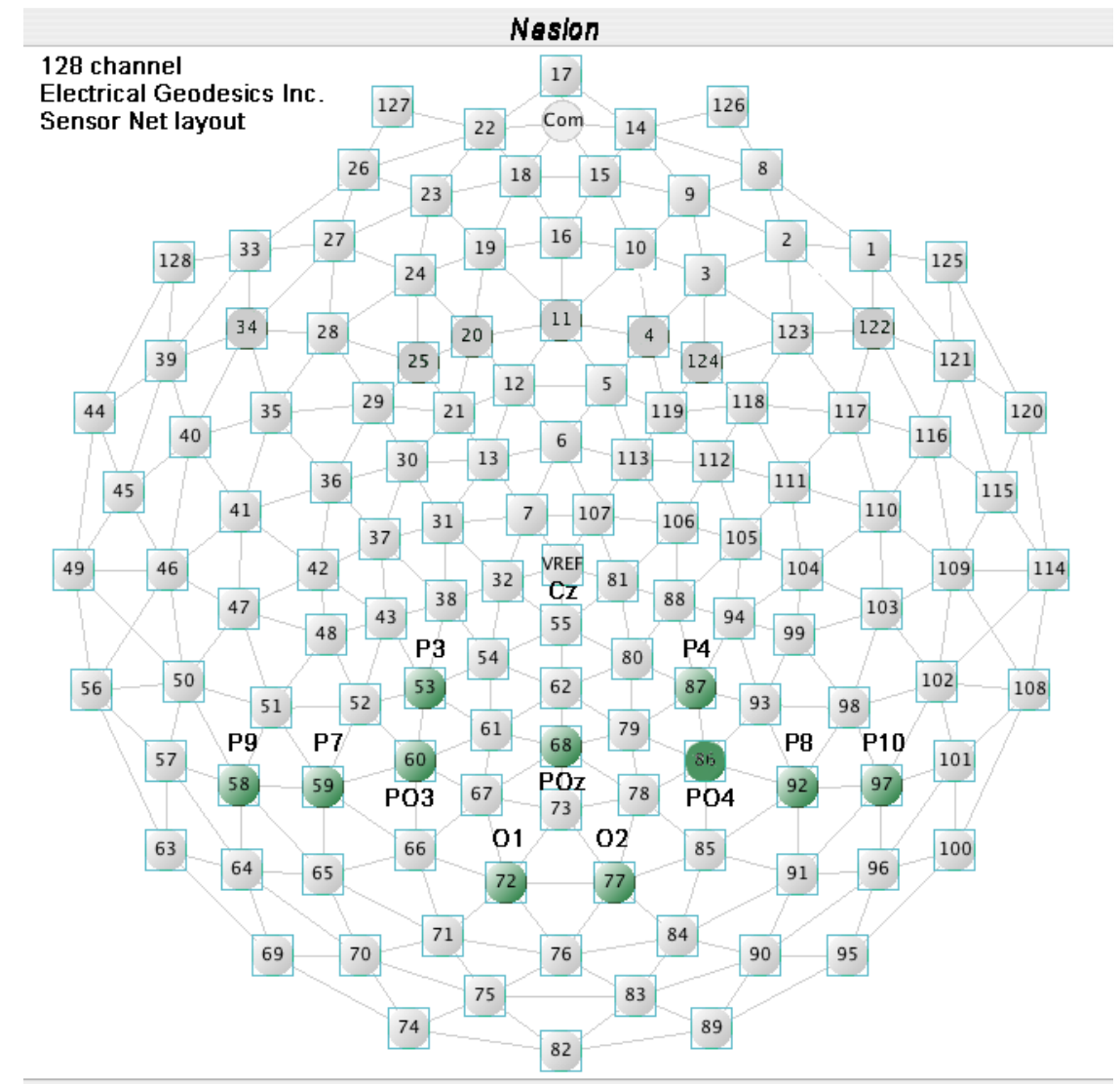

Figure 6 - Location of the eleven electrodes selected for analysis in this study. 


\section{DATA ANALYSIS}

\section{Filtering Technique}

After the collected EEG trials from the gender/emotion categorization task were organized as previously described, they were processed via Wavelet analysis. This technique allows for visualization of the collected signals in both the time and frequency domains, and can be used to isolate the frequencies of interest (i.e. the gamma band) from the broad spectra of EEG waveforms in combination with a digital filter. Wavelet analysis provides information about the dynamic changes in amplitude of gamma waveforms at varying frequencies within the selected time interval, as opposed to the static perspective offered by more traditional methods of Fourier analysis. In this study, a one-dimensional continuous wavelet transform (Equation 1) was performed using the MATLAB Wavelet Toolbox. 


$$
C W T \frac{\psi}{x}(\tau, s)=\frac{1}{\sqrt{s}} \int\left[\left(x(t) \psi *\left(\frac{t-\tau}{s}\right) d t\right]\right.
$$

Equation 1: The general formula for the continuous Wavelet transform utilized in the signal processing portion of this study.

The Morlet window was selected as the mother wavelet $(\psi)$ in this analysis, a plot of which can be seen in Figure 7. The continuous wavelet transform created 128 coefficients for each trial that underwent data analysis. The range of these coefficients contained information about the higher frequency (represented by lower coefficient numbers) and lower frequency (represented by higher coefficient number) components in the signal.

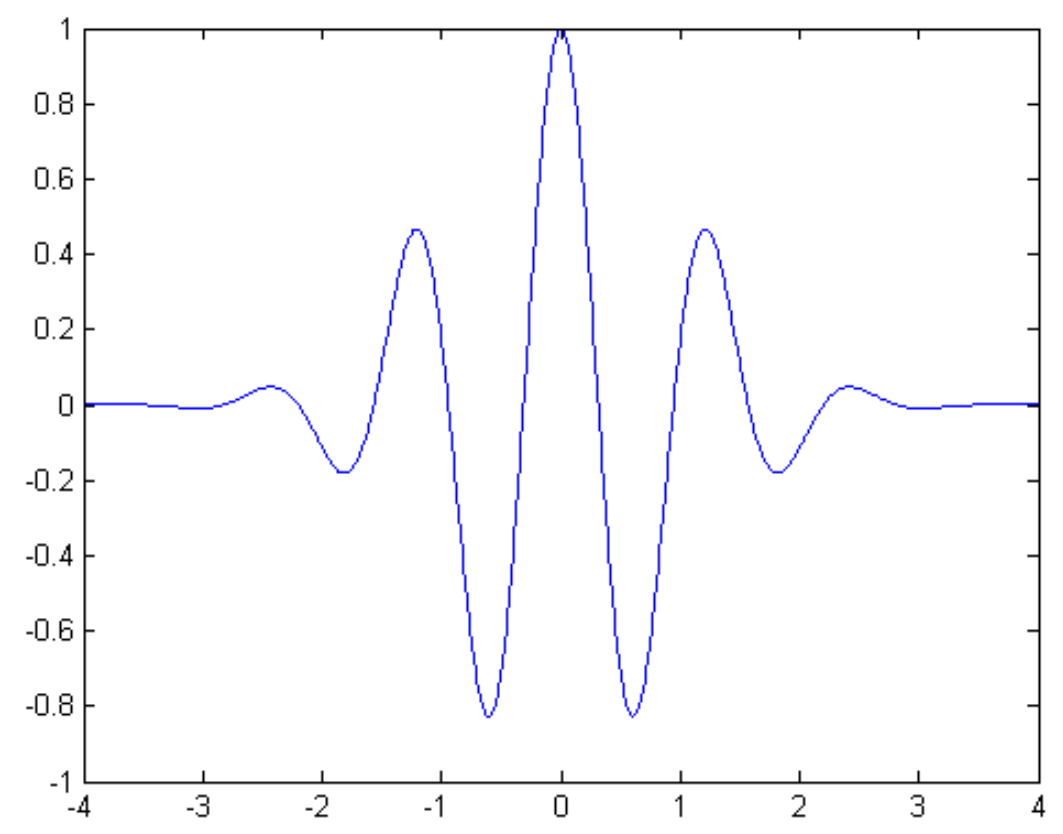

Figure 7: A graphical representation of the Morlet window used in the continuous onedimensional wavelet analysis. 
Following wavelet analysis, a custom bandpass filter with a Harris 7 window was applied to the signals to isolate frequencies of interest. This filter allowed for the passage of the gamma frequencies between $35-45 \mathrm{~Hz}$ with a two $\mathrm{Hz}$ attenuation band. The Harris window used in the filter design was composed of 725 samples. A similar Wavelet/Harris filtering technique was used in previous gamma analysis studies on neurofeedback and cue reactivity (Horrell et al., 2010).

\section{$\underline{\text { Data Alignment }}$}

Filtered data was further processed in MATLAB to create two datasets for analysis: one unaligned dataset (similar to what would be used in traditional EEG studies) to serve as a control, and another analogous dataset created after utilizing the proposed alignment technique on the segmented EEG trials. To construct the aligned dataset, segmented trials were organized into groups by subject, experimental condition, and EEG channel (i.e. thirty trials in group Eric-Anger/Disgust-P3, etc.). Within each group, the first trial was selected as the setpoint for that group to be used in the data alignment step. A $400 \mathrm{~ms}$ window from 200 to $600 \mathrm{~ms}$ post-stimulus was then segmented from the setpoint trial to capture the range of time where induced gamma activity is expected to occur.

Subsequent trials in the group were then compared to the setpoint. For each trial, a $400 \mathrm{~ms}$ window starting at $100 \mathrm{~ms}$ post-stimulus was initially selected (i.e. 100 to $500 \mathrm{~ms}$ post-stimulus). The two-dimensional Pearson-Product Moment correlation coefficient (Equation 2) was then calculated between this window and the setpoint. The window was shifted by $2 \mathrm{~ms}$ forward in time (i.e. 102 to $502 \mathrm{~ms}$ post-stimulus) and the coefficient 
calculation was repeated. This process was performed iteratively 101 times, shifting the window incrementally to cover a total time span of 100-700 ms post-stimulus in $400 \mathrm{~ms}$ segments. The $400 \mathrm{~ms}$ window with the largest positive correlation coefficient was then selected as the 'aligned' form of the signal, and was exported into the database for aligned trials. (Figure 8) This process was repeated for all signals within a group, and for all groups in the original dataset.

$$
r=\frac{\sum_{m} \sum_{n}\left(A_{m n}-\bar{A}\right)\left(B_{m n}-\bar{B}\right)}{\sqrt{\left(\sum_{m} \sum_{n}\left(A_{m n}-\bar{A}\right)^{2}\right)\left(\sum_{m} \sum_{n}\left(B_{m n}-\bar{B}\right)^{2}\right)}}
$$

Equation 2: The formula to calculate the Pearson-Product Moment correlation coefficient, which was used to find the level of similarity between the setpoint and the subsequent trials for the alignment technique. 


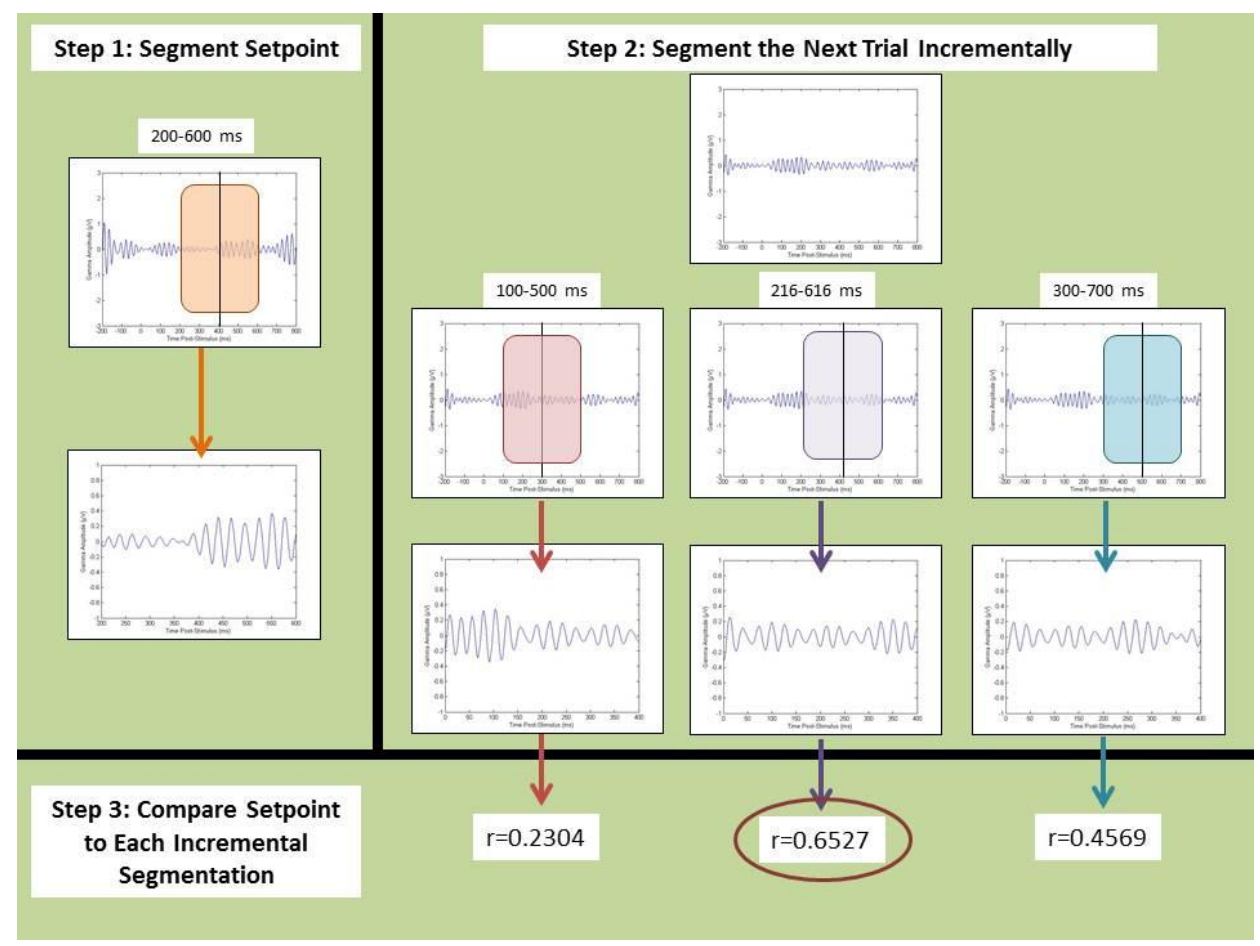

Figure 8 - The step-by-step procedure of the alignment technique. First, the setpoint is chosen by segmenting the first signal in a set from 200-600 ms post-stimulus. Subsequent trials are then incrementally segmented in $400 \mathrm{~ms}$ pieces starting at $100 \mathrm{~ms}$ post-stimulus,

with a $2 \mathrm{~ms}$ shift each increment. The correlation coefficient is calculated for each increment, and the level of shift that produces the highest positive coefficient value is selected as the 'aligned' $400 \mathrm{~ms}$ segment for analysis. This process is repeated for each trial within a set until each trial is aligned to the setpoint.

An unaligned database was also created by simply segmenting the original trials from 200 to $600 \mathrm{~ms}$ post-stimulus without utilizing any alignment technique. The unaligned segmented trials were organized into the same groups as the aligned dataset, so that they would be analogous to one another in the analysis phase. 


\section{Averaging and Gamma Power Calculation}

Trials within each group were averaged together in MATLAB to produce a 400 ms signal for both the aligned and unaligned datasets. Gamma power was calculated by summing the squares of the amplitude at each point in the averaged signals. Gamma power was reported in units of $\mu \mathrm{V}^{2}$. A flowchart depicting the data analysis steps for the aligned dataset is shown in Figure 9.

$\Rightarrow \begin{gathered}\text { EEG Data } \\ \begin{array}{c}\text { Wegmented } \\ \text { into Individual } \\ \text { Trials }\end{array}\end{gathered} \Rightarrow \begin{gathered}\text { Bandpass Filter } \\ \text { Analysis via } \\ \text { Morlet } \\ \text { Window } \\ \text { for Gamma } \\ (35-45 \mathrm{~Hz})\end{gathered} \Rightarrow \begin{gathered}\text { Data Alignment } \\ \text { via Correlation } \\ \text { Coefficient }\end{gathered} \Rightarrow \begin{gathered}\text { Grand Average } \\ \text { of Aligned } \\ \text { Signals }\end{gathered}$

Figure 9 - A flowchart depicting the steps in the data analysis procedure for the aligned dataset. The unaligned dataset was created similarly, with the exclusion of the data alignment phase in the flowchart.

Power values from both datasets were organized into tables for statistical analysis. Within each subject type and experimental condition pairing (i.e. ADHD, Anger/Disgust, etc.) outliers were identified and removed using two standard deviations from the mean as the initial exclusion criteria. Subjects who had power values excluded for a particular EEG channel were retained in the study if other channels had values that were not excluded. If a power value for a particular subject, experimental condition, and channel (i.e. Eric-Anger/Disgust-P3, etc.) was excluded in the aligned dataset, the corresponding value was also excluded in the unaligned dataset, even if the unaligned value fell within two standard deviations of the mean for the unaligned pairing. Similarly, values excluded in the unaligned dataset caused the removal of the corresponding values in the aligned 
dataset. This step was performed to ensure that two datasets could be compared to one another fairly.

\section{$\underline{\text { Statistical Analysis }}$}

Data analysis was performed in SPSS (v. 18) and MINITAB (v. 16). Gamma power values calculated in the previous step were loaded into the program following the removal of outliers. A repeated measures analysis of variance (ANOVA) was performed with a combination of the following factors: experimental condition (Anger/Disgust, Fear/Sad, etc.), channel (P3, P4, etc.), hemisphere (right or left), alignment (aligned and unaligned) and in between subjects recruited for the study. Subjects were also split into subject groups (ADHD, ASD, or control) for some ANOVA models. Models were constructed to test for significant interactions between subject group, experimental condition, hemisphere, and alignment for channel pairs (i.e. P3 and P4, P7 and P8, etc.). Experimental conditions varied in our ANOVA models. Simple models compared the gender and emotion recognition tasks generally (i.e. Gender All vs. Emotion All) while more specific models looked at the individual emotion recognition tasks separately and compared them to the gender recognition task (i.e. Anger/Disgust vs. Gender All). Greenhouse-Geisser corrected p-values were used for determination of statistical significance when appropriate. 


\section{RESULTS}

\section{$\underline{\text { Main Effect of Data Alignment }}$}

A significant main effect of alignment $(\mathrm{F}=995.89, \mathrm{p}<0.0001)$ was observed across all parietal and occipital channels collected (P3, P4, P7, P8, P9, P10, POz, PO3, PO4, O1, O2). The significant main effects and interactions of the Anger/Disgust, Fear/Sad, Gender-All model are reported in Table I. This main effect of alignment was observed in all ANOVA models regardless of the experimental conditions selected for comparison. Similarly, the significant main effect for alignment was observed individually in all channels and hemispheric channel pairs. Line plots created in MINITAB depict the difference between averaged aligned and unaligned power values across subject and experimental conditions, as shown in Figure 10. 
TABLE I

ANOVA TABLE FOR INDUCED GAMMA POWER

\begin{tabular}{|c|c|c|c|c|c|c|c|c|}
\hline \multirow{2}{*}{$\frac{\text { Factor }}{\text { Condition }}$} & \multirow{2}{*}{$\frac{\text { Type }}{\text { fixed }}$} & Levels & \multicolumn{6}{|l|}{ Values } \\
\hline & & 3 & \multicolumn{4}{|c|}{ Anger-Disgust, Fear-Sad, Gender-All } & & \\
\hline Alignment & fixed & 2 & \multicolumn{4}{|c|}{ Aligned, Unaligned } & & \\
\hline Group & fixed & 3 & \multicolumn{4}{|c|}{ ADHD, Autism, Control } & & \\
\hline \multicolumn{9}{|c|}{ Analysis of Variance for Power-P, using Adjusted SS for Tests } \\
\hline \multicolumn{3}{|l|}{ Source } & $\mathrm{DF}$ & Seq SS & Adj SS & Adj MS & $\mathbf{F}$ & $\mathbf{P}$ \\
\hline \multicolumn{3}{|l|}{ Condition } & 2 & 11.41 & 11.52 & 5.76 & 3.45 & 0.032 \\
\hline \multicolumn{3}{|l|}{ Alignment } & 1 & 1670.95 & 1663.13 & 1663.13 & 995.89 & 0.000 \\
\hline \multicolumn{3}{|l|}{ Group } & 2 & 80.12 & 80.03 & 40.01 & 23.96 & 0.000 \\
\hline \multicolumn{3}{|c|}{ Condition*Alignment } & 2 & 2.64 & 2.52 & 1.26 & 0.76 & 0.470 \\
\hline \multicolumn{3}{|c|}{ Condition*Group } & 4 & 2.39 & 2.39 & 0.60 & 0.36 & 0.839 \\
\hline \multicolumn{3}{|c|}{ Alignment*Group } & 2 & 0.98 & 1.04 & 0.52 & 0.31 & 0.733 \\
\hline \multicolumn{3}{|c|}{ Condition*Alignment*Group } & 4 & 17.91 & 17.91 & 4.48 & 2.68 & 0.030 \\
\hline \multicolumn{3}{|l|}{ Error } & 1824 & 3046.07 & 3046.07 & 1.67 & & \\
\hline \multicolumn{3}{|l|}{ Total } & 1841 & 4832.46 & & & & \\
\hline
\end{tabular}

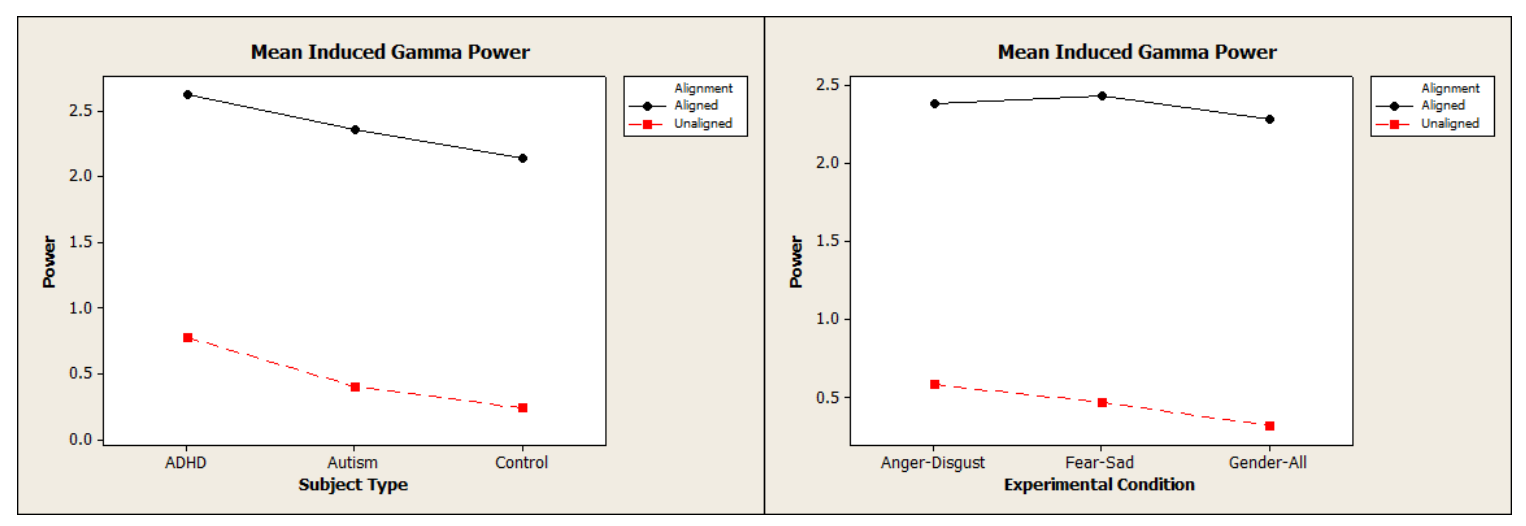

Figure 10 - Line plots emphasizing the difference between aligned and unaligned averaged power values across subject types (Left) and experimental conditions (Right).

A direct comparison of the aligned and unaligned signals was performed in MATLAB. Coinciding with the statistical analysis previously described, the amplitude of 
the aligned waveforms appeared to be higher, resulting in greater overall power values for the aligned dataset. Two graphs prepared in MATLAB shown in Figure 11 provide an example of the difference between the aligned and unaligned waveforms for a single channel, subject, and experimental condition (i.e. P7-Eric-Anger/Disgust).
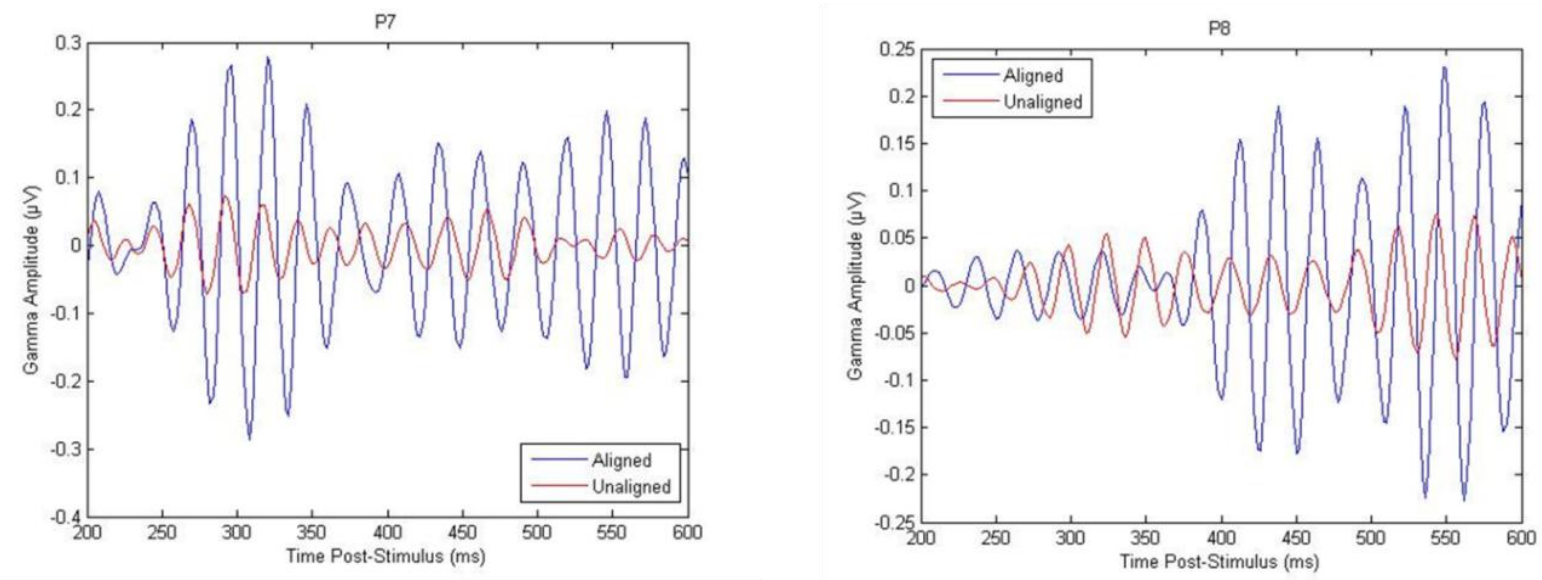

Figure 11 - An example of aligned and unaligned EEG signals in parietal channels for a single subject and experimental condition (i.e. Eric - Anger/Disgust) in two different channels.

\section{Additional Main Effects}

Significant main effects for experimental condition $(\mathrm{F}=3.45, \mathrm{p}=0.032)$ and subject group $(\mathrm{F}=23.96, \mathrm{p}=0.000)$ were also present across all parietal and occipital channels in the Anger/Disgust, Fear/Sad and Gender-All ANOVA model, as reported in Table I. Figure 12 depicts these main effects across both the aligned and unaligned datasets. 


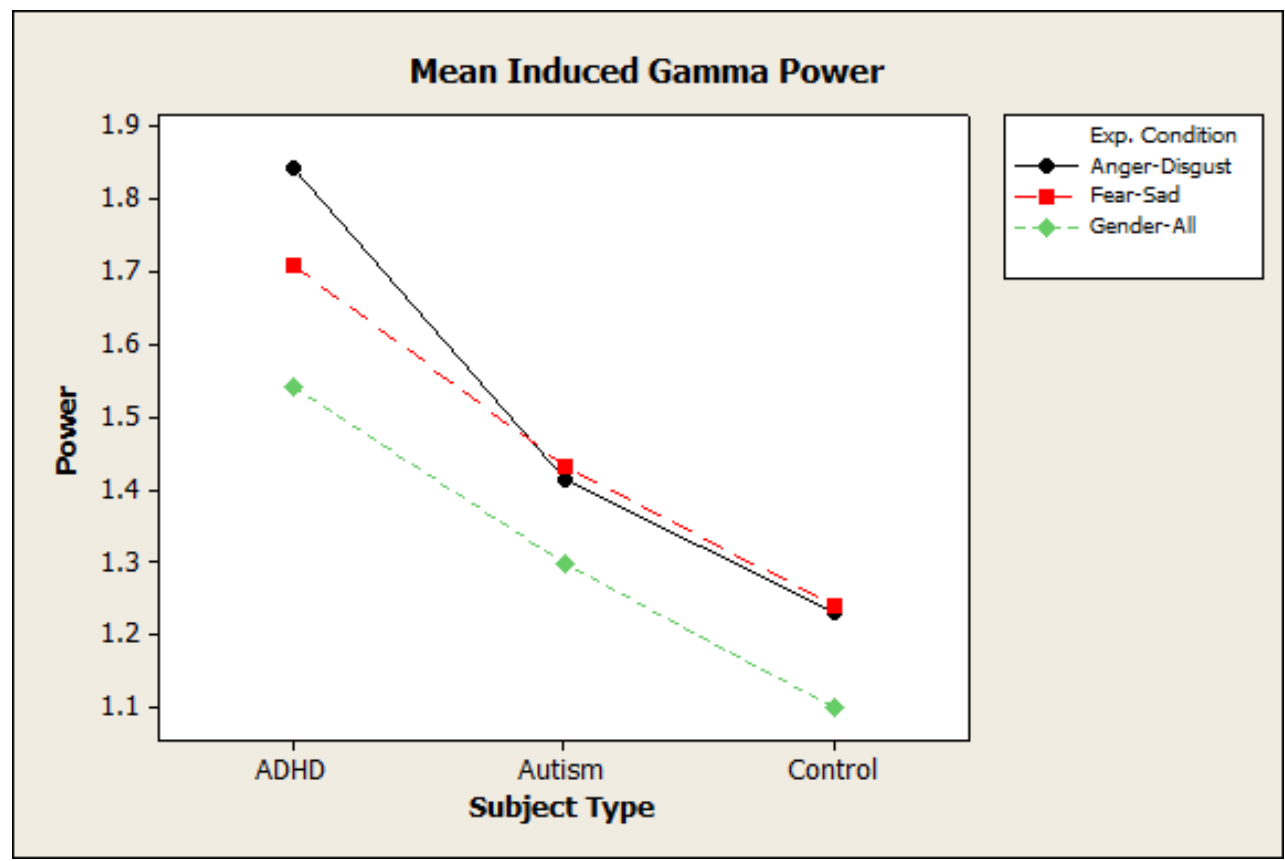

Figure 12 - A graph depicting the main effects of experimental condition and subject type across both the aligned and unaligned datasets. The emotional tasks were significantly higher in average mean induced gamma power for all subject types. Similarly, power values from $\mathrm{ADHD}$ subjects appeared higher than those from autistic and control subjects.

\section{$\underline{\text { Significant Interactions }}$}

Significant Group-Condition-Alignment three-way interactions were observed generally across the parietal and occipital channels in the Anger/Disgust, Fear/Sad, Gender-All ANOVA model $(\mathrm{F}=2.68, \mathrm{p}=0.030)$. No significant two-way interactions were present across all channels when using this model.

In an ANOVA model that compared the Anger/Disgust recognition task to the gender recognition task, significant interactions could be seen in the P3-P4 channels $(\mathrm{F}=3.43, \mathrm{p}=0.048)$ and $\mathrm{P} 7-\mathrm{P} 8$ channels $(\mathrm{F}=4.304, \mathrm{p}=0.025)$. As shown in Figure 13, significant effects of Condition-Group pairings became more apparent in the aligned 
datasets. Descriptive statistics for P3-P4 and P7-P8 three-way interaction groups are provided in Table II.
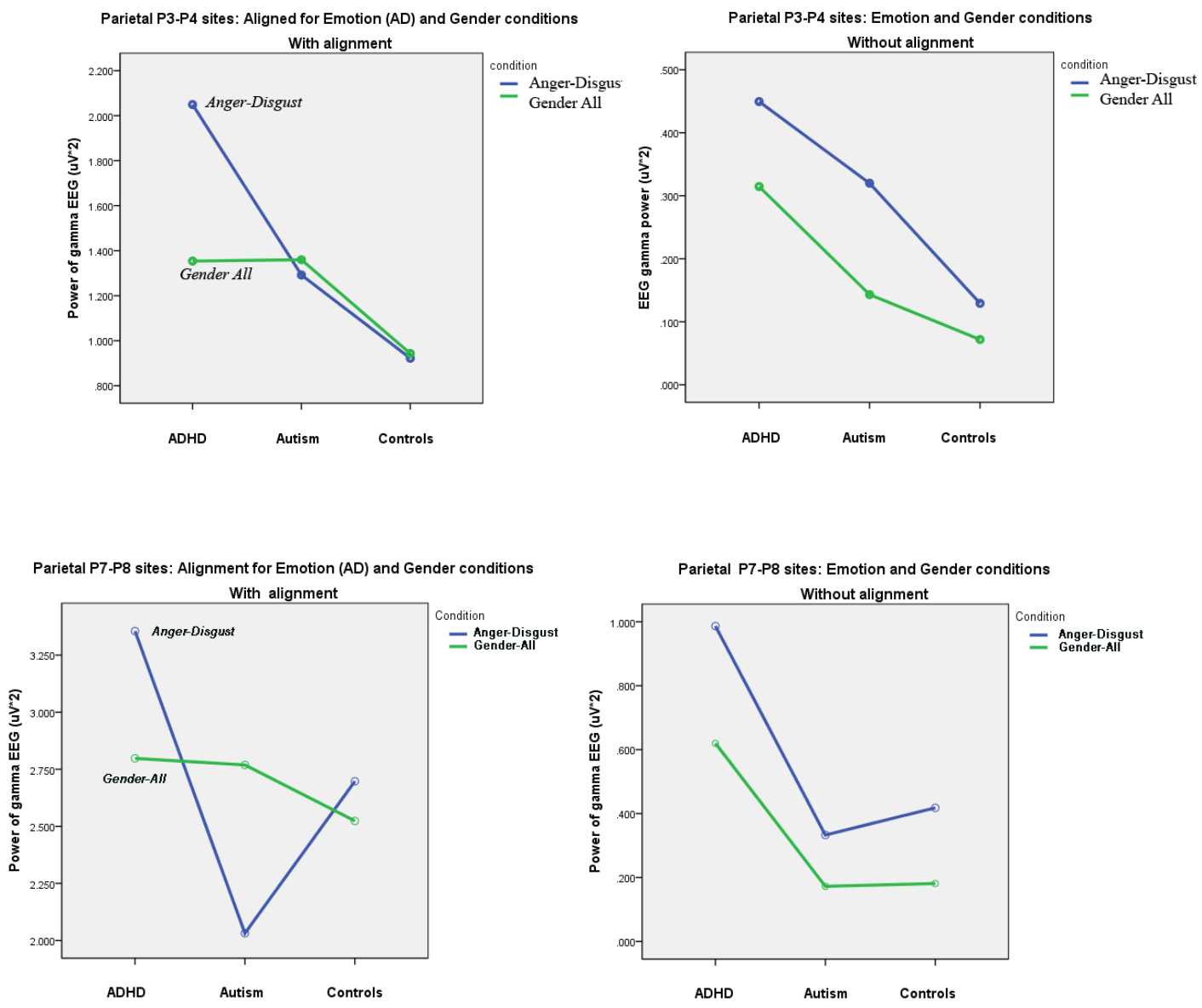

Figure 13 - Interaction plots for parietal channels depicting differences in Condition, Group, and Alignment pairings. Plots revealed significant interactions in the aligned dataset that would otherwise have gone unnoticed. Top: Channel pair P3-P4, Bottom:

Channel pair: P7-P8 
TABLE II

DESCRIPTIVE STATISTICS FOR SIGNIFICANT PARIETAL CHANNEL PAIRINGS

\begin{tabular}{|c|c|c|c|c|c|c|}
\hline & & & \multicolumn{2}{|c|}{ Aligned } & \multicolumn{2}{c|}{ Unaligned } \\
\hline \multirow{4}{*}{$\begin{array}{c}\text { Patient } \\
\text { Group }\end{array}$} & $\begin{array}{c}\text { Experimental } \\
\text { Condition }\end{array}$ & Mean & $\begin{array}{c}\text { Standard } \\
\text { Error }\end{array}$ & Mean & $\begin{array}{c}\text { Standard } \\
\text { Error }\end{array}$ \\
\hline & ADHD & Anger/Disgust & 2.049 & 0.286 & 0.450 & 0.126 \\
\cline { 2 - 7 } & ADHD & Gender All & 1.354 & 0.203 & 0.315 & 0.084 \\
\cline { 2 - 7 } & Autism & Anger/Disgust & 1.292 & 0.283 & 0.320 & 0.126 \\
\cline { 2 - 7 } & Autism & Gender All & 1.360 & 0.203 & 0.143 & 0.084 \\
\cline { 2 - 7 } & Control & Anger/Disgust & 0.922 & 0.271 & 0.129 & 0.120 \\
\cline { 2 - 7 } & Control & Gender All & 0.943 & 0.192 & 0.072 & 0.080 \\
\hline \multirow{4}{*}{ P7 - P8 } & ADHD & Anger/Disgust & 3.355 & 0.500 & 0.987 & 0.215 \\
\cline { 2 - 7 } & ADHD & Gender All & 2.798 & 0.491 & 0.620 & 0.160 \\
\cline { 2 - 7 } & Autism & Anger/Disgust & 2.031 & 0.530 & 0.333 & 0.228 \\
\cline { 2 - 7 } & Autism & Gender All & 2.769 & 0.520 & 0.172 & 0.169 \\
\cline { 2 - 7 } & Control & Anger/Disgust & 2.697 & 0.474 & 0.418 & 0.204 \\
\cline { 2 - 7 } & Control & Gender All & 2.524 & 0.465 & 0.181 & 0.151 \\
\hline
\end{tabular}




\section{DISCUSSION}

This study attempted to answer two proposed questions: can the attenuation observed in the induced portion of collected gamma oscillations be reduced by using a method of data alignment, and can this method contribute to the analysis of differences between ASD, ADHD, and TD subjects? The obtained results contributed to answering both of these questions. The method of data alignment used in this study, while simple in its implementation, is novel in its application to power analysis of EEG signals. This study serves as a pilot investigation for future Theory of Mind influenced experiments comparing ASD, ADHD, and TD subjects.

\section{$\underline{\text { Main Effect of Alignment }}$}

Overall, the main effect of the alignment technique $(\mathrm{p}<0.0001)$ was the most profound in the entire study. With very few exceptions, the aligned averaged power of the induced gamma oscillations had a higher value than their unaligned counterpart. This effect is most notably observed in Figure 11 and Table I, and suggests that the data alignment technique employed in this study effectively reduces the attenuation of induced

gamma waveforms for all channels, subject groups, and experimental conditions observed. 
The extremely large main effect of alignment may be explained by the nature of the MATLAB program utilized in this study. Our program aligned trials by shifting them within a fixed window of time to maximize the amount of overlap that occurs. This reduced the attenuation of the averaged signal. If the maximum overlap hypothetically occurred from trial to trial before performing any shift on the time axis, the 'aligned' dataset would be identical to the 'unaligned' dataset. Thus, the power of the aligned averaged waveform should always be equal to or greater than the power of the unaligned averaged waveform, since the program will not produce an aligned signal that is more attenuated than the unaligned signal. This effect was confirmed visually by examining the graphs of aligned and unaligned waveforms produced in MATLAB, as shown in Figure 11.

The averaged induced gamma oscillations graphed in MATLAB Figure 11 verify the conclusions drawn from the statistical analysis, clearly showing that the aligned counterpart had a higher maximum amplitude on average, and consequently, a higher overall power value. This effect does not appear to be entirely random. The aligned oscillation for channel P8 in Figure shows that the amplitude of the aligned signal remains relatively close to that of the unaligned signal until approximately $400 \mathrm{~ms}$ poststimulus. At this point, the aligned oscillation quickly grows in amplitude for the remainder of the segment. This suggests that the alignment technique used in this study does not artificially increase the amplitude at all points. If the induced gamma activity is only active during a particular window of the total time, then the aligned averaged oscillation produced will reflect that phenomena. Thus, the aligned averaged response appears to remain true to the behavior of the constituent signals. 


\section{Other Main Effects}

Although the focus of this study was on the effect of alignment, and how the technique may further understanding in the study of ADHD, ASD, and TD subjects, the experimental condition and subject group main effects are important to note. Had these effects appeared insignificant in the statistical analysis, the justification for using data alignment in these particular kinds of experiments would be significantly weakened. Detection of differences in the performance of subjects across different experimental conditions and subject groups verifies that this study is working with meaningful metrics, and coincides with expectations in the literature.

The main effect of experimental condition $(\mathrm{p}=0.032)$, as reported in Table I, suggests that the type of recognition task the subject was asked to perform had an effect on the induced gamma power recorded on average, regardless of the alignment method used, channel selected, or subject group observed. As shown in Figure 10, the emotion recognition tasks (i.e. Anger/Disgust, Fear/Sad) appeared to produce higher power levels on average than the gender recognition tasks. This coincides with the original hypothesis that suggested that the emotional recognition tasks would be more intensive than the simpler, gender recognition task.

Similarly, the main effect of subject group $(\mathrm{p}<0.01)$ reported in Table 1 suggests that the different types of subjects (i.e. ADHD, ASD, and TD) performed differently in the various tasks. This effect may also be observed in Figure 10, which suggests that the induced gamma power was higher in individuals with ADHD or ASD on average, across all channels, experimental conditions, and alignment methods. Because it is expected that 
children with neurodevelopmental disorders will struggle with these recognition tasks more than TD children, this result seems reasonable.

\section{$\underline{\text { Significant Interactions }}$}

Significant Group-Condition-Alignment three-way interactions seen in the parietal channels suggest that the alignment procedure produces data that better resolves the differences between Group-Condition pairings. Whereas significant Group-Condition effects would have gone unnoticed in the parietal channels with traditional techniques, alignment provided a means of visualizing these significant differences between ADHD, ASD and control subjects. This effect was observed across all parietal and occipital channels using the Anger/Disgust, Fear/Sad, Gender-All ANOVA model, as observed in Figure 12 and Table I, and in individual parietal channel pairings using the Anger/Disgust and Gender-All ANOVA model as shown in Figure 13 and Table II.

Multiple ANOVA models were used to identify the situations where the most significant results were produced. Although a general three-way significant interaction was observed using the Anger/Disgust, Fear/Sad, Gender-All ANOVA model across all parietal and occipital channels, the same effect was only observed in individual channel pairings (i.e. P3 and P4, P7 and P8) when the ANOVA model was changed to Anger/Disgust and Gender-All only. It is hypothesized that the Anger/Disgust task may produce the strongest emotional response during the study, effecting the highest induced power levels. Thus, by limiting the statistical analysis to the Anger/Disgust recognition task and the less difficult gender-recognition task, more significant interactions were observed when looking at the individual channel pairings. This simplified ANOVA 
model still provides useful information, because it compares an emotional recognition task to the gender recognition task across the various subject types and experimental conditions.

\section{Comparison of Induced Gamma Power in Subject Groups}

Prior to analysis, it was hypothesized that the emotion recognition tasks would be more challenging for ADHD and ASD subjects than the gender recognition tasks, and would be more likely to effect changes in the induced gamma waveforms between the subject groups. The significant interactions in Figure 13 reveal some trends that support this hypothesis. Within the aligned datasets, the power of the gender recognition task remained relatively constant between ASD, ADHD, and control subjects. Much greater variation is seen in the anger/disgust recognition task. ADHD subjects typically exhibited a higher induced gamma power during this task compared to the gender recognition task. Conversely, ASD subjects had a lower induced gamma in the anger/disgust recognition task versus the gender recognition task. Control subjects had relatively small differences between the induced power of the two tasks compared to ADHD (P3-P4 and P7-P8) and ASD (P7-P8) subjects.

Although these effects were not observed in other channel pairings, their effect was strong enough to cause the three-way interaction to be present in the statistical analysis of all of the parietal and occipital channels, as shown in Table 1. It is possible there was an insufficient amount of subjects or data samples in this study to reveal the significant three-way interaction in all channel pairings. It is also possible that this interaction may be limited to the parietal region covered by channels P3, P4, P7, P8. 
The parietal/occipital channels are of particular interest and were chosen for analysis because of their involvement with mentalizing and visual processes, and their proximity to the temporal region, where the fusiform face area is located. These regions are hypothesized to be connected to facial recognition mechanisms, and are the subjects of study in Theory of Mind research, particularly those studies that involve subjects with ASD.

This study is merely a pilot for future research into the induced gamma behavior of ASD, ADHD, and TD subjects during facial categorization and other ToM tasks. The statistical analysis demonstrated that the alignment method used identified interactions between subject groups and experimental conditions that would otherwise have gone unnoticed, and these differences coincide with expectations from the literature. Further investigation would be necessary to draw more rigorous conclusions from this type of study.

\section{Data Processing Method}

The outlined alignment procedure may be modified for future studies. A wide 400 ms window was selected to ensure that the induced gamma region of the signals was captured, though this window could be changed to any value less than the total length of the signal. Similarly, the selection of the setpoint window from 200 to $600 \mathrm{~ms}$ poststimulus could be shifted if the induced gamma is anticipated to occur at a different point in time. The incremental comparisons between the setpoint and subsequent trials in a group were made every $2 \mathrm{~ms}$ based on the system sampling frequency of $500 \mathrm{~Hz}$, though this value could be increased to improve the speed of the program at the cost of lower 
resolution. The time range examined in the incremental comparisons was set from 100 to 700 ms post-stimulus, but this range may be changed as needed.

A potential source of error this alignment technique introduces is the selection of a setpoint. In this study, the first trial in each Subject-Condition-Channel group was segmented from 200-600 ms, and used to align the subsequent trials in the group. If this trial had artifacts or grossly abnormal induced gamma activity, it is possible that the system may align the subsequent trials improperly. This may be alleviated by examining trials prior to analysis, as was done in this study. Future efforts may include incorporating an algorithm that examines the setpoint prior to alignment, and accepts or rejects it based on user-contributed criteria (i.e. amplitude threshold, minimum power, etc.).

An additional source of potential error in this study is the selection of EEG channels for analysis. Although the selected electrodes are organized into a standardized system to allow for some universal comparison, only ten of the 128 recording electrodes were analyzed. Many of these electrodes were in regions of no interest in this study (i.e. frontal, etc.) but other parietal/occipital electrodes could have been selected, that may have yielded different results upon analysis. 


\section{FUTURE WORK}

A potential modification to the data alignment technique involving peak detection was investigated during this study, but would require further refinement before it could be implemented for use. In brief, the MATLAB program would be designed to identify the region within the segmented trials with the highest amplitude (presumably where the peak of the induced gamma oscillations were occurring) and would take a power reading over a small window centered at that point. This could potentially eliminate the iterative process used in this study to align the signals to one another, which would reduce the time required to run the program. A future study could be performed comparing this alignment method to the correlation coefficient method proposed in this study.

Although the parietal and occipital channels were the subject of interest in this study, the same analysis could be applied to the frontal channels, where higher cognitive activities may be involved in the processing of the recognition tasks. As previously mentioned, the parameters of the data alignment process may be freely changed prior to analysis. If differences in the induced gamma behavior distinguished the frontal EEG channels from the parietal/occipital channels (i.e. window of activity), it would simply be a matter of identifying that behavior prior to analysis, and modifying the alignment procedure to compensate for those differences. 
This study compared differences between ADHD, ASD, and control subjects, but this same technique could be employed for other conditions, such as Parkinson's disease, Alzheimer's disease, post-traumatic stress disorder, and addiction disorders. Any condition where a visual, emotional, or attentional task may evoke unusual responses could serve as a potential candidate for further study via induced gamma waveform analysis. Similarly, the frequency band of interest may be modified simply by changing the Wavelet/Bandpass filter. Though $30-45 \mathrm{~Hz}$ is typically the region of interest for induced gamma studies, it is possible to expand the filter to include the higher gamma frequencies up to $80 \mathrm{~Hz}$. 


\section{REFERENCES}

American Psychiatric Association, (2000). Diagnostic and statistical manual of mental disorders : DSM-IV-TR. Washington, DC: American Psychiatric Association.

Baker, K. F., Montgomery, A. A., \& Abramson, R. (2010). Brief Report: Perception and lateralization of spoken emotion by youths with high-functioning forms of Autism. Journal of Autism \& Developmental Disorders, 40(1), 123-129. doi: 10.1007/s10803-0090841-1

Baron-Cohen, S. (2000). Theory of mind and autism: A review. In G. Laraine Masters (Ed.), International Review of Research in Mental Retardation (Vol. Volume 23, pp. 169-184): Academic Press.

Baron-Cohen, S., Wheelwright, S., Jolliffe, \& Therese. (1997). Is there a "Language of the Eyes"? evidence from normal adults, and adults with Autism or Asperger syndrome. Visual Cognition, 4(3), 311-331. doi: 10.1080/713756761

Başar-Eroglu, C., Strüber, D., Schürmann, M., Stadler, M., \& Başar, E. (1996). Gamma-band responses in the brain: a short review of psychophysiological correlates and functional significance. International Journal of Psychophysiology, 24(1-2), 101-112. doi: 10.1016/s0167-8760(96)00051-7

Başar, E., Schürmann, M., Başar-Eroglu, C., \& Demiralp, T. (2001). Selectively distributed gamma band system of the brain. International Journal of Psychophysiology, 39(2-3), 129-135. doi: 10.1016/s0167-8760(00)00136-7

Begeer, S., Koot, H. M., Rieffe, C., Meerum Terwogt, M., \& Stegge, H. (2008). Emotional competence in children with Autism: Diagnostic criteria and empirical evidence. Developmental Review, 28(3), 342-369. doi: 10.1016/j.dr.2007.09.001

Bora, E., Yücel, M., \& Pantelis, C. (2009). Theory of mind impairment: a distinct trait-marker for Schizophrenia spectrum disorders and bipolar disorder? Acta Psychiatrica Scandinavica, 120(4), 253-264. doi: 10.1111/j.1600-0447.2009.01414.x

Bosl, W., Tierney, A., Tager-Flusberg, H., \& Nelson, C. (2011). EEG complexity as a biomarker for autism spectrum disorder risk. BMC Medicine, 9(1), 18-33. doi: 10.1186/1741-7015-9-18

Brown, C., Gruber, T., Boucher, J., Rippon, G., \& Brock, J. (2005). Gamma abnormalities during perception of illusory figures in Autism. Cortex, 41(3), 364-376. doi: 10.1016/s00109452(08)70273-9 
Bühler, E., Bachmann, C., Goyert, H., Heinzel-Gutenbrunner, M., \& Kamp-Becker, I. (2011). Differential diagnosis of Autism spectrum disorder and Attention Deficit Hyperactivity Disorder by means of inhibitory control and 'Theory of Mind'. Journal of Autism \& Developmental Disorders, 41(12), 1718-1726. doi: 10.1007/s10803-011-1205-1

Buitelaar, J. K., Van Der Wees, M., Swaab-Barneveld, H., \& Van Der Gaag, R. J. (1999). Theory of mind and emotion-recognition functioning in Autistic spectrum disorders and in psychiatric control and normal children. Development and Psychopathology, 11(1), 3958.

Casanova, M. F., El-Baz, A., Elnakib, A., Switala, A. E., Williams, E. L., Williams, D. L., . . Conturo, T. E. (2011). Quantitative analysis of the shape of the corpus callosum in patients with Autism and comparison individuals. Autism: The International Journal of Research \& Practice, 15(2), 223-238. doi: 10.1177/1362361310386506

Chlebowski, C., Green, J. A., Barton, M. L., \& Fein, D. (2010). Using the childhood Autism rating scale to diagnose Autism spectrum Disorders. Journal of Autism \& Developmental Disorders, 40(7), 787-799. doi: 10.1007/s10803-009-0926-x

Clarke, A. R., Barry, R. J., Irving, A. M., McCarthy, R., \& Selikowitz, M. (2011). Children with Attention-Deficit/Hyperactivity Disorder and Autistic features: EEG evidence for comorbid disorders. Psychiatry Research, 185(1-2), 225-231. doi: 10.1016/j.psychres.2009.09.004

Colle, L., Baron-Cohen, S., \& Hill, J. (2007). Do children with Autism have a Theory of Mind? A non-verbal test of Autism vs. specific language impairment. Journal of Autism \& Developmental Disorders, 37(4), 716-723. doi: 10.1007/s10803-006-0198-7

Da Fonseca, D., Seguier, V., Santos, A., Poinso, F., \& Deruelle, C. (2009). Emotion understanding in children with ADHD. Child Psychiatry \& Human Development, 40(1), 111-121. doi: 10.1007/s10578-008-0114-9

Daoust, A.-M., Lusignan, F.-A., Braun, C. M. J., Mottron, L., \& Godbout, R. (2008). EEG correlates of emotions in dream narratives from typical young adults and individuals with Autistic spectrum disorders. Psychophysiology, 45(2), 299-308. doi: 10.1111/j.14698986.2007.00626.x

El-Baz, A., Elnakib, A., Casanova, M., Gimel'farb, G., Switala, A., Jordan, D., \& Rainey, S. (2011). Accurate automated detection of Autism related corpus callosum abnormalities. Journal of Medical Systems, 35(5), 929-939. doi: 10.1007/s10916-010-9510-3 
Faraone, S. V., Sergeant, J., Gillberg, C., \& Biederman, J. (2003). The worldwide prevalence of ADHD: is it an American condition?

First, M. B., Spitzer, Robert L, Gibbon Miriam, and Williams, Janet B.W. (2002a). Structured clinical interview for DSM-IV-TR Axis I Disorders, Research Version, Non-patient Edition. New York State Psychiatric Institute: Biometrics Research.

First, M. B., Spitzer, Robert L, Gibbon Miriam, and Williams, Janet B.W. (2002b). Structured clinical interview for DSM-IV-TR Axis I Disorders, Research Version, Patient Edition. New York State Psychiatric Institute: Biometrics Research.

Groen, Y., Wijers, A. A., Mulder, L. J. M., Waggeveld, B., Minderaa, R. B., \& Althaus, M. (2008). Error and feedback processing in children with ADHD and children with Autistic Spectrum Disorder: An EEG event-related potential study. Clinical Neurophysiology, 119(11), 2476-2493. doi: 10.1016/j.clinph.2008.08.004

Hakkaart-van Roijen, L., Zwirs, B. W. C., Bouwmans, C., Tan, S. S., Schulpen, T. W. J., Vlasveld, L., \& Buitelaar, J. K. (2007). Societal costs and quality of life of children suffering from attention deficient hyperactivity disorder (ADHD). European Child \& Adolescent Psychiatry, 16(5), 316-326. doi: 10.1007/s00787-007-0603-6

Herrmann, C. S., \& Demiralp, T. (2005). Human EEG gamma oscillations in neuropsychiatric disorders. Clinical Neurophysiology, 116(12), 2719-2733. doi: 10.1016/j.clinph.2005.07.007

Horrell, T., El-Baz, A., Baruth, J., Tasman, A., Sokhadze, G., Stewart, C., \& Sokhadze, E. (2010). Neurofeedback effects on evoked and induced EEG gamma band reactivity to drugrelated cues in cocaine addiction. Journal of Neurotherapy, 14(3), 195-216. doi: $10.1080 / 10874208.2010 .501498$

Kawatani, M., Hiratani, M., Kometani, H., Nakai, A., Tsukahara, H., Tomoda, A., . . Ohshima, Y. (2012). Focal EEG abnormalities might reflect neuropathological characteristics of pervasive developmental disorder and attention-deficit/hyperactivity disorder. Brain and Development(0). doi: 10.1016/j.braindev.2011.11.009

Knutson, K. C., \& O'Malley, M. (2010). Adult attention-deficit/hyperactivity disorder: A survey of diagnosis and treatment practices K.C. Knutson \& M. O'Malley Adult ADHD. Journal of the American Academy of Nurse Practitioners, 22(11), 593-601. doi: 10.1111/j.17457599.2010.00546.x 
Koehler, S., Lauer, P., Schreppel, T., Jacob, C., Heine, M., Boreatti-Hümmer, A., . . . Herrmann, M. J. (2009). Increased EEG power density in alpha and theta bands in adult ADHD patients. Journal of Neural Transmission, 116(1), 97-104. doi: 10.1007/s00702-008-0157-x

Kovatchev, B., Cox, D., Hill, R., Reeve, R., Robeva, R., \& Loboschefski, T. (2001). A Psychophysiological marker of Attention Deficit/Hyperactivity Disorder (ADHD)defining the EEG consistency index. Applied Psychophysiology \& Biofeedback, 26(2), 127-140.

Kuusikko, S., Haapsamo, H., Jansson-Verkasalo, E., Hurtig, T., Mattila, M.-L., Ebeling, H., . . . Moilanen, I. (2009). Emotion recognition in children and adolescents with Autism spectrum disorders. Journal of Autism \& Developmental Disorders, 39(6), 938-945. doi: 10.1007/s10803-009-0700-0

Le Couteur, A., Lord, C., \& Rutter, M. (2003). Autism diagnostic interview-revised: Autism Genetic Resource Exchange.

Lenz, D., Krauel, K., Flechtner, H.-H., Schadow, J., Hinrichs, H., \& Herrmann, C. S. (2010). Altered evoked gamma-band responses reveal impaired early visual processing in ADHD children. Neuropsychologia, 48(7), 1985-1993. doi:

10.1016/j.neuropsychologia.2010.03.019

Lerner, M., Hutchins, T., \& Prelock, P. (2011). Brief Report: Preliminary evaluation of the Theory of Mind inventory and its relationship to measures of social skills. Journal of Autism and Developmental Disorders, 41(4), 512-517. doi: 10.1007/s10803-010-1066-z

Lind, S. E., \& Bowler, D. M. (2010). Impaired performance on see-know tasks amongst children with Autism: Evidence of specific difficulties with Theory of Mind or domain-general task factors? Journal of Autism \& Developmental Disorders, 40(4), 479-484. doi: 10.1007/s10803-009-0889-y

Moore, C., \& Pure, K. (1990). Children's understanding of the modal expression of speaker certainty and uncertainty and its relation to the development of a representational Theory of Mind. Child Development, 61(3), 722. doi: 10.1111/1467-8624.ep5858729

Müller, M. M., Gruber, T., \& Keil, A. (2000). Modulation of induced gamma band activity in the human EEG by attention and visual information processing. International Journal of Psychophysiology, 38(3), 283-299. doi: 10.1016/s0167-8760(00)00171-9

Mulligan, A., Anney, R., O’Regan, M., Chen, W., Butler, L., Fitzgerald, M., . . Kuntsi, J. (2009). Autism symptoms in Attention-Deficit/Hyperactivity Disorder: A familial trait which 
correlates with conduct, oppositional defiant, language and motor disorders. Journal of Autism \& Developmental Disorders, 39(2), 197-209. doi: 10.1007/s10803-008-0621-3

Newschaffer, C. J., Croen, L. A., Daniels, J., Giarelli, E., Grether, J. K., Levy, S. E., . . Windham, G. C. (2007). The epidemiology of Autism spectrum disorders. Annual Review of Public Health, 28(1), 235-258. doi: 10.1146/annurev.publhealth.28.021406.144007

Nydén, A., Niklasson, L., Stahlberg, O., Anckarsater, H., Wentz, E., Rastam, M., \& Gillberg, C. (2010). Adults with Autism spectrum disorders and ADHD neuropsychological aspects. Research in Developmental Disabilities, 31(6), 1659-1668. doi: 10.1016/j.ridd.2010.04.010

Oberman, L. M., Hubbard, E. M., McCleery, J. P., Altschuler, E. L., Ramachandran, V. S., \& Pineda, J. A. (2005). EEG evidence for mirror neuron dysfunction in Autism spectrum disorders. Cognitive Brain Research, 24(2), 190-198. doi: 10.1016/j.cogbrainres.2005.01.014

Onishi, K. H., \& Baillargeon, R. (2005). Do 15-month-old infants understand false beliefs? Science (New York, N.Y.), 308(5719), 255-258.

Orekhova, E. V., Stroganova, T. A., Nygren, G., Tsetlin, M. M., Posikera, I. N., Gillberg, C., \& Elam, M. (2007). Excess of high frequency electroencephalogram oscillations in boys with Autism. Biological Psychiatry, 62(9), 1022-1029. doi: 10.1016/j.biopsych.2006.12.029

Perner, J., Kain, W., \& Barchfeld, P. (2002). Executive control and higher-order theory of mind in children at risk of ADHD. Infant \& Child Development, 11(2), 141-158. doi: 10.1002/icd.302

Rescorla, A. (2001). Child Behavior Checklist or Teacher Report Form

Ribeiro, L. A., \& Fearon, P. (2010). Theory of mind and attentional bias to facial emotional expressions: A preliminary study. Scandinavian Journal of Psychology, 51(4), 285-289. doi: $10.1111 / j .1467-9450.2009 .00797 . x$

Rommelse, N. N. J., Geurts, H. M., Franke, B., Buitelaar, J. K., \& Hartman, C. A. (2011). A review on cognitive and brain endophenotypes that may be common in Autism spectrum disorder and Attention-Deficit/Hyperactivity Disorder and facilitate the search for pleiotropic genes. Neuroscience \&amp; Biobehavioral Reviews, 35(6), 1363-1396. doi: 10.1016/j.neubiorev.2011.02.015 
Ronald, A., Simonoff, E., Kuntsi, J., Asherson, P., \& Plomin, R. (2008). Evidence for overlapping genetic influences on Autistic and ADHD behaviours in a community twin sample. Journal of Child Psychology \& Psychiatry, 49(5), 535-542. doi: 10.1111/j.14697610.2007.01857.x

Ryan, C., \& Charragáin, C. (2010). Teaching emotion recognition skills to children with Autism. Journal of Autism \& Developmental Disorders, 40(12), 1505-1511. doi: 10.1007/s10803010-1009-8

Schulte-Rüther, M., Markowitsch, H. J., Fink, G. R., \& Piefke, M. (2007). Mirror neuron and Theory of Mind mechanisms involved in face-to-face interactions: A functional magnetic resonance imaging approach to empathy. Journal of Cognitive Neuroscience, 19(8), 1354-1372.

Tallon-Baudry, C. (2003). Oscillatory synchrony and human visual cognition. Journal of Physiology-Paris, 97(2-3), 355-363. doi: 10.1016/j.jphysparis.2003.09.009

Tallon-Baudry, C., \& Bertrand, O. (1999). Oscillatory gamma activity in humans and its role in object representation. Trends in Cognitive Sciences, 3(4), 151-162. doi: 10.1016/s13646613(99)01299-1

Träuble, B., Marinovi, V., \& Pauen, S. (2010). Early Theory of Mind competencies: Do infants understand others' beliefs? Infancy, 15(4), 434-444. doi: 10.1111/j.15327078.2009.00025.x

Wechsler, D. (2003). WISC - IV Australian Administration and Scoring Manual. Harcourt Assessment.

Wechsler, D. (2004). Wechsler Abbreviated Scale of Intelligence

Wolf, F., Brüne, M., \& Assion, H.-J. (2010). Theory of Mind and neurocognitive functioning in patients with bipolar disorder. Bipolar Disorders, 12(6), 657-666. doi: 10.1111/j.13995618.2010.00854.x

Yeargin-Allsopp, M., Rice, C., Karapurkar, T., Doernberg, N., Boyle, C., \& Murphy, C. (2003). Prevalence of Autism in a US Metropolitan Area. JAMA: The Journal of the American Medical Association, 289(1), 49-55. doi: 10.1001/jama.289.1.49 
Yuill, N., \& Lyon, J. (2007). Selective difficulty in recognising facial expressions of emotion in boys with ADHD. European Child \& Adolescent Psychiatry, 16(6), 398-404. doi: 10.1007/s00787-007-0612-5

Zobel, I., Werden, D., Linster, H., Dykierek, P., Drieling, T., Berger, M., \& Schramm, E. (2010). Theory of Mind deficits in chronically depressed patients. Depression \& Anxiety (10914269), 27(9), 821-828. doi: 10.1002/da.20713 


\section{APPENDIX I - MATLAB ALIGNMENT CODE}

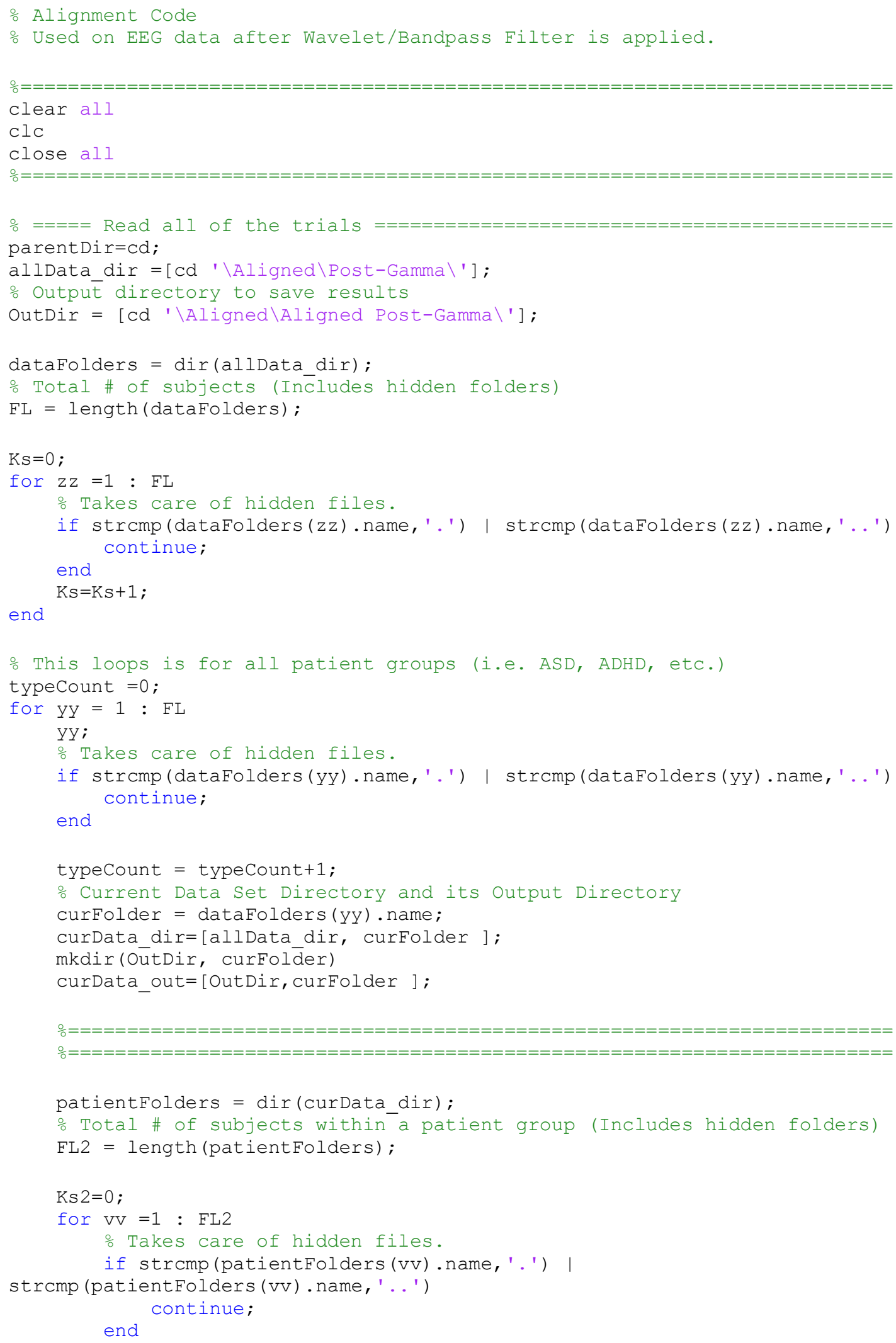




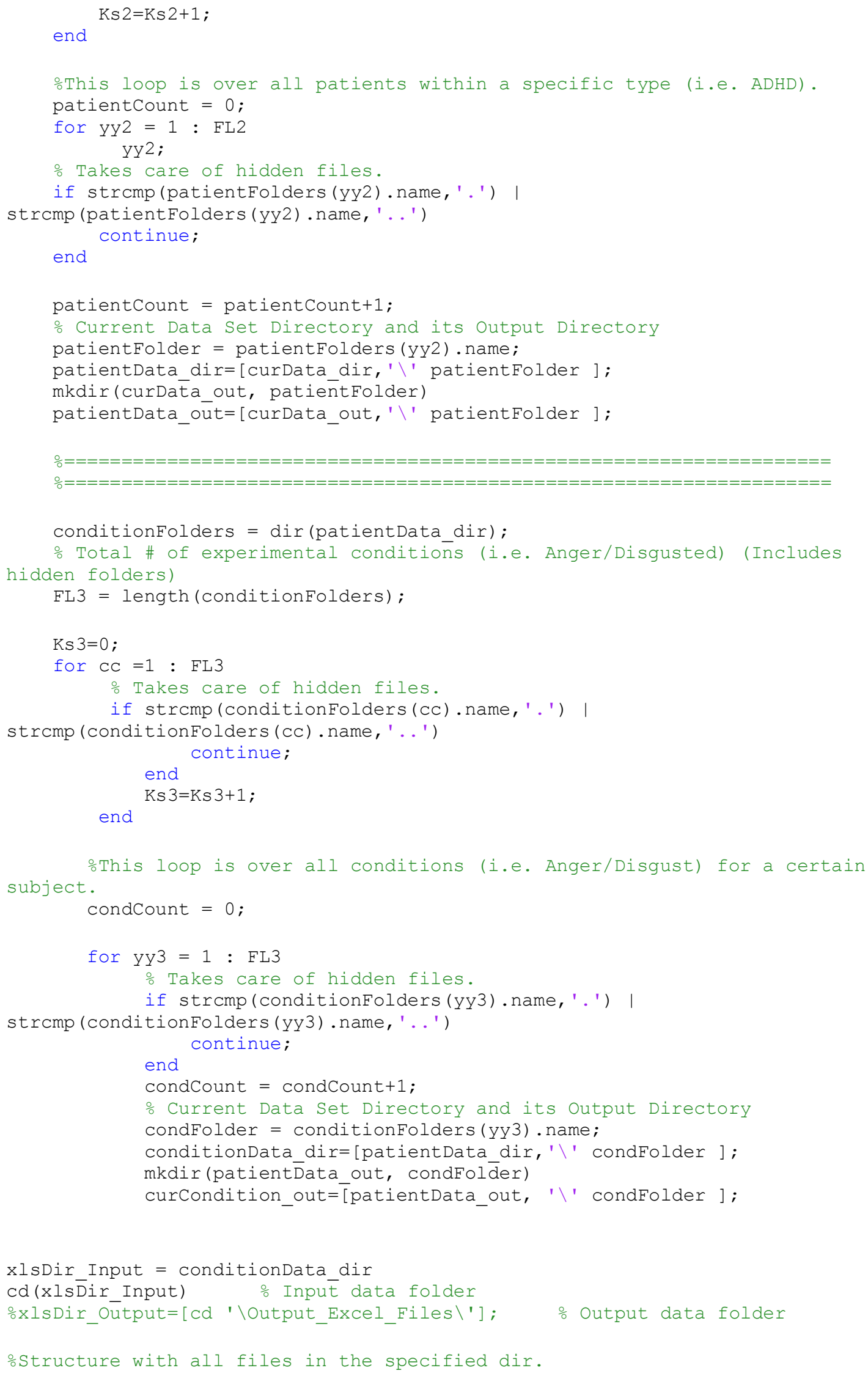




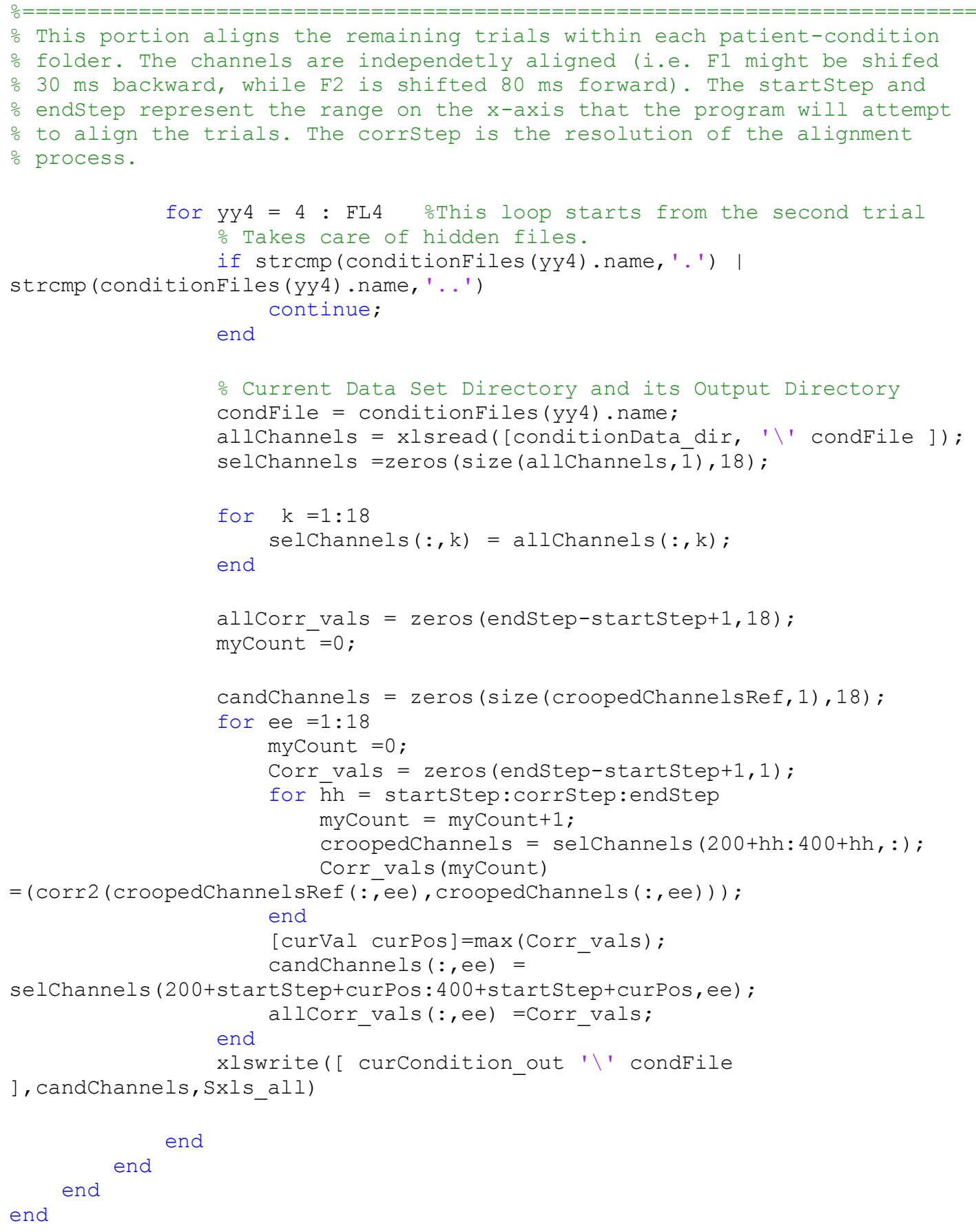




\section{APPENDIX II - DATA TABLES}

\section{TABLE III - INDUCED GAMMA POWER TABLE}

\begin{tabular}{|c|c|c|c|c|c|c|c|c|c|c|c|c|c|c|c|c|c|c|c|}
\hline \multirow{2}{*}{\multicolumn{2}{|c|}{ Anger-Disgust Aligned }} & 20 & 4 & 25 & 124 & 34 & 122 & 11 & 53 & 87 & 59 & 92 & 68 & 60 & 86 & 58 & 97 & 72 & 77 \\
\hline & & F1_AD & F2_AD & F3_AD & F4_AD & F7_AD & F8_AD & Fz_AD & P3_AD & P4_AD & P7_AD & P8_AD & POz_AD & PO3_AD & PO4_AD & P9_AD & P10_AD & O1_AD & O2_AD \\
\hline AD_1' & ADHD & 1.619 & 1.898 & 1.463 & 2.205 & 2.455 & 3.935 & 2.076 & 0.638 & 0.986 & 2.094 & 1.668 & 1.823 & 1.643 & 2.409 & 2.099 & 2.448 & 2.862 & 2.998 \\
\hline AD_2 & ADHD & 0.755 & 0.975 & 1.867 & 1.147 & 3.061 & 0.771 & 1.092 & 2.324 & 1.795 & 3.736 & 4.787 & 2.602 & 3.748 & 3.053 & 4.090 & 2.849 & 6.195 & 5.921 \\
\hline${\text { AD_ } 3{ }^{\prime}}^{\prime}$ & ADHD & 3.356 & 1.922 & 2.442 & 1.832 & 2.212 & 3.026 & 3.122 & 0.093 & 0.342 & 0.391 & 1.662 & 0.352 & 0.985 & 0.392 & 0.376 & 1.240 & 0.393 & 0.327 \\
\hline AD_4' & ADHD & 1.238 & 2.575 & 2.762 & & & & 1.544 & 1.412 & 1.385 & 5.898 & 5.623 & 3.282 & 2.457 & 4.266 & & 5.976 & 4.680 & \\
\hline AD_5' & ADHD & 0.443 & 2.323 & $\begin{array}{l}0.803 \\
\end{array}$ & 2.116 & 1.666 & 2.480 & 0.205 & 1.858 & 6.800 & 2.449 & 4.910 & 2.751 & 2.429 & 1.436 & 2.435 & 2.494 & 5.856 & 6.377 \\
\hline AD_6' & ADHD & 1.564 & 2.246 & 1.804 & 3.115 & 2.997 & & 1.617 & 2.807 & 1.480 & 2.070 & 1.631 & 2.332 & 4.873 & 5.236 & 1.805 & 1.568 & 2.616 & 2.460 \\
\hline AD_7' & ADHD & & 3.033 & 4.091 & & 2.118 & & 1.983 & 1.620 & 4.756 & 3.032 & 6.575 & 5.341 & 3.116 & 4.866 & 3.037 & & $\begin{array}{l}4.214 \\
\end{array}$ & 4.688 \\
\hline AD_8 & ADHD & 1.315 & 1.861 & 1.593 & 1.739 & 2.007 & 2.387 & 1.957 & 2.571 & 2.856 & 1.856 & 4.401 & 0.766 & 1.800 & 1.421 & 2.046 & 4.465 & 0.506 & 1.010 \\
\hline AD_ $g^{\prime}$ & ADHD & 2.641 & 2.867 & 2.549 & 1.859 & 2.337 & & & 0.970 & 2.195 & 5.154 & 2.458 & 5.237 & 4.051 & 2.786 & 4.212 & 2.712 & 4.225 & 3.124 \\
\hline AS_1' & Autism & & & & & & & & 1.578 & 2.522 & 1.357 & 4.485 & 1.349 & 1.355 & 4.086 & 2.567 & & 1.266 & 3.407 \\
\hline AS_2' & Autism & 1.468 & 1.324 & 1.048 & 1.168 & 1.800 & 1.843 & 1.340 & 0.788 & 1.144 & 2.312 & 0.931 & 0.442 & 1.063 & 2.638 & 1.435 & 0.855 & 1.355 & 1.291 \\
\hline AS_3' & Autism & 0.980 & 0.065 & 1.203 & $\begin{array}{l}0.499 \\
\end{array}$ & 1.228 & 1.920 & 0.786 & 1.053 & 0.187 & 1.850 & 1.979 & 0.235 & 1.174 & 1.301 & 2.931 & 1.236 & 2.697 & 4.139 \\
\hline AS_4' & Autism & 7.002 & 5.736 & 6.608 & & 5.301 & & 6.075 & 0.593 & 0.106 & 0.520 & 0.139 & 0.380 & 0.566 & 1.143 & 0.578 & 0.435 & 0.375 & 0.319 \\
\hline AS_5' & Autism & 2.235 & 2.555 & 1.940 & 2.728 & 3.103 & 2.945 & 3.692 & 2.524 & 1.677 & & 2.960 & 2.251 & 3.933 & 3.199 & & 2.596 & & \\
\hline AS_6' $^{\prime}$ & Autism & 1.383 & 2.673 & 2.765 & & 6.538 & & 1.857 & 1.578 & 2.364 & 3.076 & 3.190 & 1.145 & 3.404 & 3.956 & 5.576 & 3.134 & 4.018 & 5.869 \\
\hline AS_7' & Autism & 2.059 & 3.782 & & 4.719 & & 3.668 & 3.710 & 3.690 & & 3.431 & & 2.303 & 3.836 & & 3.020 & & 6.807 & 6.292 \\
\hline AS_8 ' $^{\prime}$ & Autism & 2.614 & 3.037 & 3.154 & 3.868 & & 6.191 & 2.246 & 1.092 & 0.461 & 1.292 & 1.937 & 0.865 & 1.523 & 1.426 & 1.246 & 2.057 & 0.921 & 1.166 \\
\hline AS_9' & Autism & 0.623 & 1.047 & 0.925 & 1.165 & 0.844 & 1.159 & 1.128 & 1.058 & 0.635 & 2.341 & 0.992 & 2.954 & 2.370 & 0.966 & 1.071 & 0.954 & 3.435 & 3.528 \\
\hline AS_10 $10^{\prime}$ & Autism & 1.208 & 0.865 & 1.323 & 1.104 & 3.253 & 5.675 & 1.307 & 3.088 & 0.807 & 3.012 & 3.089 & 4.192 & 4.084 & 1.318 & $\begin{array}{l}3.037 \\
\end{array}$ & 1.830 & 5.100 & 6.219 \\
\hline$C_{-} 1^{\prime}$ & Control & 0.411 & 0.317 & 0.563 & & 2.715 & 2.980 & 0.049 & 1.022 & $\begin{array}{l}1.976 \\
\end{array}$ & 7.562 & 3.250 & 5.550 & 7.162 & 2.050 & 6.749 & 3.775 & & \\
\hline$c_{-} 2^{\prime}$ & Control & 0.519 & 0.418 & 2.832 & 2.095 & & 4.053 & 0.885 & 0.821 & 1.958 & 2.710 & & 1.736 & 2.630 & 3.717 & 3.326 & 4.658 & & 3.568 \\
\hline$c_{-} 3^{\prime}$ & Control & 1.224 & 2.783 & 1.403 & 4.541 & 1.409 & & 1.045 & 0.279 & 0.278 & 0.354 & 2.360 & 0.102 & 0.259 & 2.801 & 0.392 & 2.671 & 0.245 & 0.121 \\
\hline C_4' & Control & 1.116 & 1.283 & 1.694 & 1.619 & 1.956 & 2.812 & 0.904 & 0.802 & 1.168 & 2.835 & 1.646 & 1.118 & 1.369 & 3.333 & 2.733 & 4.320 & 3.403 & 3.923 \\
\hline$C_{-} 5^{\prime}$ & Control & 0.934 & 1.090 & 0.875 & 1.631 & 1.022 & 1.840 & 1.608 & 0.482 & 1.389 & 1.301 & 2.527 & 2.333 & 1.073 & 2.037 & 1.414 & 3.176 & 1.936 & 2.191 \\
\hline$C_{-} 6^{\prime}$ & Control & 1.175 & 1.558 & 1.184 & 1.972 & 4.148 & 4.331 & 1.316 & 1.626 & 1.647 & 3.189 & 4.978 & 2.522 & 2.641 & 2.082 & 2.079 & 1.895 & 6.849 & 7.098 \\
\hline C_7 & Control & 0.775 & 1.476 & 0.919 & $\begin{array}{l}4.543 \\
\end{array}$ & 1.291 & & 0.976 & 0.545 & 0.601 & 0.495 & 2.307 & 0.186 & 0.509 & 0.196 & \begin{tabular}{|l|l|l}
0.777 \\
\end{tabular} & 2.423 & 0.371 & 0.237 \\
\hline C__ $8^{\prime}$ & Control & 3.010 & 1.341 & 3.182 & 1.315 & 3.452 & 4.774 & 1.153 & 1.060 & 0.318 & 0.749 & 1.357 & 0.342 & 0.776 & 0.447 & 0.916 & 5.033 & 0.648 & 0.619 \\
\hline c_-9' & Control & 2.303 & 4.234 & 3.669 & 4.223 & 4.862 & & 2.376 & 1.509 & 0.029 & 2.225 & 2.506 & 0.776 & 2.217 & 0.028 & & 3.532 & 1.026 & 1.195 \\
\hline$C_{-} 10^{\prime}$ & Control & 2.149 & 0.686 & 1.696 & 0.818 & 4.165 & 4.048 & 2.822 & 0.357 & 0.576 & 0.745 & 1.775 & 0.046 & 0.403 & 0.582 & 1.371 & 2.632 & 0.846 & 0.777 \\
\hline C_11' & Control & 2.722 & 3.348 & 3.005 & 3.264 & 4.399 & 4.878 & 3.658 & 5.951 & 3.882 & 7.471 & 4.314 & 6.576 & & 3.692 & & 6.796 & & \\
\hline \multirow{2}{*}{\multicolumn{2}{|c|}{ Emotion All Aligned }} & 20 & 4 & 25 & 124 & 34 & 122 & 11 & 53 & 87 & 59 & 92 & 68 & 60 & 86 & 58 & 97 & 72 & 77 \\
\hline & & F1_EM & F2_EM & F3_EM & F4_EM & F7_EM & F8_EM & Fz_EM & P3_EM & P4_EM & P7_EM & P8_EM & POz_EM & PO3_EM & PO4_EM & P9_EM & P10_EM & O1_EM & O2_EM \\
\hline AD_1' & ADHD & 1.634 & 1.895 & 1.529 & 2.080 & 2.788 & 3.333 & 1.930 & 0.699 & 1.290 & 1.941 & 2.026 & 1.732 & 1.533 & 2.957 & 2.063 & 2.270 & 2.868 & 3.213 \\
\hline AD_2' & ADHD & 0.585 & 1.079 & 1.378 & 1.242 & 1.728 & 0.726 & 1.095 & 2.181 & 0.958 & 3.544 & 3.251 & 2.870 & 3.632 & 1.772 & 4.106 & 2.011 & & 4.969 \\
\hline AD_3' & ADHD & 2.825 & 2.148 & 2.479 & 2.312 & 2.044 & 4.258 & 4.248 & 0.146 & 0.346 & 0.474 & 1.597 & 0.424 & 1.091 & 0.344 & 0.566 & 1.190 & 0.434 & 0.373 \\
\hline AD_4' & ADHD & 1.083 & 1.113 & 2.005 & 4.567 & & & 1.020 & 1.579 & 1.373 & 4.261 & 4.851 & 2.391 & 2.013 & 4.070 & \begin{tabular}{ll|l}
4.813 \\
\end{tabular} & 5.914 & 3.594 & \\
\hline AD_5' & ADHD & 0.458 & 1.997 & 0.696 & 1.730 & 1.640 & 2.413 & 0.223 & 2.080 & 3.658 & 2.644 & 4.510 & 2.030 & 2.482 & 1.286 & 1.963 & 2.681 & 4.969 & 5.263 \\
\hline$A D \_66^{\prime}$ & ADHD & 1.668 & 2.225 & 1.960 & 3.669 & 3.247 & 5.172 & 1.680 & 2.607 & 2.020 & 2.121 & 2.230 & 2.576 & 5.007 & 5.511 & 2.397 & 2.021 & 2.945 & 4.014 \\
\hline$A D_{-} 7^{\prime}$ & ADHD & & 2.769 & 3.549 & 4.085 & 1.703 & 3.990 & 1.686 & 1.425 & 3.672 & 2.830 & 4.759 & 4.446 & 2.691 & 4.281 & 2.836 & & 3.406 & 3.743 \\
\hline AD_8 $8^{\prime}$ & ADHD & 1.454 & 2.080 & 1.471 & 2.159 & 1.885 & 3.696 & 1.830 & 2.171 & 1.644 & 1.167 & 4.445 & 0.537 & 1.431 & 1.227 & 1.323 & 4.585 & 0.352 & 0.979 \\
\hline AD_9' & ADHD & 2.267 & 2.870 & 2.464 & 2.257 & 2.405 & & & 1.591 & 2.791 & & 2.405 & 4.216 & 4.401 & 3.648 & 3.940 & 2.469 & 4.439 & 3.525 \\
\hline AS_1' & Autism & & & & & & & & 0.897 & 1.620 & 1.071 & 3.008 & 0.901 & 1.031 & 2.495 & 2.578 & & 0.893 & 1.515 \\
\hline AS_2' & Autism & 1.500 & 1.298 & 1.127 & 1.030 & 2.121 & 1.854 & 1.487 & 1.626 & 1.171 & 3.020 & 1.570 & 0.844 & 2.614 & 3.061 & 2.186 & 0.906 & 1.917 & 1.384 \\
\hline AS_3' & Autism & 0.901 & 0.095 & 1.224 & 0.819 & 1.503 & 2.437 & 0.837 & 0.956 & 0.217 & 1.944 & 2.238 & 0.282 & 1.113 & 1.470 & 2.380 & $\begin{array}{l}1.528 \\
\end{array}$ & 2.384 & 3.594 \\
\hline AS_4' & Autism & 4.158 & 4.153 & 4.345 & & 2.503 & & 4.179 & 0.426 & 0.074 & 0.357 & 0.101 & 0.211 & 0.428 & 1.531 & 0.391 & 0.255 & 0.269 & 0.161 \\
\hline AS_5' & Autism & 3.746 & 3.715 & 2.074 & 2.769 & 3.697 & 3.759 & 3.492 & 1.716 & 1.604 & 4.784 & 3.661 & 2.246 & 3.141 & 2.950 & 4.965 & 1.732 & 4.898 & \\
\hline AS_6 ${ }^{\prime}$ & Autism & 1.088 & 2.586 & 2.114 & & 4.258 & & 1.896 & 1.404 & 2.731 & 3.194 & 3.612 & 1.350 & 3.921 & 4.030 & 6.005 & 3.400 & 4.298 & 6.419 \\
\hline AS_7' & Autism & 0.921 & 2.005 & 2.983 & 3.161 & 4.606 & 5.143 & 3.210 & 4.462 & & & & & & & & 7.244 & & \\
\hline AS_8 A $^{\prime}$ & Autism & 3.245 & 2.926 & 3.330 & 4.221 & & & 2.282 & 1.198 & 0.567 & 1.757 & 2.239 & 2.185 & 2.433 & 1.566 & 1.776 & 3.234 & 1.896 & 1.766 \\
\hline AS_9' A $^{\prime}$ & Autism & 0.505 & 1.059 & 0.788 & 1.169 & 0.798 & 1.143 & 1.086 & 1.117 & $\begin{array}{l}0.738 \\
\end{array}$ & 2.437 & 1.170 & 3.173 & 2.511 & 1.122 & $\begin{array}{l}1.084 \\
\end{array}$ & 1.126 & 3.206 & 3.430 \\
\hline AS_10 & Autism & 1.345 & 0.856 & 1.473 & 1.073 & 2.676 & 3.698 & 1.222 & 3.402 & 0.955 & & 3.816 & 4.474 & 6.901 & 1.674 & 3.876 & 2.659 & 4.052 & 5.920 \\
\hline C_1 & Control & 0.445 & 0.296 & 0.672 & & 2.463 & 2.447 & 0.050 & 1.043 & 1.906 & 7.804 & 3.293 & 5.731 & 6.380 & 1.991 & 7.290 & 3.258 & & \\
\hline$c_{-} 2^{\prime}$ & Control & 0.510 & 0.311 & 3.326 & 1.928 & 5.706 & 3.238 & 0.670 & 0.855 & 1.703 & 3.193 & & 1.759 & 3.156 & 3.796 & 3.616 & 5.416 & & 3.729 \\
\hline c_- $3^{\prime}$ & Control & 1.328 & 1.976 & 1.400 & 2.970 & 1.447 & & 1.059 & 0.391 & 0.329 & 0.440 & 2.756 & 0.149 & 0.408 & 2.841 & 0.511 & 2.862 & 0.374 & 0.173 \\
\hline C__ $4^{\prime}$ & Control & 1.036 & 1.292 & 1.563 & 1.575 & 1.734 & 2.734 & 0.895 & 1.329 & 1.059 & 2.541 & 1.600 & 1.093 & 1.244 & 3.343 & 2.576 & 3.537 & 3.468 & 3.928 \\
\hline$c_{-} 5^{\prime}$ & Control & 0.946 & 1.096 & 0.824 & 1.675 & 1.103 & 1.782 & 1.664 & 0.568 & 0.859 & 1.335 & 2.528 & 2.373 & 1.134 & 2.191 & 1.457 & 3.034 & 2.043 & 2.188 \\
\hline C__6 ${ }^{\prime}$ & Control & 1.439 & 1.461 & 1.395 & 2.519 & 3.362 & $\begin{array}{l}4.362 \\
\end{array}$ & 1.215 & 1.564 & 2.249 & 7.341 & 5.057 & 1.760 & 3.223 & 2.060 & 2.438 & 1.917 & 3.695 & 6.052 \\
\hline$c_{-} 7^{\prime}$ & Control & 0.666 & 1.190 & 0.908 & 3.501 & 1.273 & 5.612 & 0.835 & 0.545 & 0.487 & 0.490 & 1.367 & 0.184 & 0.516 & 0.224 & 0.877 & 1.619 & 0.491 & 0.416 \\
\hline C_-8 & Control & & 1.636 & & 1.509 & & 6.451 & 1.836 & 1.418 & 0.417 & 1.386 & 1.645 & 0.502 & 1.437 & 0.735 & 1.030 & 6.311 & 1.069 & 1.175 \\
\hline C_ $9^{\prime}$ & Control & 2.553 & 4.832 & 4.191 & 4.794 & 5.388 & & 2.684 & 1.577 & 0.028 & 2.331 & 2.331 & 0.808 & 2.316 & 0.025 & 6.866 & 3.440 & 1.043 & 1.217 \\
\hline$C_{-} 10^{\prime}$ & Control & 1.404 & 0.633 & 1.144 & 0.775 & 2.748 & 3.315 & 2.178 & 0.427 & 0.545 & 0.738 & 1.732 & 0.060 & 0.474 & 0.588 & 1.648 & 2.741 & 0.901 & 0.747 \\
\hline C_11' & Control & & & 2.619 & 2.943 & 3.143 & 2.727 & 5.368 & 4.312 & 2.976 & 7.437 & 3.979 & 5.977 & 4.682 & 6.670 & & 3.987 & 7.760 & 6.303 \\
\hline
\end{tabular}


TABLE III (continued)

\begin{tabular}{|c|c|c|c|c|c|c|c|c|c|c|c|c|c|c|c|c|c|c|c|}
\hline \multirow{2}{*}{\multicolumn{2}{|c|}{ Fear-Sad Aligned }} & 20 & 4 & 25 & 124 & 34 & 122 & 11 & 53 & 87 & 59 & 92 & 68 & 60 & 86 & 58 & 97 & 72 & 77 \\
\hline & & F1_FS & F2_FS & F3_FS & F4_FS & F7_FS & F8_FS & Fz_FS & P3_FS & P4_FS & P7_FS & P8_FS & POz_FS & PO3_FS & \begin{tabular}{|l|} 
PO4_FS \\
\end{tabular} & P9_FS & P10_FS & O1_FS & O2_FS \\
\hline AD_1' & ADHD & 1.443 & 1.756 & 1.502 & 2.302 & 2.120 & 3.091 & 1.633 & 0.769 & 1.740 & 2.078 & 2.600 & 1.763 & 1.541 & 2.739 & 2.488 & 3.225 & 4.375 & 4.210 \\
\hline AD_2' & ADHD & $\begin{array}{l}0.549 \\
\end{array}$ & 1.161 & 1.003 & 1.318 & 1.109 & $\begin{array}{l}0.828 \\
\end{array}$ & 1.174 & 2.043 & 0.368 & 3.384 & 2.021 & 1.981 & 3.487 & 1.109 & 3.874 & 1.541 & 5.032 & 3.564 \\
\hline AD_3' & ADHD & 3.343 & 2.358 & 2.430 & 2.321 & 2.016 & 4.128 & 4.796 & 0.142 & 0.377 & 0.556 & 1.560 & 0.469 & 1.306 & 0.360 & 0.574 & 1.110 & 0.472 & 0.401 \\
\hline AD_4' & ADHD & 1.000 & 1.193 & 2.203 & & & & 1.150 & 1.475 & 1.460 & 4.366 & & 2.987 & 1.876 & 4.435 & 4.993 & & 3.839 & \\
\hline AD_5 & ADHD & 0.476 & 1.763 & 0.601 & 1.511 & 1.704 & 2.291 & 0.209 & 1.574 & 1.878 & 2.309 & 4.882 & 1.718 & 2.259 & 1.210 & 2.101 & 3.370 & 5.378 & 5.669 \\
\hline AD_6 $6^{\prime}$ & ADHD & 1.455 & 2.981 & 2.289 & 4.414 & 3.873 & 2.634 & 1.459 & 1.941 & 2.581 & 2.357 & 2.227 & 1.593 & 4.960 & 5.142 & 3.419 & 1.821 & 2.682 & 2.738 \\
\hline AD_7 $7^{\prime}$ & ADHD & & 2.494 & 5.375 & 3.716 & 1.763 & 4.182 & 1.466 & 1.563 & 3.309 & 3.689 & 4.394 & 3.493 & 3.687 & 4.805 & 3.925 & 6.110 & 3.663 & 3.755 \\
\hline AD_8' & ADHD & 1.413 & 2.458 & 1.448 & 2.579 & 2.060 & 3.986 & 2.025 & 1.811 & 1.409 & 0.927 & 4.550 & $\begin{array}{l}0.570 \\
\end{array}$ & 1.254 & 1.071 & 1.154 & 4.757 & 0.367 & 0.988 \\
\hline AD_9 $9^{\prime}$ & ADHD & 2.745 & 3.004 & 2.740 & 2.516 & 2.187 & & & 1.542 & 2.261 & & 2.073 & $\begin{array}{l}2.956 \\
\end{array}$ & 3.037 & 3.370 & 4.524 & 1.956 & 3.368 & 3.139 \\
\hline AS_1 & Autism & & & & & & & & 0.988 & 1.631 & 1.241 & 2.999 & 0.989 & 1.181 & 2.287 & 2.763 & & 0.999 & 1.433 \\
\hline AS_2 $2^{\prime}$ & Autism & 1.648 & 1.540 & 1.343 & 1.196 & 2.482 & 2.051 & 1.936 & 2.460 & 1.123 & 3.988 & 1.722 & 1.177 & 4.704 & 3.531 & 2.203 & 1.128 & 2.457 & 1.529 \\
\hline AS__3 & Autism & 0.859 & 0.097 & 1.014 & 0.878 & 1.557 & 2.233 & 1.004 & 0.695 & 0.212 & 1.813 & 2.378 & 0.250 & 1.098 & 1.537 & 2.364 & 1.641 & 2.183 & 3.618 \\
\hline AS_4' & Autism & 3.954 & 4.325 & 4.018 & 6.188 & 2.173 & & 4.029 & 0.483 & 0.059 & 0.333 & 0.092 & 0.270 & 0.465 & 1.881 & 0.376 & 0.257 & 0.301 & 0.164 \\
\hline AS_5' & Autism & 5.718 & 4.793 & 2.197 & 2.789 & 4.941 & 3.852 & 3.838 & 1.854 & 2.335 & 4.641 & 4.419 & 3.087 & 3.062 & 3.247 & 4.888 & 1.687 & 5.127 & \\
\hline AS_6 6 & Autism & 1.131 & 2.719 & 2.166 & & 3.405 & & 2.157 & 1.548 & 3.180 & 3.245 & 4.305 & 1.435 & 4.412 & 4.638 & 6.991 & 3.903 & 4.883 & 6.748 \\
\hline AS_7 & Autism & 0.921 & 2.005 & 2.983 & 3.161 & 4.606 & 5.143 & 3.210 & 4.462 & 8.378 & & & & & & 8.076 & 7.244 & & \\
\hline AS_8' & Autism & 3.067 & 2.920 & 3.972 & 4.446 & & 6.872 & 2.527 & 1.668 & $\begin{array}{l}0.491 \\
\end{array}$ & 1.761 & 3.817 & 1.823 & 2.889 & 1.024 & 2.144 & 4.962 & 2.012 & 1.416 \\
\hline AS_g' & Autism & 0.539 & 1.441 & 0.739 & 1.657 & 1.126 & 1.578 & 1.143 & 1.347 & 0.933 & 2.053 & 1.246 & 3.200 & 1.975 & 1.176 & 1.127 & 1.960 & 2.320 & 2.680 \\
\hline AS_10 & Autism & 1.358 & 0.966 & 1.620 & 1.157 & 2.960 & 3.813 & 1.346 & 4.068 & 1.078 & & 3.931 & 5.291 & & 1.820 & 3.818 & 2.793 & 4.228 & 5.979 \\
\hline $\mathrm{C}_{-} 1^{\prime}$ & Control & 0.742 & 0.292 & 0.988 & 6.332 & 2.031 & 1.927 & 0.046 & 1.379 & 1.599 & & 3.559 & 6.942 & 6.810 & 1.751 & 7.564 & 3.804 & & \\
\hline C__2' & Control & 0.497 & 0.316 & 3.827 & 1.896 & 4.655 & 3.400 & 0.684 & 0.898 & 1.751 & 3.129 & & 1.853 & 3.077 & 4.067 & 4.040 & 6.120 & & 3.926 \\
\hline C_3' & Control & 1.775 & 2.052 & 1.837 & 3.443 & 1.796 & 7.002 & 1.417 & 0.554 & 0.412 & 0.671 & 2.682 & 0.223 & 0.579 & 3.764 & 0.705 & 2.823 & 0.510 & 0.241 \\
\hline C_4' & Control & 1.041 & 1.200 & 1.430 & 1.186 & 1.512 & 2.255 & 0.949 & 2.161 & 0.926 & 2.581 & 1.566 & 1.394 & 1.156 & 3.331 & 2.544 & 3.913 & 3.097 & 3.390 \\
\hline $\mathrm{C}_{-} 5^{\prime}$ & Control & 0.726 & 1.796 & 0.861 & 2.080 & 1.315 & 2.039 & 1.376 & 0.857 & 0.598 & 1.339 & 2.151 & 2.186 & 1.130 & 2.539 & 1.447 & 1.828 & 2.055 & 2.284 \\
\hline C_6 ${ }^{\prime}$ & Control & 2.117 & 1.874 & 1.665 & 3.004 & 4.525 & 5.648 & 1.663 & 1.787 & 2.110 & & 6.170 & 1.438 & 2.875 & 2.221 & 2.767 & 1.931 & 2.625 & 4.925 \\
\hline$c_{-} 7^{\prime}$ & Control & 0.598 & 0.971 & 0.804 & 2.172 & 1.442 & 3.492 & 0.727 & 0.601 & 0.760 & 0.694 & 1.046 & 0.195 & 0.642 & 0.241 & 0.894 & 1.242 & 0.835 & 0.756 \\
\hline C_ $8^{\prime}$ & Control & & 1.556 & & 1.549 & & & 2.187 & 1.355 & 0.425 & 1.405 & 1.680 & 0.539 & 1.401 & 0.785 & 0.947 & 6.782 & 1.155 & 1.249 \\
\hline C_.9' & Control & 2.617 & 4.559 & 3.874 & 4.715 & 4.629 & & 2.802 & 1.652 & 0.023 & 2.677 & 2.193 & 0.883 & 2.481 & 0.024 & 6.054 & 3.173 & 1.215 & 1.392 \\
\hline C_10' & Control & 1.306 & 0.581 & 1.124 & 0.695 & 2.480 & 3.043 & 2.052 & 0.452 & 0.566 & 0.807 & 1.500 & 0.067 & 0.491 & 0.587 & 1.841 & 2.387 & 0.878 & 0.746 \\
\hline C_11 & Control & 2.593 & 3.250 & 3.865 & 2.750 & & 4.459 & 3.650 & & 4.489 & 6.041 & 5.679 & $\begin{array}{l}6.842 \\
\end{array}$ & & 4.247 & 7.509 & 7.124 & & \\
\hline \multirow{2}{*}{\multicolumn{2}{|c|}{ Gender All Aligned }} & 20 & 4 & 25 & 124 & 34 & 122 & 11 & 53 & 87 & 59 & 92 & 68 & 60 & 86 & 58 & 97 & 72 & 77 \\
\hline & & F1_GE & F2_GE & F3_GE & F4_GE & F7_GE & F8_GE & Fz_GE & P3_GE & P4_GE & P7_GE & P8_GE & POz_GE & PO3_GE & \begin{tabular}{|l|} 
PO4_GE \\
\end{tabular} & P9_GE & P10_GE & O1_GE & O2_GE \\
\hline AD_1' & ADHD & 2.049 & 2.210 & 2.179 & 2.857 & 2.241 & 3.075 & 1.889 & 0.779 & 1.752 & 2.882 & 2.661 & 2.129 & 1.780 & 4.052 & 3.788 & 4.472 & 5.452 & 5.708 \\
\hline AD_2' & ADHD & 0.641 & 0.786 & 0.992 & 0.885 & 1.427 & 0.680 & 0.719 & 1.908 & 1.116 & 2.567 & 2.729 & 4.534 & 2.745 & 1.859 & 2.778 & 3.208 & 5.656 & 4.379 \\
\hline AD_3 $3^{\prime}$ & ADHD & 2.999 & 1.579 & 2.445 & 1.449 & 2.397 & & 3.564 & 0.180 & 0.599 & 0.914 & 1.034 & 0.673 & 1.187 & 0.636 & 0.878 & 0.989 & 0.836 & 0.769 \\
\hline AD_4' & ADHD & 1.048 & 1.935 & 1.328 & & & & 1.192 & 1.835 & 1.678 & 4.278 & 6.280 & 5.051 & 1.928 & & 6.018 & & 4.085 & \\
\hline AD_5 & ADHD & 0.390 & 2.289 & 0.593 & 1.796 & 1.390 & 1.931 & 0.193 & 1.743 & 0.732 & 1.866 & 2.671 & 0.958 & 2.560 & 1.125 & 1.626 & 1.861 & 3.953 & 4.735 \\
\hline AD_6 $6^{\prime}$ & ADHD & 1.176 & 1.461 & 1.292 & 1.933 & 3.216 & 2.746 & 1.234 & 1.023 & 1.213 & 1.204 & 2.002 & 2.019 & 4.850 & 2.023 & 1.927 & 1.855 & 2.415 & 2.397 \\
\hline AD_7' & ADHD & & 1.834 & 3.344 & 2.563 & 1.854 & 2.812 & 3.027 & 1.185 & 3.131 & 3.936 & 5.953 & 2.857 & 3.886 & 4.414 & 4.038 & & 3.678 & 4.289 \\
\hline AD_8' & ADHD & 1.516 & 2.154 & 1.562 & 2.224 & 1.896 & 3.687 & 1.624 & 1.211 & 1.112 & 0.596 & 4.136 & 0.461 & 0.774 & 0.916 & 0.826 & 4.396 & 0.291 & 1.079 \\
\hline AD_9' & ADHD & 1.821 & 3.105 & 2.551 & 2.545 & 2.013 & & 4.110 & 1.206 & 1.967 & 2.754 & 1.893 & 1.603 & 1.610 & 2.635 & 3.335 & 1.770 & 2.194 & 2.343 \\
\hline AS_1 $1^{\prime}$ & Autism & & & & & & & & 1.945 & 1.901 & 2.038 & 3.805 & 1.556 & 1.914 & 2.371 & 3.701 & & 2.018 & 2.117 \\
\hline AS_2' & Autism & 2.317 & 1.498 & 1.228 & 1.241 & 3.769 & 2.060 & 1.560 & 1.886 & 1.346 & 2.822 & 1.907 & 1.783 & 3.801 & 4.167 & 2.203 & 1.216 & 1.940 & 1.281 \\
\hline AS__3 & Autism & 1.032 & 0.040 & 0.722 & 0.571 & 1.584 & 2.491 & 0.902 & 0.502 & 0.093 & 1.591 & 1.523 & 0.160 & 0.613 & 1.122 & 2.231 & 1.226 & 1.699 & 2.535 \\
\hline AS_4' & Autism & 1.421 & 1.452 & 1.838 & 2.118 & 1.122 & & 2.249 & 0.316 & 0.028 & 0.357 & 0.100 & $\begin{array}{l}0.241 \\
\end{array}$ & 0.282 & 0.629 & 0.380 & 0.203 & 0.279 & 0.200 \\
\hline AS_5' & Autism & 1.988 & 2.125 & 1.944 & 1.557 & 2.962 & 2.052 & 2.461 & 1.227 & 0.861 & 5.297 & 1.722 & 1.770 & 2.572 & 2.508 & 5.582 & 1.506 & 2.744 & 5.052 \\
\hline AS_6 6 & Autism & 0.980 & 1.819 & 2.152 & & 3.135 & & 1.959 & 1.645 & 3.453 & 3.707 & 4.343 & 1.467 & 3.106 & 4.365 & & 4.167 & 3.406 & 5.707 \\
\hline AS_7 & Autism & 1.049 & 2.315 & 1.980 & 3.263 & 3.274 & 5.104 & 2.957 & 5.310 & 5.634 & & & & & & & 5.966 & & \\
\hline AS_8 $8^{\prime}$ & Autism & & 3.361 & 2.809 & 4.450 & & & 2.564 & 1.095 & 1.893 & 1.693 & 5.187 & 1.444 & 1.961 & 3.087 & 2.766 & 6.474 & 1.934 & 2.237 \\
\hline AS_9' & Autism & 0.614 & 1.101 & 0.756 & 1.062 & 0.966 & 1.114 & 1.068 & 0.912 & 1.045 & 3.642 & 2.119 & 0.720 & 3.330 & 2.017 & 1.111 & 1.969 & 5.092 & 5.948 \\
\hline AS_10 $10^{\prime}$ & Autism & 1.546 & 0.868 & 1.632 & 1.104 & 2.480 & 3.500 & 1.375 & 3.433 & 0.893 & 6.196 & 3.269 & 4.062 & & 2.836 & 3.269 & 1.987 & 3.129 & 4.020 \\
\hline $\mathrm{C}_{-} 1^{\prime}$ & Control & 0.217 & 0.194 & 0.285 & 1.721 & 2.854 & 2.390 & 0.067 & 0.542 & 1.177 & 3.913 & 2.706 & 2.044 & & 1.443 & 5.875 & 3.021 & 4.554 & \\
\hline C__ $2^{\prime}$ & Control & 0.296 & 0.210 & 2.242 & 1.466 & 5.361 & 3.658 & 0.497 & 0.786 & 1.192 & 2.310 & & 1.081 & 2.394 & 2.272 & 3.420 & 4.139 & & 2.347 \\
\hline C_3' & Control & 1.351 & 2.421 & 1.508 & 3.656 & 1.756 & \begin{tabular}{|l|l|}
4.119 \\
\end{tabular} & 1.269 & 0.319 & 0.225 & 0.302 & 0.790 & 0.067 & 0.305 & 1.660 & 0.366 & 1.009 & 0.192 & 0.084 \\
\hline C_-4' & Control & 1.111 & 1.039 & 1.271 & 1.321 & 1.410 & 2.551 & 0.851 & 1.132 & 1.245 & 4.272 & 1.832 & 1.551 & 2.047 & 2.653 & 4.268 & 3.201 & 4.381 & 4.898 \\
\hline C_5' & Control & 0.666 & 0.936 & 0.774 & 1.160 & 1.013 & 1.573 & 0.901 & 0.760 & 2.422 & 1.184 & 1.728 & 0.863 & 0.987 & 3.716 & 1.212 & 1.849 & 1.315 & 1.465 \\
\hline$c_{-} 6^{\prime}$ & Control & 1.526 & 1.914 & 1.264 & 2.763 & 3.687 & 5.386 & 1.608 & 1.623 & 1.976 & 5.329 & 4.400 & 1.846 & 2.517 & 2.889 & 2.667 & 2.474 & & 6.539 \\
\hline$c_{-} 7^{\prime}$ & Control & 1.727 & 1.456 & 2.024 & 3.513 & 2.173 & & 0.928 & 0.459 & 0.536 & 0.731 & 1.943 & 0.447 & 0.403 & 0.504 & 1.153 & 2.491 & 0.448 & 0.801 \\
\hline C_ $8{ }^{\prime}$ & Control & 3.093 & 1.004 & 3.320 & 1.020 & 4.537 & & 1.722 & 0.857 & 0.194 & 0.791 & 1.400 & 0.279 & 0.778 & 0.527 & 0.841 & 4.724 & 0.931 & 0.884 \\
\hline C_ $9^{\prime}$ & Control & 2.469 & 4.176 & 3.288 & 4.176 & 4.551 & & 2.722 & 1.737 & 0.026 & 2.581 & 2.678 & 0.791 & 2.427 & 0.026 & & 4.112 & 1.033 & 1.281 \\
\hline C_10 $10^{\prime}$ & Control & 0.931 & 0.758 & 1.329 & 1.049 & 2.506 & 4.272 & 1.451 & 0.459 & 1.199 & 0.794 & 2.968 & $\begin{array}{l}0.058 \\
\end{array}$ & 0.523 & 1.327 & 1.417 & 4.224 & 0.969 & 1.060 \\
\hline C_11 & Control & 3.035 & 3.262 & 3.296 & 2.708 & & 5.149 & 3.096 & & 3.769 & 4.728 & 5.402 & 4.294 & 3.844 & 4.244 & 5.823 & 5.452 & & 6.384 \\
\hline
\end{tabular}




\section{TABLE III (continued)}

\begin{tabular}{|c|c|c|c|c|c|c|c|c|c|c|c|c|c|c|c|c|c|c|c|}
\hline \multirow{2}{*}{\multicolumn{2}{|c|}{ Anger-Disgust 4}} & 20 & 4 & 25 & 124 & 34 & 122 & 11 & 53 & 87 & 59 & 92 & 68 & 60 & 86 & 58 & 97 & 72 & 77 \\
\hline & & F1_AD & F2_AD & F3_AD & F4_AD & F7_AD & F8_AD & Fz_AD & P3_AD & P4_AD & P7_AD & P8_AD & POz_AD & PO3_AD & \begin{tabular}{|l|} 
PO4_AD \\
\end{tabular} & P9_AD & \begin{tabular}{|l|} 
P10_AD \\
\end{tabular} & 01_AD & O2_AD \\
\hline AD_1 ${ }^{\prime}$ & ADHD & 0.098 & 0.148 & 0.169 & 0.164 & 0.304 & 0.489 & 0.085 & 0.194 & 0.283 & 0.394 & 0.437 & 1.108 & 0.657 & 0.768 & 0.338 & 0.326 & 2.124 & 1.416 \\
\hline AD_2 $2^{\prime}$ & ADHD & 0.143 & 0.093 & 0.474 & 0.098 & 0.787 & 0.121 & 0.103 & 0.349 & 0.338 & 0.611 & 0.745 & 0.509 & 0.648 & 0.480 & 0.663 & 0.482 & 0.959 & 1.035 \\
\hline AD_3' & ADHD & 0.484 & 0.247 & 0.269 & 0.216 & 0.267 & 0.282 & 0.637 & $\begin{array}{l}0.012 \\
\end{array}$ & 0.051 & 0.075 & 0.167 & 0.124 & 0.171 & 0.063 & 0.097 & 0.090 & 0.128 & 0.099 \\
\hline AD_4' & ADHD & 0.052 & 0.136 & 0.135 & & & & 0.072 & 0.236 & 0.132 & 0.909 & 0.649 & 0.314 & 0.219 & 0.532 & & 0.409 & 1.670 & \\
\hline AD_ $5^{\prime}$ & ADHD & 0.127 & 0.584 & 0.102 & 0.350 & 0.093 & 0.220 & 0.060 & 0.252 & 0.452 & 0.267 & 0.402 & 0.122 & 0.223 & 0.125 & 0.199 & 0.119 & 0.443 & 0.502 \\
\hline AD_6 $6^{\prime}$ & ADHD & 0.479 & 0.172 & 0.669 & 0.154 & 0.252 & & 0.135 & 0.251 & 0.261 & 0.366 & 0.306 & 0.850 & 0.525 & 0.483 & 0.372 & 0.316 & 0.794 & 0.710 \\
\hline AD_ $7^{\prime}$ & ADHD & & 1.700 & 0.505 & 2.929 & & & 0.754 & 1.217 & 2.558 & 3.227 & 3.648 & 3.013 & 3.141 & 3.331 & 3.324 & & 3.390 & 3.674 \\
\hline AD_8 & ADHD & 0.813 & 0.761 & 0.791 & 0.736 & 0.884 & 0.823 & 0.864 & 0.502 & 0.274 & 0.692 & 2.561 & 0.267 & 0.415 & 0.600 & 0.743 & 2.366 & 0.172 & 0.234 \\
\hline AD_ $9^{\prime}$ & ADHD & 0.132 & 1.595 & 0.206 & 0.234 & 0.323 & & & 0.273 & 0.457 & 1.518 & 0.785 & 1.028 & 1.177 & 0.747 & 0.733 & 0.641 & 1.269 & 1.087 \\
\hline AS_1' & Autism & & & & & & & & $\begin{array}{l}0.717 \\
\end{array}$ & 0.609 & 0.350 & 1.262 & 0.777 & 0.374 & 0.896 & 1.411 & & 0.645 & 2.087 \\
\hline As_2 $2^{\prime}$ & Autism & 0.051 & 0.046 & 0.056 & 0.052 & 0.068 & 0.086 & 0.064 & 0.072 & 0.046 & 0.142 & 0.115 & 0.126 & 0.302 & 0.132 & 0.184 & 0.081 & 0.153 & 0.131 \\
\hline AS_3' $^{\prime}$ & Autism & 0.170 & 0.010 & 0.493 & 0.059 & 0.087 & 0.139 & 0.060 & 0.097 & 0.021 & 0.228 & 0.268 & 0.031 & 0.277 & 0.349 & 0.275 & 0.180 & 0.237 & 0.243 \\
\hline AS_4' & Autism & 2.470 & 1.384 & 2.486 & & 2.030 & & 1.568 & 0.310 & 0.036 & 0.286 & 0.022 & 0.113 & 0.267 & 0.300 & 0.328 & 0.203 & 0.168 & 0.076 \\
\hline AS_5 $5^{\prime}$ & Autism & 0.305 & 0.221 & 0.385 & 0.259 & 0.603 & 0.434 & 0.215 & 0.393 & 0.318 & & 0.519 & 0.285 & 0.371 & 0.313 & & 0.331 & & \\
\hline AS_6 $6^{\prime}$ & Autism & 0.146 & 0.243 & 0.399 & & 0.470 & & 0.356 & 0.169 & 0.315 & 0.318 & 0.358 & 0.114 & 0.301 & 0.518 & 0.978 & 0.301 & 0.329 & 0.561 \\
\hline As_7' & Autism & 2.059 & 3.782 & & 4.719 & & 3.668 & 3.710 & 3.690 & & $\begin{array}{l}3.431 \\
\end{array}$ & & 2.303 & 3.836 & & 3.020 & & 6.807 & 6.292 \\
\hline AS_8' & Autism & $\begin{array}{l}0.472 \\
\end{array}$ & 0.447 & 0.344 & 0.473 & & 0.890 & 0.307 & 0.182 & 0.028 & 0.087 & 0.073 & 0.081 & 0.212 & 0.047 & 0.138 & 0.155 & 0.115 & 0.109 \\
\hline AS_ $^{\prime}$ & Autism & 0.077 & 0.139 & 0.139 & 0.126 & 0.128 & 0.114 & 0.179 & 0.020 & 0.096 & 0.392 & 0.169 & 0.388 & 0.374 & 0.148 & 0.055 & 0.154 & 0.580 & 0.660 \\
\hline AS_10' & Autism & 0.122 & 0.207 & 0.278 & 0.306 & 0.408 & 0.942 & 0.217 & 2.210 & 0.118 & 0.853 & 0.400 & 3.212 & 1.661 & 0.253 & 0.598 & 0.094 & 1.157 & 1.120 \\
\hline$C_{-} 1^{\prime}$ & Control & 0.043 & 0.040 & 0.069 & & 0.365 & 0.409 & 0.004 & 0.164 & 0.276 & 1.243 & 0.283 & 0.682 & 0.893 & 0.292 & 1.187 & 0.311 & & \\
\hline$C_{-} 2^{\prime}$ & Control & 0.089 & 0.067 & 0.685 & 0.277 & & 0.397 & 0.155 & $\begin{array}{l}0.148 \\
\end{array}$ & 0.162 & 0.376 & & 0.351 & 0.373 & 0.450 & 0.534 & 0.900 & & 0.458 \\
\hline $\mathrm{C}_{-} 3^{\prime}$ & Control & 0.152 & 0.225 & 0.164 & 0.397 & 0.165 & & 0.105 & $\begin{array}{l}0.033 \\
\end{array}$ & 0.016 & 0.040 & 0.368 & 0.015 & 0.030 & 0.313 & 0.069 & 0.330 & 0.034 & 0.011 \\
\hline C_4' & Control & 0.139 & 0.116 & 0.112 & 0.115 & 0.112 & 0.242 & 0.136 & 0.220 & 0.086 & 0.166 & 0.202 & 0.654 & 0.422 & 0.226 & 0.229 & 0.286 & 0.412 & $\begin{array}{l}0.533 \\
\end{array}$ \\
\hline C_5' & Control & 0.113 & 0.352 & 0.164 & 0.489 & 0.353 & 0.504 & 0.231 & 0.090 & 0.174 & 0.113 & 0.618 & 0.189 & 0.053 & 0.394 & 0.157 & 0.503 & 0.326 & 0.383 \\
\hline C_6' & Control & 0.264 & 0.308 & 0.081 & 0.436 & 0.301 & 0.386 & 0.090 & 0.273 & 0.222 & 0.555 & 0.984 & 0.292 & 0.431 & 0.265 & 0.159 & 0.265 & 0.631 & 0.943 \\
\hline$c_{-} 7^{\prime}$ & Control & 0.059 & 0.142 & 0.054 & 0.151 & 0.101 & & 0.061 & 0.030 & 0.117 & 0.028 & 0.249 & 0.019 & 0.027 & 0.032 & 0.024 & 0.279 & 0.021 & 0.049 \\
\hline C_ $8^{\prime}$ & Control & 1.008 & 0.195 & 1.161 & 0.222 & 0.270 & 0.772 & 0.127 & 0.147 & 0.033 & 0.146 & 0.203 & 0.048 & 0.156 & 0.046 & 0.110 & 0.765 & 0.103 & 0.107 \\
\hline $\mathrm{C}_{-} 9^{\prime}$ & Control & 0.110 & 0.569 & 0.126 & 0.586 & 0.177 & & 0.317 & 0.199 & 0.003 & 0.317 & 0.232 & 0.068 & 0.362 & 0.002 & & 0.330 & 0.110 & 0.109 \\
\hline C_10' & Control & 0.093 & 0.120 & 0.072 & 0.173 & 0.587 & 0.290 & 0.122 & 0.077 & 0.115 & 0.126 & 0.317 & 0.012 & 0.080 & 0.129 & 0.251 & 0.545 & 0.141 & 0.108 \\
\hline C_11' & Control & 0.326 & 0.309 & 0.518 & 0.279 & 0.899 & 0.351 & 0.258 & $\begin{array}{l}0.778 \\
\end{array}$ & 0.628 & 1.509 & 0.661 & 0.765 & & 0.779 & & 0.636 & & \\
\hline \multirow{2}{*}{\multicolumn{2}{|c|}{ Emotion All Unaligned }} & 20 & 4 & 25 & 124 & 34 & 122 & 11 & 53 & 87 & 59 & 92 & 68 & 60 & 86 & 58 & 97 & 72 & 77 \\
\hline & & F1_EM & F2_EM & F3_EM & F4_EM & F7_EM & F8_EM & Fz_EM & P3_EM & P4_EM & P7_EM & P8_EM & POz_EM & PO3_EM & PO4_EM & P9_EM & \begin{tabular}{|l|} 
P10_EM \\
\end{tabular} & O1_EM & O2_EM \\
\hline AD_1 ${ }^{\prime}$ & ADHD & 0.095 & 0.045 & 0.220 & 0.055 & 0.166 & 0.239 & 0.057 & 0.209 & 0.361 & 0.305 & 0.557 & 1.186 & 0.627 & 0.958 & 0.172 & 0.281 & 2.830 & 2.021 \\
\hline AD_2 & ADHD & 0.104 & 0.084 & 0.261 & 0.092 & 0.360 & 0.074 & 0.090 & 0.176 & 0.127 & 0.328 & 0.306 & 0.338 & 0.346 & 0.173 & 0.368 & 0.256 & & 0.500 \\
\hline $\mathrm{AD}_{-} \mathrm{B}^{\prime}$ & ADHD & 0.350 & 0.207 & 0.137 & 0.112 & 0.117 & 0.290 & 0.445 & 0.014 & 0.035 & 0.069 & 0.097 & 0.067 & 0.088 & 0.042 & 0.073 & 0.074 & 0.079 & 0.070 \\
\hline $\mathrm{AD}_{4} 4^{\prime}$ & ADHD & 0.042 & 0.065 & 0.067 & 0.321 & & 0.299 & 0.038 & 0.140 & 0.076 & 0.132 & 0.267 & 0.289 & 0.111 & 0.227 & 0.220 & 0.361 & 0.912 & \\
\hline AD_5 $5^{\prime}$ & ADHD & 0.119 & 0.426 & \begin{tabular}{|c|}
0.074 \\
\end{tabular} & 0.252 & 0.061 & 0.185 & 0.045 & 0.154 & 0.173 & 0.084 & 0.217 & 0.071 & 0.119 & 0.057 & 0.094 & 0.178 & $\begin{array}{l}0.197 \\
\end{array}$ & 0.223 \\
\hline${\mathrm{AD} \_6^{\prime}}^{\prime}$ & ADHD & 0.359 & 0.138 & 0.525 & 0.232 & 0.205 & 0.617 & 0.093 & 0.092 & 0.201 & 0.193 & 0.388 & 0.527 & 0.324 & 0.325 & 0.339 & 0.429 & 0.488 & 0.623 \\
\hline AD_7 & ADHD & & 1.839 & 0.119 & 2.970 & 1.006 & 2.868 & 0.663 & 1.230 & 2.237 & 3.097 & 3.273 & 2.754 & 3.003 & 3.359 & 3.170 & & 3.179 & 3.378 \\
\hline AD_8 $8^{\prime}$ & ADHD & 0.533 & 0.544 & 0.508 & 0.553 & 0.609 & 0.558 & 0.642 & 0.250 & 0.093 & 0.362 & 2.748 & 0.147 & 0.189 & 0.382 & 0.427 & 2.810 & 0.099 & 0.365 \\
\hline AD_ $9^{\prime}$ & ADHD & 0.130 & 0.978 & 0.146 & 0.482 & 0.298 & & & 0.481 & 0.546 & & 0.994 & 0.723 & 1.274 & 0.910 & 1.207 & 0.902 & 1.591 & 1.434 \\
\hline AS_1 $^{\prime}$ & Autism & & & & & & & & 0.140 & 0.233 & 0.156 & 0.482 & 0.246 & 0.136 & 0.522 & 0.532 & & 0.276 & 0.629 \\
\hline AS_2' & Autism & 0.024 & 0.049 & 0.045 & 0.029 & 0.111 & 0.076 & 0.041 & 0.086 & 0.023 & 0.182 & 0.072 & 0.156 & 0.299 & 0.086 & 0.158 & 0.054 & 0.111 & 0.099 \\
\hline AS_3' $^{\prime}$ & Autism & 0.065 & 0.010 & 0.300 & 0.056 & 0.107 & 0.133 & 0.092 & $\begin{array}{l}0.038 \\
\end{array}$ & 0.010 & 0.098 & 0.062 & 0.019 & 0.068 & 0.109 & 0.165 & 0.067 & 0.043 & 0.067 \\
\hline AS_4' & Autism & 0.396 & 0.331 & 0.400 & & 0.326 & & 0.340 & $\begin{array}{l}0.024 \\
\end{array}$ & 0.011 & 0.026 & 0.010 & 0.021 & 0.022 & 0.247 & $\begin{array}{l}0.028 \\
\end{array}$ & 0.019 & 0.049 & 0.013 \\
\hline AS_5' & Autism & 0.076 & 0.194 & 0.133 & 0.149 & 0.151 & 0.204 & 0.210 & $\begin{array}{l}0.091 \\
\end{array}$ & 0.059 & 0.485 & 0.222 & 0.107 & 0.238 & 0.113 & 0.468 & 0.100 & 0.284 & \\
\hline AS_6' & Autism & 0.053 & 0.116 & 0.098 & & 0.173 & & 0.419 & 0.069 & 0.194 & 0.273 & 0.230 & 0.090 & 0.298 & 0.267 & 0.712 & 0.222 & 0.318 & 0.365 \\
\hline AS_7' & Autism & 0.212 & 0.676 & 0.699 & 0.677 & 0.392 & 1.161 & 0.910 & 1.459 & & & & & & & & 1.621 & & \\
\hline AS_ $^{\prime}$ & Autism & 0.183 & 0.202 & 0.237 & 0.224 & & & 0.129 & 0.104 & 0.030 & 0.141 & 0.124 & 0.144 & 0.231 & 0.058 & 0.183 & 0.218 & 0.122 & 0.119 \\
\hline AS_ $^{\prime}$ & Autism & 0.050 & 0.077 & 0.085 & 0.062 & 0.099 & 0.060 & 0.045 & 0.041 & 0.041 & 0.107 & 0.057 & 0.189 & 0.113 & 0.054 & 0.052 & 0.082 & 0.157 & 0.190 \\
\hline AS_10' & Autism & 0.102 & 0.162 & 0.320 & 0.213 & 0.236 & 0.272 & 0.172 & 1.705 & 0.106 & & 0.375 & 2.264 & 1.589 & 0.114 & 0.215 & 0.226 & 0.517 & 0.411 \\
\hline$C_{-} 1^{\prime}$ & Control & 0.027 & 0.017 & 0.043 & & 0.123 & 0.215 & 0.002 & 0.100 & 0.131 & 0.413 & 0.170 & 0.359 & 0.410 & 0.138 & 0.506 & 0.104 & & \\
\hline$C_{-} 2^{\prime}$ & Control & 0.029 & 0.026 & 0.175 & 0.104 & 0.223 & 0.213 & 0.054 & 0.101 & 0.142 & 0.311 & & 0.323 & 0.313 & 0.229 & 0.196 & 0.330 & & 0.239 \\
\hline$C_{-} 3^{\prime}$ & Control & 0.065 & 0.068 & 0.071 & 0.101 & 0.071 & & 0.035 & 0.015 & 0.014 & 0.020 & 0.074 & 0.009 & 0.015 & 0.297 & 0.032 & 0.098 & 0.032 & 0.007 \\
\hline C_4' & Control & 0.109 & 0.108 & 0.086 & 0.103 & 0.092 & 0.184 & 0.110 & 0.245 & 0.057 & 0.123 & 0.063 & 0.545 & 0.361 & 0.116 & 0.172 & 0.128 & 0.129 & 0.127 \\
\hline$c_{-} 5^{\prime}$ & Control & 0.053 & 0.225 & 0.106 & 0.311 & 0.275 & 0.434 & 0.177 & 0.082 & 0.053 & 0.088 & 0.535 & 0.153 & 0.054 & 0.382 & 0.123 & 0.471 & 0.347 & 0.377 \\
\hline$c_{-} 6^{\prime}$ & Control & 0.269 & $\begin{array}{l}0.341 \\
\end{array}$ & 0.132 & 0.520 & 0.260 & 0.467 & 0.127 & 0.257 & 0.321 & 0.387 & 0.326 & 0.194 & 0.293 & 0.072 & 0.272 & 0.275 & 0.281 & 0.284 \\
\hline$c_{-} 7^{\prime}$ & Control & 0.025 & 0.054 & 0.031 & 0.154 & 0.040 & 0.213 & 0.049 & 0.036 & 0.023 & 0.028 & 0.105 & 0.007 & 0.036 & 0.026 & 0.035 & 0.125 & 0.033 & 0.026 \\
\hline$C_{-} 8^{\prime}$ & Control & & 0.071 & & 0.062 & & 0.870 & 0.163 & 0.051 & 0.021 & 0.049 & 0.087 & 0.026 & 0.051 & 0.038 & 0.112 & 0.312 & 0.045 & 0.049 \\
\hline$C_{-} 9^{\prime}$ & Control & 0.081 & 0.186 & 0.115 & 0.191 & 0.131 & & 0.141 & 0.070 & 0.001 & 0.101 & 0.111 & 0.033 & 0.115 & 0.001 & 0.453 & 0.145 & 0.046 & 0.052 \\
\hline C_10 $10^{\prime}$ & Control & 0.043 & 0.056 & 0.034 & 0.102 & 0.393 & 0.161 & 0.062 & 0.029 & 0.083 & 0.050 & 0.182 & 0.003 & 0.031 & 0.077 & 0.139 & 0.302 & 0.068 & 0.060 \\
\hline C_11' & Control & 0.084 & 0.116 & 0.154 & 0.067 & 0.361 & 0.179 & 0.085 & 0.575 & 0.191 & 0.650 & 0.176 & 0.321 & & 0.203 & 0.873 & 0.304 & & \\
\hline
\end{tabular}


TABLE III (continued)

\begin{tabular}{|c|c|c|c|c|c|c|c|c|c|c|c|c|c|c|c|c|c|c|c|}
\hline \multirow{2}{*}{\multicolumn{2}{|c|}{ Fear-Sad Unaligned }} & 20 & 4 & 25 & 124 & 34 & 122 & 11 & 53 & 87 & 59 & 92 & 68 & 60 & 86 & 58 & 97 & 72 & 77 \\
\hline & & F1_FS & F2_FS & F3_FS & F4_FS & F7_FS & F8_FS & Fz_FS & P3_FS & P4_FS & P7_FS & P8_FS & POz_FS & PO3_FS & PO4_FS & P9_FS & P10_FS & O1_FS & O2_FS \\
\hline AD_1' & ADHD & 0.287 & 0.214 & 0.475 & 0.189 & 0.176 & 0.322 & 0.258 & 0.192 & 0.490 & 0.275 & 0.648 & 1.345 & \begin{tabular}{ll|}
0.619 \\
\end{tabular} & 1.209 & 0.155 & 0.181 & 3.445 & 3.037 \\
\hline AD_2' & ADHD & 0.125 & $\begin{array}{l}0.174 \\
\end{array}$ & 0.214 & 0.215 & 0.248 & 0.124 & 0.187 & 0.300 & 0.053 & 0.448 & 0.241 & 0.649 & 0.472 & 0.170 & 0.476 & 0.192 & 0.679 & 0.381 \\
\hline AD_3' & ADHD & 0.481 & 0.365 & 0.223 & 0.146 & 0.152 & 0.595 & 0.610 & 0.017 & 0.046 & 0.061 & 0.210 & 0.062 & 0.097 & 0.057 & 0.061 & \begin{tabular}{|l|l|}
0.097 \\
\end{tabular} & 0.070 & 0.072 \\
\hline AD_4' & ADHD & 0.142 & 0.304 & 0.104 & & & & 0.220 & 0.114 & 0.095 & 0.575 & & 0.392 & 0.104 & 0.306 & 0.685 & & 1.024 & \\
\hline AD_5 $5^{\prime}$ & ADHD & 0.181 & 0.502 & 0.118 & 0.367 & 0.197 & 0.379 & 0.054 & 0.213 & 0.122 & 0.160 & 0.581 & 0.176 & 0.318 & 0.114 & 0.116 & 0.437 & 0.569 & 0.669 \\
\hline AD_6 $6^{\prime}$ & ADHD & 0.704 & 0.395 & 0.956 & 0.488 & 0.329 & 0.286 & 0.238 & 0.205 & 0.693 & 0.219 & 0.695 & 0.701 & 0.404 & 0.674 & 0.397 & 0.607 & 0.765 & 1.097 \\
\hline AD_7 $7^{\prime}$ & ADHD & & 2.216 & 0.331 & 3.309 & 1.132 & 3.379 & 0.775 & 1.320 & 2.004 & 3.199 & 3.023 & 2.655 & 3.118 & 3.467 & 3.263 & 3.259 & 3.103 & 3.228 \\
\hline AD_8' & ADHD & 0.490 & 0.547 & 0.462 & 0.558 & 0.604 & 0.715 & 0.749 & 0.179 & 0.243 & 0.248 & 3.446 & 0.122 & 0.128 & 0.332 & 0.366 & $\begin{array}{l}3.887 \\
\end{array}$ & 0.072 & 0.588 \\
\hline AD_9' & ADHD & 0.350 & 0.814 & 0.231 & 0.841 & 0.359 & & & 0.783 & 0.431 & & 1.218 & 0.740 & 1.190 & 0.938 & 1.560 & 1.058 & 1.718 & 1.843 \\
\hline AS_1' & Autism & & & & & & & & 0.218 & 0.341 & 0.175 & 0.658 & 0.161 & 0.160 & 0.682 & 0.347 & & 0.208 & 0.541 \\
\hline As_2' & Autism & 0.062 & 0.091 & 0.087 & 0.064 & 0.275 & 0.153 & 0.079 & 0.172 & 0.046 & 0.349 & 0.117 & 0.217 & 0.392 & 0.189 & 0.219 & 0.096 & 0.192 & 0.166 \\
\hline $\mathrm{AS}_{3} 3^{\prime}$ & Autism & 0.082 & 0.011 & 0.228 & 0.120 & 0.188 & 0.151 & 0.175 & 0.065 & 0.021 & 0.233 & 0.169 & 0.033 & 0.125 & 0.169 & 0.322 & 0.172 & 0.172 & 0.327 \\
\hline AS_4' & Autism & 1.009 & 0.842 & 1.007 & 1.086 & 0.728 & & 1.073 & 0.098 & 0.008 & 0.104 & 0.014 & 0.061 & 0.098 & 0.315 & 0.126 & $\begin{array}{l}0.028 \\
\end{array}$ & 0.109 & 0.040 \\
\hline AS_5' & Autism & 0.317 & 0.658 & 0.212 & $\begin{array}{l}0.283 \\
\end{array}$ & 0.321 & 0.457 & 0.437 & 0.167 & 0.204 & 0.520 & 0.387 & 0.246 & 0.228 & 0.264 & 0.510 & $\begin{array}{l}0.229 \\
\end{array}$ & 0.184 & \\
\hline AS_6 $6^{\prime}$ & Autism & 0.075 & 0.162 & 0.071 & & 0.346 & & 0.688 & 0.079 & 0.328 & 0.399 & 0.355 & 0.116 & 0.505 & 0.330 & 0.937 & 0.350 & 0.559 & 0.534 \\
\hline AS_7 ${ }^{\prime}$ & Autism & 0.212 & 0.676 & 0.699 & 0.677 & 0.392 & 1.161 & 0.910 & 1.459 & 1.268 & & & & & & 1.212 & 1.621 & & \\
\hline AS_8' & Autism & 0.396 & 0.395 & 0.260 & 0.655 & & $\begin{array}{l}0.842 \\
\end{array}$ & 0.308 & 0.189 & 0.130 & 0.247 & 0.423 & 0.192 & 0.564 & 0.168 & 0.394 & $\begin{array}{l}0.599 \\
\end{array}$ & 0.302 & 0.292 \\
\hline AS_9' & Autism & 0.083 & 0.146 & 0.107 & 0.106 & 0.161 & 0.097 & 0.147 & $\begin{array}{l}0.132 \\
\end{array}$ & 0.054 & 0.048 & 0.063 & 0.222 & 0.057 & 0.061 & 0.104 & \begin{tabular}{|l|l|}
0.107 \\
\end{tabular} & 0.102 & 0.101 \\
\hline AS_10 $10^{\prime}$ & Autism & 0.121 & 0.276 & 0.406 & 0.344 & 0.265 & 0.403 & 0.291 & 1.906 & 0.100 & & 0.691 & 2.132 & & 0.172 & 0.448 & 0.374 & 0.956 & 0.938 \\
\hline $\mathrm{C}_{-} 1^{\prime}$ & Control & 0.057 & 0.013 & 0.071 & 0.328 & 0.138 & 0.171 & 0.002 & 0.110 & 0.285 & & 0.181 & 0.220 & 0.645 & 0.295 & 0.484 & 0.466 & & \\
\hline C__2' & Control & 0.044 & 0.045 & 0.219 & 0.168 & 0.279 & 0.353 & 0.095 & 0.110 & 0.188 & 0.445 & & 0.322 & 0.445 & 0.372 & 0.275 & 0.522 & & 0.362 \\
\hline C_-3' & Control & 0.165 & 0.259 & 0.175 & 0.332 & 0.193 & 0.885 & 0.130 & 0.036 & 0.052 & 0.049 & 0.118 & 0.015 & 0.042 & 0.555 & 0.052 & 0.102 & 0.043 & 0.018 \\
\hline C_4' & Control & 0.151 & 0.199 & 0.122 & 0.234 & 0.144 & 0.347 & 0.145 & 0.406 & 0.089 & 0.277 & 0.092 & 0.588 & 0.363 & 0.467 & 0.331 & 0.330 & 0.221 & 0.171 \\
\hline $\mathrm{C}_{-} 5^{\prime}$ & Control & 0.110 & 0.220 & 0.148 & 0.354 & 0.280 & 0.356 & 0.262 & 0.093 & 0.051 & 0.106 & 0.581 & 0.161 & 0.091 & 0.602 & 0.148 & 0.441 & 0.372 & 0.493 \\
\hline C_6 ${ }^{\prime}$ & Control & 0.324 & 0.362 & 0.185 & 0.631 & 0.461 & 0.771 & 0.171 & 0.480 & 0.573 & & 0.634 & 0.249 & 0.735 & 0.138 & 0.663 & 0.402 & 0.548 & 0.661 \\
\hline$c_{-} 7^{\prime}$ & Control & 0.014 & 0.074 & 0.033 & 0.265 & 0.028 & 0.278 & 0.065 & 0.117 & 0.047 & 0.093 & 0.115 & 0.023 & 0.123 & 0.030 & 0.116 & 0.155 & 0.125 & 0.116 \\
\hline C_ $8^{\prime}$ & Control & & 0.291 & & 0.290 & & & 0.439 & 0.114 & 0.048 & 0.126 & 0.293 & 0.083 & 0.127 & 0.139 & 0.202 & 1.026 & 0.171 & 0.181 \\
\hline C_ $9^{\prime}$ & Control & 0.169 & 0.294 & 0.258 & 0.320 & 0.305 & & 0.176 & 0.074 & 0.002 & 0.084 & 0.104 & 0.050 & 0.100 & 0.001 & 0.388 & $\begin{array}{l}0.125 \\
\end{array}$ & 0.056 & 0.078 \\
\hline C_-10 & Control & 0.059 & 0.045 & 0.053 & 0.095 & 0.378 & 0.178 & 0.073 & 0.029 & 0.115 & 0.068 & 0.255 & 0.005 & 0.032 & 0.099 & 0.154 & 0.429 & 0.096 & 0.091 \\
\hline C_-11' & Control & 0.106 & 0.138 & 0.159 & 0.116 & & 0.389 & 0.172 & & 0.256 & 0.336 & 0.148 & 0.242 & & 0.198 & 0.527 & $\begin{array}{l}0.516 \\
\end{array}$ & & \\
\hline \multirow{2}{*}{\multicolumn{2}{|c|}{ Gender All Unaligned }} & 20 & 4 & 25 & 124 & 34 & 122 & 11 & 53 & 87 & 59 & 92 & 68 & 60 & 86 & 58 & 97 & 72 & 77 \\
\hline & & F1_GE & F2_GE & F3_GE & F4_GE & F7_GE & F8_GE & Fz_GE & P3_GE & P4_GE & P7_GE & P8_GE & POz_GE & PO3_GE & PO4_GE & P9_GE & P10_GE & 01_GE & O2_GE \\
\hline AD_1' & ADHD & 0.458 & 0.245 & 0.424 & 0.211 & 0.140 & 0.350 & 0.258 & 0.202 & 0.472 & 0.352 & 0.532 & 1.368 & 0.550 & 0.935 & 0.389 & 0.277 & 3.370 & 2.049 \\
\hline AD_2 $2^{\prime}$ & ADHD & 0.063 & 0.095 & 0.082 & 0.117 & 0.105 & 0.099 & 0.099 & 0.274 & 0.111 & 0.398 & 0.222 & 0.996 & 0.431 & 0.199 & 0.416 & 0.255 & 0.931 & 0.609 \\
\hline AD_- $3^{\prime}$ & ADHD & 0.446 & 0.334 & 0.079 & 0.061 & 0.077 & & 0.464 & 0.056 & 0.058 & 0.172 & 0.084 & 0.117 & 0.189 & 0.076 & 0.167 & 0.077 & 0.128 & 0.088 \\
\hline AD_4' & ADHD & 0.057 & 0.080 & 0.095 & & & & 0.104 & 0.066 & 0.119 & 0.177 & 0.211 & 0.199 & 0.056 & & 0.305 & & 0.656 & \\
\hline AD_5' & ADHD & 0.168 & 0.252 & 0.135 & 0.176 & 0.145 & 0.225 & 0.065 & 0.069 & 0.069 & 0.105 & 0.227 & 0.053 & 0.115 & 0.065 & 0.088 & 0.152 & $\begin{array}{ll}0.274 \\
\end{array}$ & 0.352 \\
\hline AD_6 $6^{\prime}$ & ADHD & 0.155 & 0.063 & 0.203 & 0.049 & 0.130 & 0.042 & 0.074 & 0.165 & 0.258 & 0.270 & 0.332 & 1.265 & 0.681 & 0.590 & 0.281 & $\begin{array}{ll}0.327 \\
\end{array}$ & 0.917 & 1.104 \\
\hline AD_7' & ADHD & & 1.057 & 0.480 & 1.986 & 0.537 & 2.204 & 2.309 & 0.887 & 1.873 & 2.396 & 3.041 & 2.527 & 2.360 & 2.809 & 2.406 & & 2.938 & 3.190 \\
\hline AD_8 & ADHD & 0.365 & 0.373 & 0.363 & 0.381 & 0.647 & 0.414 & 0.276 & 0.087 & 0.125 & 0.084 & 1.579 & 0.074 & 0.053 & 0.305 & 0.094 & 1.487 & 0.041 & 0.139 \\
\hline AD_ $9^{\prime}$ & ADHD & 0.224 & 1.021 & 0.335 & 0.643 & 0.426 & & 0.551 & 0.405 & 0.366 & 0.544 & 0.429 & 0.536 & 0.466 & 0.596 & 0.816 & 0.341 & 0.685 & 0.766 \\
\hline AS_1' & Autism & & & & & & & & 0.111 & 0.275 & 0.120 & 0.547 & 0.117 & 0.113 & 0.408 & 0.242 & & 0.219 & 0.285 \\
\hline AS_2' & Autism & 0.145 & 0.102 & 0.089 & 0.066 & 0.169 & 0.128 & 0.111 & 0.140 & 0.067 & 0.208 & 0.165 & 0.073 & 0.387 & 0.132 & 0.070 & 0.088 & 0.153 & 0.143 \\
\hline $\mathrm{AS}_{3} 3^{\prime}$ & Autism & $\begin{array}{l}0.083 \\
\end{array}$ & 0.005 & 0.221 & 0.044 & 0.060 & 0.078 & 0.085 & 0.036 & 0.018 & 0.091 & 0.138 & 0.024 & 0.053 & 0.126 & 0.110 & $\begin{array}{l}0.094 \\
\end{array}$ & 0.081 & 0.134 \\
\hline AS_4' & Autism & 0.138 & 0.181 & 0.152 & 0.141 & 0.178 & & 0.131 & 0.047 & 0.003 & 0.048 & 0.015 & 0.032 & 0.043 & 0.095 & 0.058 & $\begin{array}{l}0.026 \\
\end{array}$ & 0.037 & 0.029 \\
\hline AS_5 $5^{\prime}$ & Autism & 0.085 & 0.168 & 0.059 & 0.136 & 0.093 & 0.186 & 0.093 & 0.146 & 0.021 & 0.430 & 0.124 & 0.327 & 0.533 & 0.144 & 0.421 & $\begin{array}{l}0.083 \\
\end{array}$ & 0.269 & 2.007 \\
\hline As_6' & Autism & 0.104 & 0.238 & 0.100 & & 0.089 & & 0.628 & 0.140 & 0.164 & 0.313 & 0.150 & 0.151 & 0.233 & 0.158 & & 0.142 & 0.245 & 0.245 \\
\hline AS 7 & Autism & 0.086 & 0.171 & 0.133 & 0.268 & 0.492 & 0.546 & 0.256 & 0.430 & 0.440 & & & & & & & 0.416 & & \\
\hline AS_8 $8^{\prime}$ & Autism & & 0.308 & 0.264 & 0.385 & & & 0.332 & 0.041 & 0.177 & 0.127 & 0.335 & 0.057 & 0.106 & 0.266 & 0.260 & 0.394 & 0.131 & 0.152 \\
\hline AS_9' & Autism & 0.042 & 0.076 & 0.066 & 0.040 & 0.085 & 0.046 & 0.090 & 0.077 & 0.036 & 0.089 & 0.042 & 0.037 & 0.094 & 0.039 & 0.070 & \begin{tabular}{|l|l|}
0.077 \\
\end{tabular} & 0.095 & 0.104 \\
\hline AS_10 $10^{\prime}$ & Autism & 0.131 & 0.131 & 0.180 & 0.172 & 0.348 & 0.165 & 0.248 & 0.991 & 0.088 & 0.241 & 0.128 & 0.795 & & 0.154 & 0.115 & $\begin{array}{l}0.134 \\
\end{array}$ & 0.249 & 0.147 \\
\hline$C_{-} 1^{\prime}$ & Control & 0.016 & 0.012 & 0.022 & 0.049 & 0.170 & 0.096 & 0.003 & 0.075 & 0.038 & 0.264 & 0.147 & 0.210 & & 0.046 & 0.369 & 0.108 & 0.418 & \\
\hline$C_{-} 2^{\prime}$ & Control & 0.025 & 0.020 & 0.150 & 0.160 & 0.123 & 0.417 & 0.046 & 0.057 & 0.281 & 0.197 & & 0.312 & 0.190 & 0.427 & 0.307 & $\begin{array}{l}0.868 \\
\end{array}$ & & 0.438 \\
\hline$C_{-} 3^{\prime}$ & Control & 0.232 & 0.388 & 0.257 & 0.443 & 0.303 & 0.328 & 0.196 & 0.059 & 0.022 & 0.064 & 0.058 & 0.008 & 0.057 & 0.198 & 0.084 & 0.077 & 0.031 & 0.009 \\
\hline C__ $4^{\prime}$ & Control & 0.109 & 0.098 & 0.134 & 0.134 & 0.149 & 0.137 & 0.111 & 0.103 & 0.058 & 0.306 & 0.129 & 0.326 & 0.333 & 0.076 & 0.288 & 0.339 & 0.334 & 0.253 \\
\hline C_5 & Control & 0.078 & 0.084 & 0.076 & 0.149 & 0.115 & 0.231 & 0.098 & 0.140 & 0.069 & 0.068 & 0.406 & 0.155 & 0.059 & 0.461 & 0.088 & 0.397 & 0.346 & 0.361 \\
\hline C__6 & Control & 0.441 & 0.499 & 0.262 & 0.499 & 0.485 & 0.505 & 0.194 & 0.126 & 0.099 & 0.308 & 0.495 & 0.093 & 0.264 & 0.274 & 0.312 & 0.465 & & 0.413 \\
\hline$C_{-} 7^{\prime}$ & Control & 0.117 & 0.139 & 0.087 & 0.217 & 0.111 & & 0.106 & 0.030 & 0.035 & 0.059 & 0.222 & 0.054 & 0.031 & 0.098 & 0.061 & 0.276 & 0.031 & 0.082 \\
\hline C__ $8^{\prime}$ & Control & 0.195 & 0.026 & 0.217 & 0.028 & 0.319 & & 0.042 & 0.026 & 0.011 & 0.014 & 0.045 & 0.004 & 0.012 & 0.017 & 0.013 & 0.190 & 0.020 & 0.020 \\
\hline C_.9' & Control & 0.094 & 0.156 & 0.130 & 0.163 & 0.117 & & 0.092 & 0.096 & 0.001 & 0.090 & 0.113 & 0.010 & 0.085 & 0.001 & & \begin{tabular}{|l|l|}
0.178 \\
\end{tabular} & 0.031 & 0.021 \\
\hline C_-10 & Control & 0.036 & 0.018 & 0.035 & 0.082 & 0.073 & 0.082 & 0.067 & 0.009 & 0.102 & 0.050 & 0.225 & 0.004 & 0.013 & 0.073 & 0.130 & 0.278 & 0.089 & 0.104 \\
\hline C_11' & Control & 0.152 & 0.199 & 0.209 & 0.241 & & 0.438 & 0.143 & & 0.105 & 0.264 & 0.294 & 0.194 & 0.153 & 0.198 & 0.346 & 0.311 & & 0.366 \\
\hline
\end{tabular}




\section{APPENDIX III - FACIAL IMAGES}

\section{$\underline{\text { Male Neutral Faces }}$}

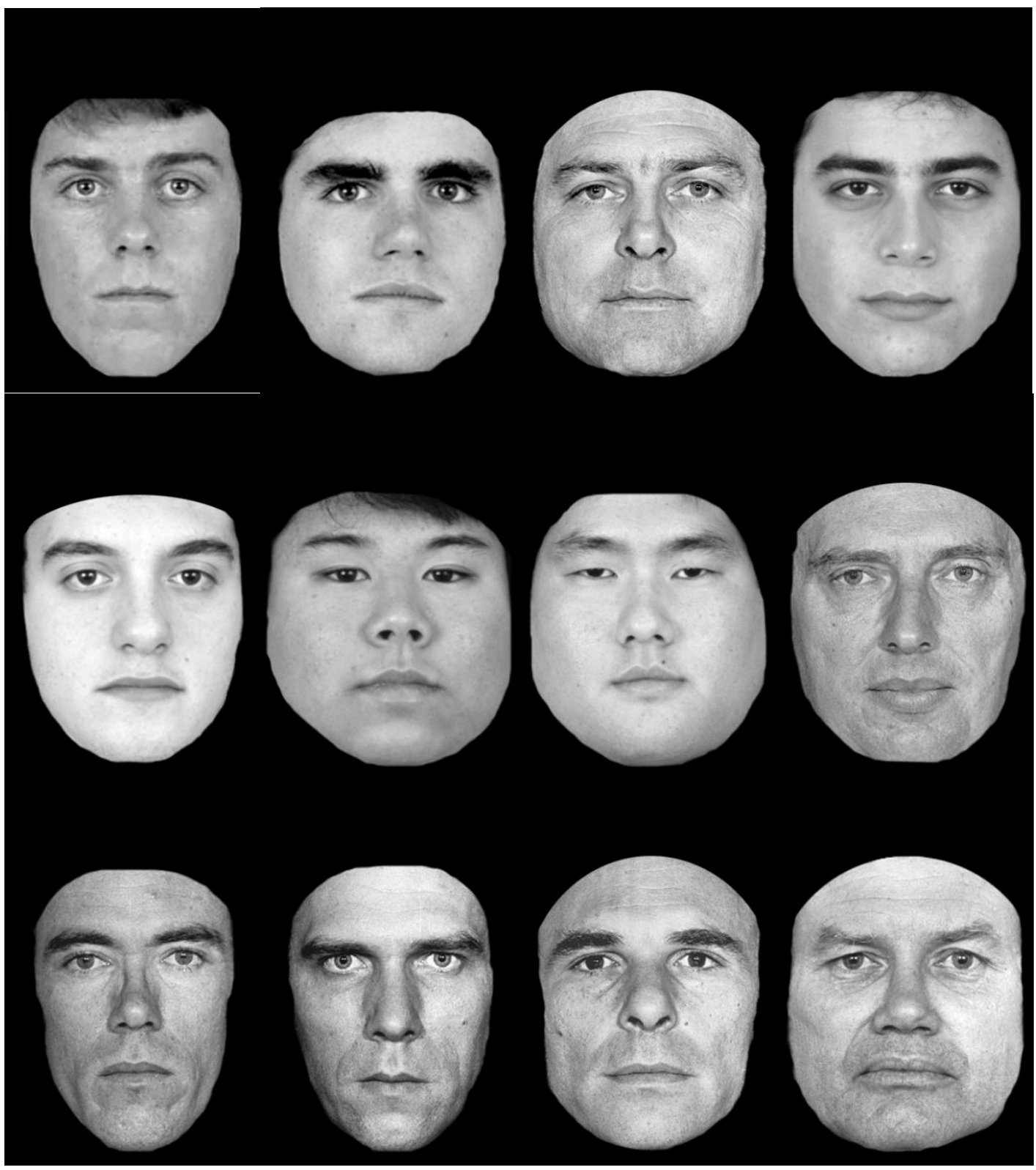


Female Neutral Faces

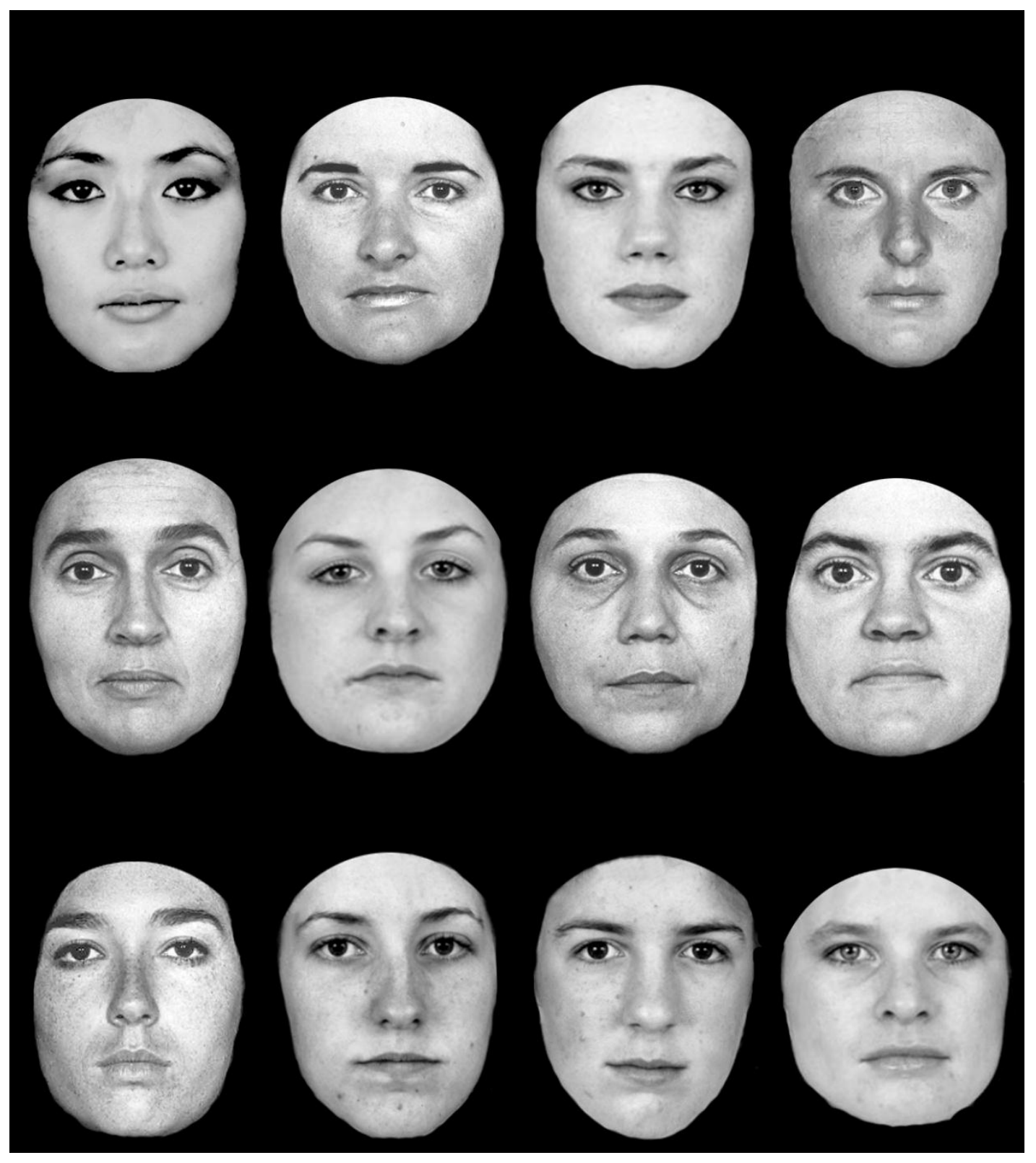


Male/Female Angry Faces

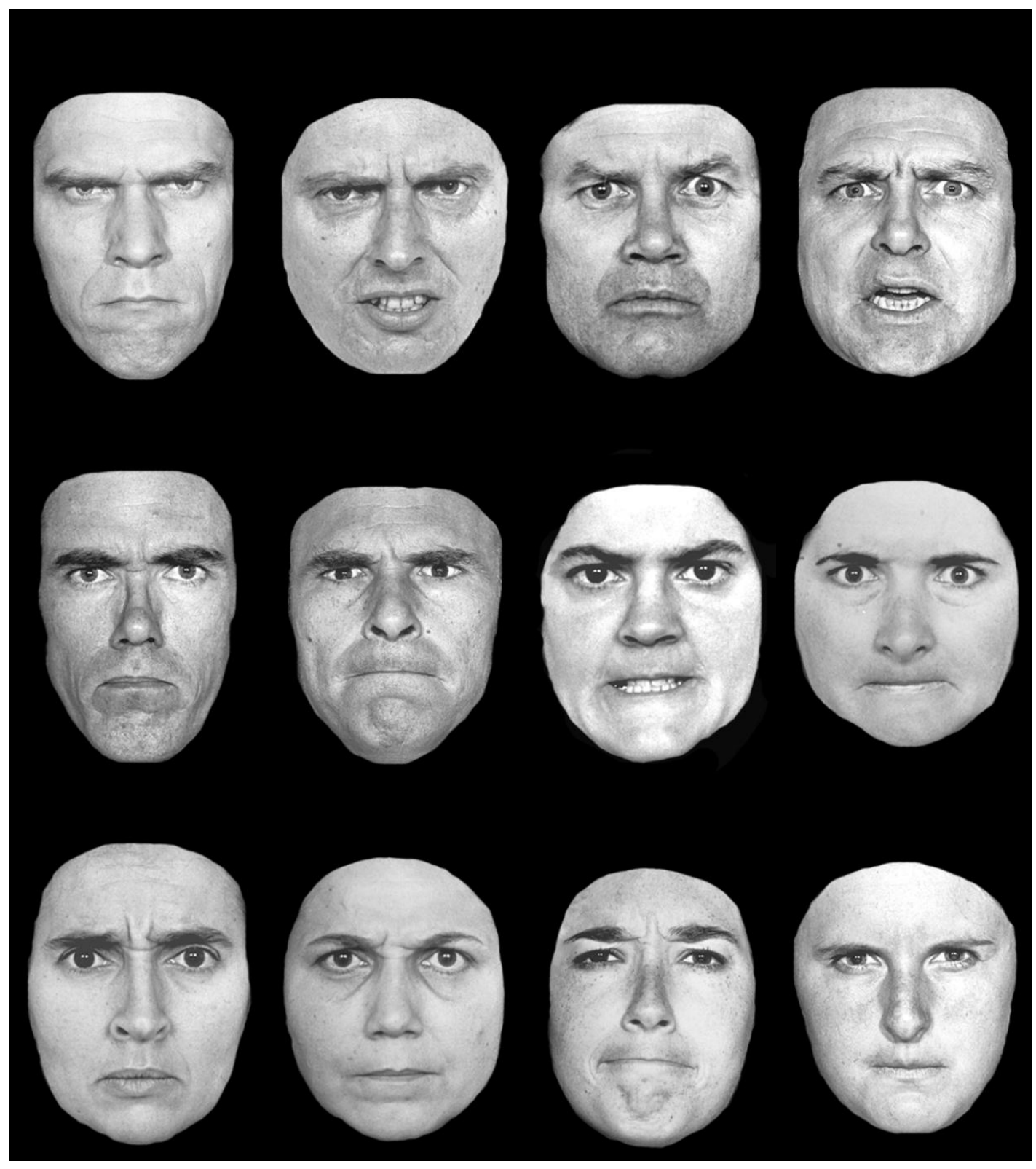


Male/Female Disgusted Faces

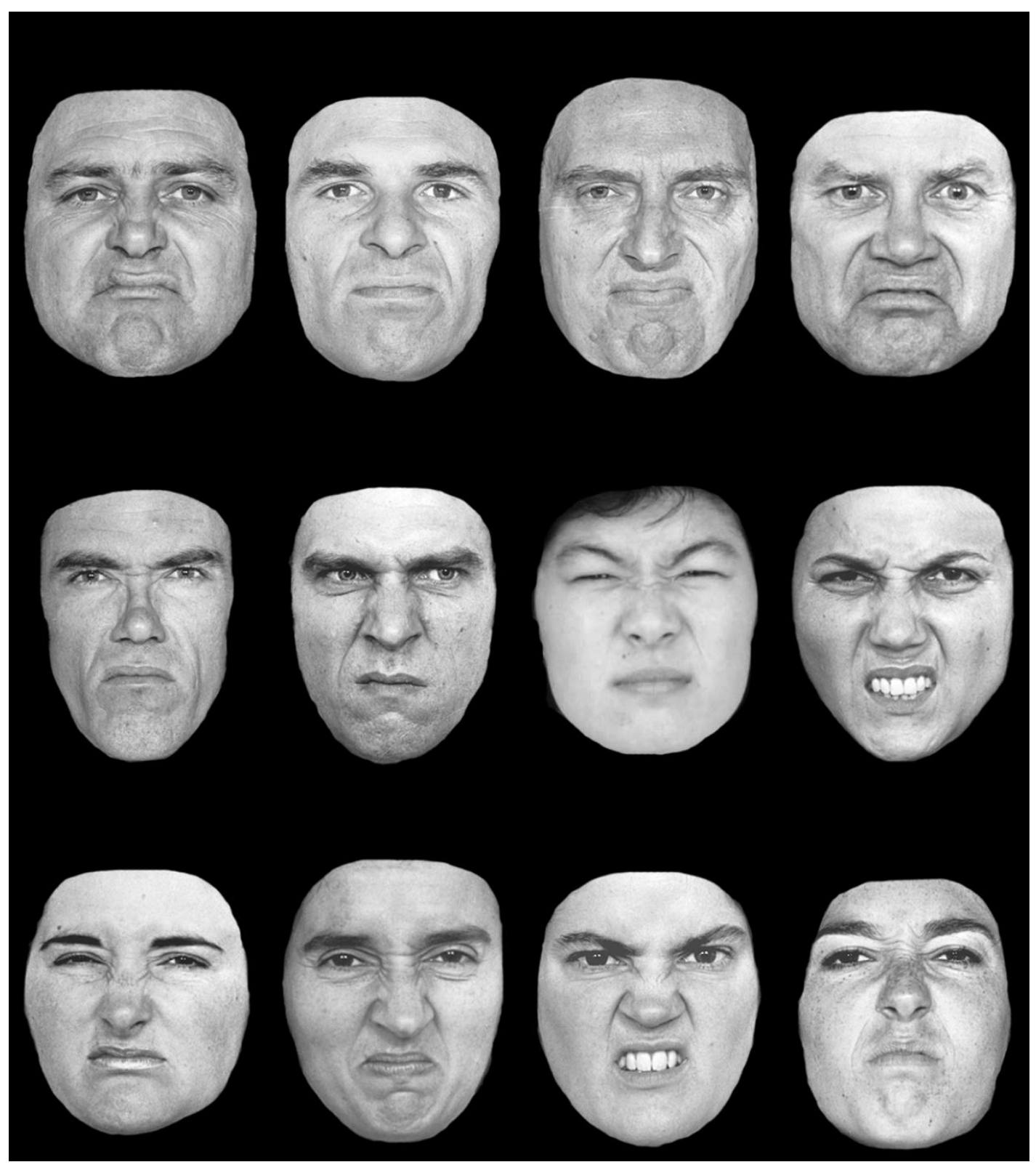


$\underline{\text { Male/Female Fearful Faces }}$

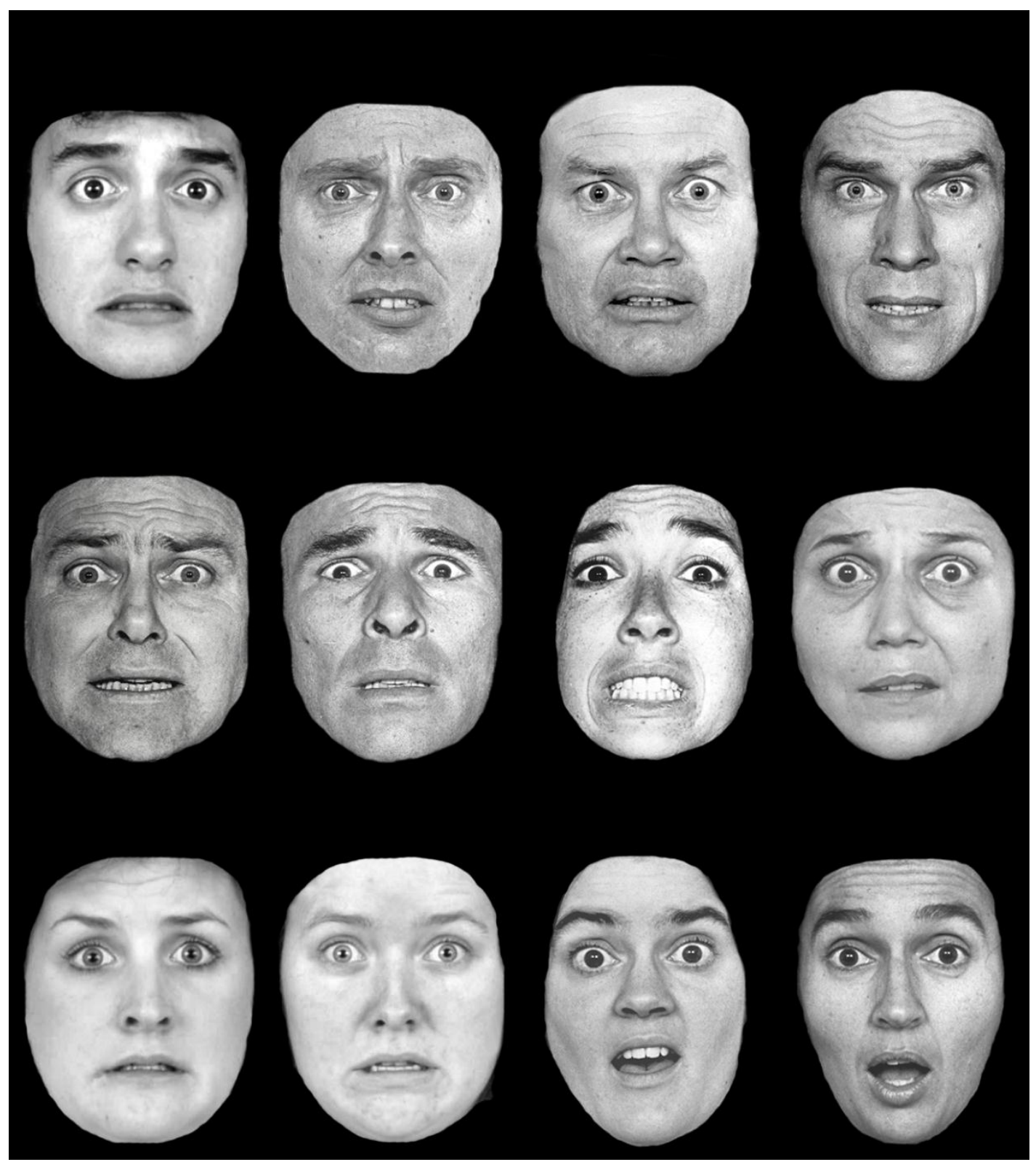


$\underline{\text { Male/Female Sad Faces }}$

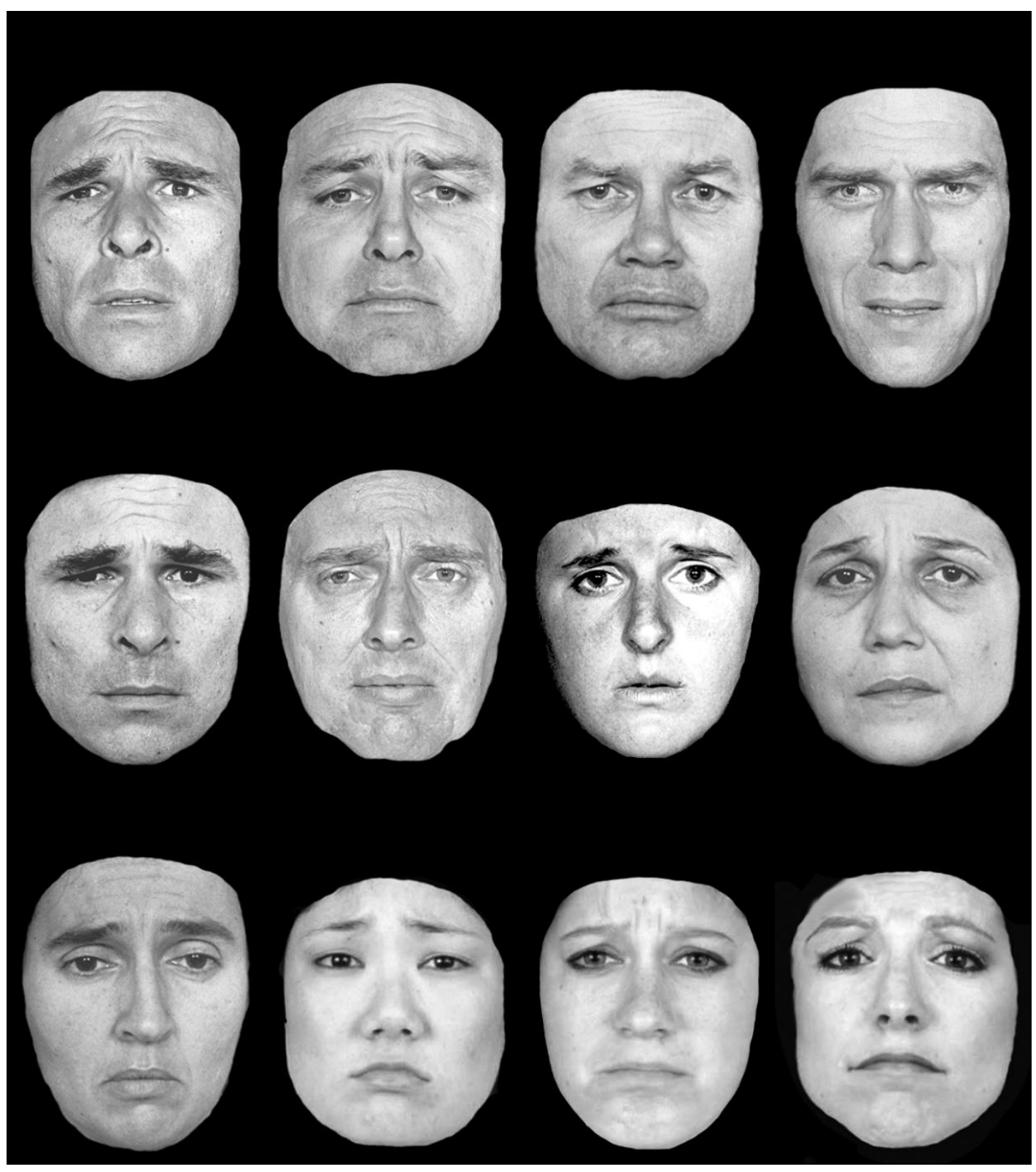




\section{VITA}

Eric Gross is currently completing his Masters of Engineering degree in Bioengineering at the University of Louisville J.B. Speed School of Engineering. He received his Bachelors of Science degree in Bioengineering from the University of Louisville in May of 2011. Notable honors and awards include receiving the Grawemeyer Scholarship, the Ronald C. Ernst Award, the Mickey R. Wilhelm Achievement Award, the Jerry and Pat Sturgeon Academic Excellent Award, and graduating with Highest Honors in his undergraduate class. The work presented in this thesis is expected to be published in the second quarter issue of the Journal of Neurotherapy in 2012. Eric plans to pursue a career in medicine following his graduation. 